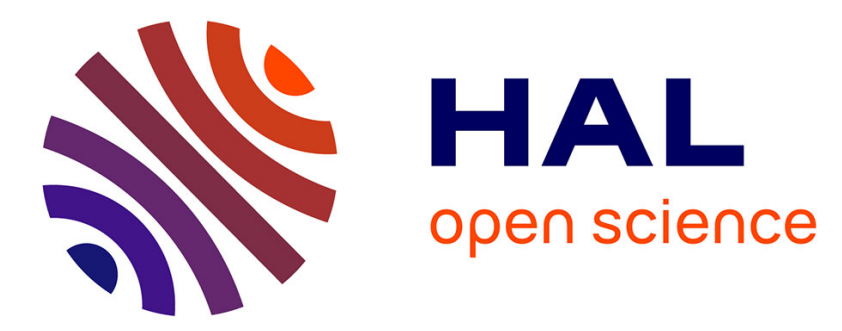

\title{
L'ensemble du grand amphithéâtre de Metz et la sigillée d'Argonne au Ve siècle \\ Didier Bayard
}

\section{To cite this version:}

Didier Bayard. L'ensemble du grand amphithéâtre de Metz et la sigillée d'Argonne au Ve siècle. Gallia - Fouilles et monuments archéologiques en France métropolitaine, 1990, 47, pp.271-319. 10.3406/galia.1990.2913. hal-01918326

\section{HAL Id: hal-01918326 \\ https://hal.science/hal-01918326}

Submitted on 20 Jan 2020

HAL is a multi-disciplinary open access archive for the deposit and dissemination of scientific research documents, whether they are published or not. The documents may come from teaching and research institutions in France or abroad, or from public or private research centers.
L'archive ouverte pluridisciplinaire HAL, est destinée au dépôt et à la diffusion de documents scientifiques de niveau recherche, publiés ou non, émanant des établissements d'enseignement et de recherche français ou étrangers, des laboratoires publics ou privés.

\section{(ㅇ)(1) $\$$}

Distributed under a Creative Commons Attribution - NonCommercial - NoDerivatives| 4.0 


\title{
L'ENSEMBLE DU GRAND AMPHITHÉÂTRE DE METZ ET LA SIGILLÉE D'ARGONNE AU V' SIÈCLE
}

\author{
par Didier BAYARD*
}

Le grand amphithéâtre de Metz, fouillé en 1902 et 1903, a livré un abondant mobilier caractéristique du $\mathbf{v}^{e} \mathbf{s}$. et en particulier plus d'une centaine de fragments de sigillée d'Argonne décorée à la molette, dont seulement une dizaine de fragments étaient connus jusqu'ici.

La "collection" de Metz s'avère être un ensemble clé pour l'étude de la sigillée d'Argonne au v" s. L'analyse des décors à la molette attestés à Metz et l'étude de leur répartition mettent en lumière un certain nombre de particularités qui ont amené l'auteur à les regrouper en quatre phases chronologiques.

La comparaison de l'ensemble de Metz avec ceux d'Altrip, Alzei, Echternach ou les thermes de SainteBarbe à Trèves relativement bien documentés, permet de préciser la chronologie de ces quatre phases et au-delà celle de l'ensemble de Metz. La première phase ou période rassemble des molettes caractéristiques de la fin du IV ${ }^{e}$ s. ; elle s'éteint vers 400-410. La période 2, dont les molettes ne se distinguent pas particulièrement de celles de la période précédente se poursuit jusqu'aux années 430 ou 440. Les molettes chrétiennes quant à elles, correspondent à la période III qui peut être datée du milieu du v $v^{e} \mathrm{~s}$.

Après un hiatus apparent, une quatrième période est attestée au tournant des $\mathrm{v}^{e}$ et $\mathrm{vi}^{e} \mathrm{~s}$. par quelques décors encore peu nombreux.

Cette nouvelle chronologie de la sigillée d'Argonne au ve s. apporte un nouvel éclairage sur l'occupation tardive de nombreux sites et spécialement celle des camps du limes rhénan ou rhétique, du tractus armoricanus et nervicanus ou des refuges de l'intérieur et même sur les campagnes gallo-romaines à la fin de l'Empire.

When the large amphitheatre at Metz was excavated in 1902 and 1903, abundant material characteristic of the 5th century A. D. was found, in particular more than a hundred Argonne samian sherds with rouletted decoration of which only about ten were known until now.

The Metz sherds are a key group for the study of 5th century Argonne samian. Analysis of the rouletting and study of the distribution has brought to light certain characteristics which have led the writer to divide them into four chronological periods.

Comparison of the Metz group with those of Altrip, Alzei, Echternach and the St. Barbe baths in Trier which are relatively well documented enables us to date the four periods and beyond, the Metz collection.

* Didier Bayard, Ingénieur à la Direction des Antiquités de Picardie, 5, rue Henri-Daussy, 80044 Amiens CEDex.

Je tiens à remercier ici tous ceux qui m'ont aidé à un moment ou un autre, pour la préparation de cet article, et en premier lieu M. G. Coudrot, conservateur au Musée de Metz qui a facilité mon accès aux collections et eut à cœur de compléter mon inventaire en recherchant les pièces qui étaient dispersées. Je remercie aussi F. Vallet, conservateur au Musée des Antiquités nationales et $\mathrm{Ph}$. Leveau, conservateur au

\begin{abstract}
Musée Carnavalet à Paris qui m'ont ouvert avec gentillesse et patience leurs réserves et toutes les personnes qui m'ont confié des fragments de sigillée pour étude et ont accepté que je les signale avant leur propre publication: $\mathbf{M}^{\text {mes }} \mathrm{D}$. Guillot, B. Ilett-Fleury, MM. T. Berredjeb, G. Blieck, J.-L. Cadoux, Ch. Chardonnet, D. Chossenot, A. Jacques, J.-P. Lémant, M. Lenoble, D. Piton, Cl. Seillier, D. Vermeersch. Je voudrais enfin signaler que toutes les figures reproduites ici ont été mises au propre par Béatrice Béthune.
\end{abstract}


The first period or phase is typified by a kind of roller stamps which is characteristic of the end of the 4th century and disappears about 400-410 A. D.

The rouletted material of period two, ranging from 410 to $440 \mathrm{~A}$. D., is hardly distinguishable from that of period one.

The christian roulted decoration - period three - can be redated to the mid-5th century.

Afler un apparent hiatus, evidence of a fourth period, at the turn of the 5th century, is provided by a few decorated sherds.

This new chronology of 5th century Argonne samian throws new light on late occupation of numerous sites, particularly the camps of the Rhine limes, of the Tractus Armoricanus and Nerviacus, on the inland refuges, and even on the gallo-roman countryside at the end of the empire.

Le $\mathrm{V}^{\mathrm{e}} \mathrm{s}$. constitue l'une des périodes les plus importantes de notre histoire. L'effondrement militaire de l'Empire d'Occident, les grandes migrations et la formation des royaumes barbares, la transformation des campagnes sont autant de processus fondamentaux qui ont alors pris un tour décisif. Les sources écrites, bien que relativement abondantes au regard des premiers siècles de notre ère, ne permettent pas de saisir le poids réel de ces événements et leurs conséquences socio-économiques; pour sa part, l'étude archéologique du ve s. souffre d'une conjonction de facteurs défavorables.

D'abord, les ateliers d'Occident n'émettent plus de monnaies de bronze après 394 en Gaule et 402 en Italie. Les officines de Trèves ou de Ravenne ne diffusent plus qu'à intervalles irréguliers des monnaics d'or ou d'argent. Les trouvailles numismatiques n'offrent donc plus que quelques jalons chronologiques ténus. D'autre part, l'évolution des rites funéraires aboutit progressivement à la disparition des dépôts de nourriture et de vaisselle. Un peu plus précoce à la ville qu'à la campagne l'évolution est accomplie à la fin du Ive $\mathrm{s}$. Même les sépultures à "caractères germaniques" subissent, avec un certain décalage et à un moindre degré, ce phénomène. Le dernier élément qui pèse encore lourdement sur notre historiographie, la grande invasion de 406-407, à longtemps constitué un terminus aux yeux des historiens et des archéologues.

Le résultat le plus flagrant de cette conjontion était, il y a quelques années encore, un "vide chronologique" de quatre-vingts ans environ entre la grande invasion de 406-407, qui semblait constituer une limite incontournable, et la victoire de Clovis à Soissons en 486 qui ouvrait la période mérovingienne. On a assisté plus récemment à un mouvement inverse: les archéologues français, conscients que toute vie ne s'était pas éteinte à la suite de la grande invasion des Alains, Suèves et Vandales, concluent de plus en plus, mais sans guère argumenter, à une continuité du peuplement. Rares sont les chercheurs, spécialement en France, qui ont réellement tenté de tracer un chemin entre le $\mathrm{IV}^{\mathrm{e}} \mathrm{s}$. romain et le $\mathrm{vI}^{\mathrm{e}} \mathrm{s}$. barbare, en isolant des jalons intermédiaires.

Pourtant, dès 1912, Loeschcke, puis, en 1936, L. Hüssong avaient attiré l'attention sur l'un de ces jalons, le dépôt des thermes Sainte-Barbe à Trèves, et avaient signalé l'intérêt que présentait la sigillée d'Argonne pour l'établissement de datations après la fin du Ive s. C'est d'ailleurs en partie sur cet ensemble que s'est. appuyée la chronologie fondamentale de Kurt Böhner pour la fin de l'Antiquité et le Haut Moyen Age dans le pays trévire'.

Les désaccords des deux spécialistes de la sigillée d'Argonne, W. Unverzagt et G. Chenet sur la fin de la production et les hésitations de ce dernier à se jeter dans le "gouffre" du $v^{e} s$. expliquent en grande partie que l'on ait si peu exploité en France la potentialité chronologique de cette céramique.

D'emblée, Unverzagt et Chenet s'étaient rejoints pour isoler la série des molettes à symboles chrétiens, nettement différentes du reste du corpus alors connu, et toujours trouvées dans des ensembles tardifs, ou du moins jugés comme tels en l'absence de repères chronologiques plus précis. Mais, alors qu'Unverzagt admettait une date aussi tardive que le milieu du $\mathbf{v}^{e} \mathbf{s}$. pour ces décors, Chenet s'est toujours refusé à envisager une production long-

1 Comme pour de nombreuses autres productions de l'Antiquité tardive, le terme de sigillée est purement conventionnel. L'appellation dérivée des sigillées paléochrétiennes d'Argonne (D.S.P.A.) serait plus correcte (sur ces problèmes de terminologie cf. Y. et J. Rigorr, H. Vertet, Essai de classement synthétique des céramiques sigillées, Revue Archéologique du Centre, XII, 1983, 1-2, p. 68-76). Sur la sigillée de Trèves, cf. S. LoEschскF, Typen rotbraun gestrichener Keramik aus den Trierer Barbarathermen, Trierer Jahresbericht, 12, 1921 , p. 56 et pl. IV; - L. Hüssong, Frühmittelalterliche Keramik aus dem trierer Bezirk, Trierer Zeitschrift, XI, 1936, p. 77 ; - K. BöHNER, Die fränkischen Altertümer des Trierer Landes, Berlin, 1968. 
temps après l'invasion de $406^{2}$. Les arguments d'Unverzagt pouvaient paraitre quelque peu "littéraires" au spécialiste français. L'ensemble du grand amphithéâtre de Metz, publié depuis 1903, était daté des années précédant 451 parce que selon Grégoire de Tours la ville avait été prise et complètement détruite par les Huns. La chronologie des thermes Sainte-Barbe de Trèves reposait en partie sur des arguments du même ordre.

D'ailleurs, comment faire glisser la datation des molettes chrétiennes jusqu'au milieu du $\mathbf{v}^{e} \mathrm{~s}$. sans admettre dans un souci de continuité qu'un certain nombre d'autres motifs moins caractéristiques étaient à placer après 406 , et lesquels choisir? Cette question s'est sans doute posée à G. Chenet comme elle se pose depuis lors à tous ceux qui ont abordé le problème.

La fouille du cimetière de Haillot (Belgique) et la révision des riches cimetières du Namurois menée par André Dasnoy ont enfin apporté les indices d'une utilisation importante de la sigillée après les années 406. On trouve dans ces publications non seulement les fameuses molettes chrétiennes, mais aussi un répertoire de formes lisses, inconnu de Chenet, de qualité extrêmement médiocre, seulement attesté jusqu'alors dans les thermes Sainte-Barbe ${ }^{3}$.

Il y a vingt ans, Wolfgang Hübener, s'attaquant de front à la chronologie de toute la sigillée d'Argonne décorée à la molette, proposait dans un article qui fait toujours référence un classement global des décors en huit groupes typologiques ${ }^{4}$. Les molettes chrétiennes étaient rassemblées, comme il se doit, dans le dernier groupe, auquel Hübener attribuait prudemment les années 395-435. La tombe de Vieuxville (Belgique), datée par deux monnaies frappées aux noms de Constantin III et Jovin entre 411 et 413 , et la tombe 11 de Haillot lui permettaient également de faire poursuivre au-delà de la date fatidique de 406 d'autres catégories de décors, en l'occurrence ses groupes 6 et 7.

2 W. Unverzagt, Terra Sigillala mit Rädchenverzierung, Francfort-sur-le-Main, 1919, p. 39; - G. Chenet, La céramique gallo-romaine d'Argonne du ive siècle et la terre sigillée décorée à la molette, Mâcon, 1941.

$3 \mathrm{~J}$. Breuer et $\mathrm{H}$. Roosens, Le cimelière franc de Haillot (avec annexes de J. Werner et A. Dasnoy), Archaeologia Belgica, 34, 1957. Pour les nombreux articles de Dasnoy parus dans les Annales de la Sociélé Archéologique de Namur, voir à la fin de l'article dans le répertoire des localités: Éprave, Han-sur-Lesse, Rochefort, Pry, Furfooz, Spontin, Jamiolle.

4 W. Hübener, Eine Studie zur spätrömischen Rädchensigillata (Argonnen-sigillata), Bonner Jahrbücher, 168, 1968, p. 240-298.
Mais cette thèse reposait encore sur des bases très fragiles : les mobiliers funéraires n'offraient pas une certitude absolue, un décalage chronologique entre les différents éléments d'une tombe ou la réutilisation tardive d'un objet étant toujours possibles. C'est pourquoi Yvan Wautelet, en 1977, dans son étude sur L'important problème de la pseudosigillée dans la province de Namur, reprenait la thèse de Chenet de l'abandon des ateliers d'Argonne en 406, y compris pour celui de Châtel-Chéhéry, centre d'origine des molettes chrétiennes ${ }^{5}$. Il apportait cependant un élément nouveau à la discussion en publiant des décors d'une nouvelle génération manifestement dérivés des molettes chrétiennes de Châtel-Chéhéry, toutes inconnues de Chenet, et associées au répertoire tardif publié par Breuer, Dasnoy et Roosens. Selon lui, ces productions ne devaient être comprises que comme des imitations plus ou moins maladroites des Ardennes au même titre que la rotgestrichene Keramik mise en évidence par Loeschcke aux thermes Sainte-Barbe à Trèves aux côtés de produits purement argonnais.

La position de Wautelet aurait peut-être ébranlé la chronologie de W. Hübener si son ouvrage avait connu une plus grande diffusion. Sa critique mettait surtout en valeur la faiblesse des maillons intermédiaires et la quasi-absence de sites datés de la première moitié du $v^{e} \mathbf{s}$. L'étude du mobilier funéraire des tombes des Ardennes entraînant une surreprésentation de contextes de la fin du $v^{e}$ et du $\mathrm{vI}^{\mathrm{e}}$ s., Yvan Wautelet était en droit de douter d'une réelle continuité des productions de sigillées et de pseudo-sigillées.

A l'évidence, on raisonnait à partir de collections trop restreintes, souvent rassemblées anciennement. La recherche d'une solution exigeait des fouilles nouvelles ou la révision minutieuse de collections anciennes plus fournies.

En 1980 et 1981, Helmut Bernhard a repris le dossier du castellum d'Alzei, véritable pierre angulaire de la chronologie du début du $\mathrm{v}^{\mathrm{r}} \mathrm{s}$. et de deux burgi voisins à Bad-Dürkheim et Eisenberg (RFA). Sans entrer dans le détail des interventions successives sur le camp d'Alzei de 1912 jusqu'à nos jours, très bien résumées par Bernhard ${ }^{6}$, on peut remarquer que plusieurs découvertes ont singulièrement

5 Y. Wautelet, L'important problème de la "pseudosigillée" dans la province de Namur, Pro Antiqua, Bulletin de la Socièté Archéologique, Paléontologique el Géologique, 7, 1977, p. 21.

6 H. Bernhard, Zur Spätantiken Besiedlung im Alzeier Raum, Alzeyer Geschichtsblätter, 16, 1981, p. 123-143. 
modifié notre perception des occupations tardives du castellum. En 1912, Unverzagt interprétait la série monétaire qui provenait du camp comme le signe d'une occupation importante vers $370-380$ suivie d'une fréquentation du site plus sporadique jusque vers 406, 410 au maximum? . Depuis lors, la découverte d'une couche cendreuse dans les casernes occidentales contenant des décors de sigillée comparables à ceux des thermes Sainte-Barbe de Trèves ainsi qu'une monnaie frappée sous Valentinien III (425-455) ont amené Unverzagt à proposer une date d'abandon vers 430 , l'absence sur le camp d'un type de céramique propre aux thermes Sainte-Barbe, la rotgestrichene Keramik, marquant la fin de l'horizon Alzei ${ }^{8}$.

L'étude détaillée du mobilier, par Bernhard, spécialement de la céramique trouvée dans les niveaux les plus récents, confirme largement la nouvelle chronologie d'Unverzagt. Les types tardifs en sigillée d'Argonne, comme l'assiette en sigillée Alzei 9/11 (une variante tardive du Chenet 304) ou l'assiette-couvercle à collerette, marquent la fin de l'occupation à Alzei comme dans les deux burgi voisins. En revanche, il sont complètement absents dans le castellum d'Altrip.

Enfin les fouilles récentes de Jürgen Oldenstein avec la découverte de quelques tessons de rotgestrichene Keramik ${ }^{9}$ ont remis en question la date d'abandon d'Alzei ${ }^{10}$. Mais, que l'on doive ou non retarder cette date, les recherches récentes ont définitivement établi l'occupation de certains camps du limes rhénan bien après l'invasion de 406 .

Avec la publication du mobilier du réduit fortifié de l'église consacrée aux saints Pierre et Paul à Echternach, L. Bakker a fait découvrir en 1981 une collection remarquablement homogène, comparable à celle des thermes Sainte-Barbe de Trèves mais deux fois plus importante et qui vient valider cet ensemble bien isolé jusqu'ici. Selon l'auteur, la

7 H. Bfrnhard, Die spātrömischen Burgi von Bad Dürkheim-Ungstein und Eisenberg. Eine Untersuchung zum spätantiken Siedlungswesen in ausgewählten Teilgebieten der Pfalz, Saalburg Jahrbuch, Bericht des Saalburg Museums, 37, 1981 , p. $23-85$.

8 W. Unverzagt, Die Keramik des Kastells Alzei, Francfort-sur-le-Main, 1916; - ID., Zur Zeitsbestimmung des Kastells Alzei (Rheinhessen), Germania, 13, 1929, p. 177-187.

9 J. Or.densteın, Das spätrömische Kastell von Alzei, Studien zu den Militärgrenzen Roms III, Stuttgart, 1986, p. 235-243.

10 Sur l'importance de la chronologie d'Alzei, J. Oldenstein rapporte la phrase suivante : *Alzey selber bildet einen chronologischen Fixpunkt für sehr viele Datierungsversuche, die natürlich immer mitschwanken, wenn sich die Datierung von Alzey ändert», cf. J. Ot.denstein, op. cit. fortification qui peut dater de la fin du $\mathbf{I I I}^{\mathrm{e}}$ s. a connu une occupation au milieu du $\mathrm{IV}^{\mathrm{e}} \mathrm{s}$. dont on a retrouvé quelques éléments bien identifiables et surtout à la fin $d u I^{e} s$. et pendant la première moitié $d u v^{e} s$. après l'abandon d'une très grande villa voisine ${ }^{11}$. Les recoupements opérés entre Echternach, Trèves, la couche de destruction d'Alzei ainsi que d'autres gisements ont permis à Bakker de proposer une nouvelle datation des molettes chrétiennes dans les deuxième et troisième quarts du $v^{e} \mathrm{~s}$. et, en outre, d'isoler quelques autres décors tardifs comme les $\mathrm{n}^{\text {os }} 83,124,154,174,178$ de Chenet ${ }^{12}$.

Enfin, dernier élément à considérer dans cette série de monographies déterminantes, la publication du cimetière de Vireux-Molhain dans un bulletin spécial du musée de Mayence, qui aide à mieux fixer la chronologie mouvante de la première moitié du $\mathrm{V}^{\mathrm{e}} \mathbf{s .}^{13}$. J.-P. Lémant a fouillé dans les Ardennes un petit cimetière exceptionnel. Non seulement le mobilier est très riche, trait commun aux petites nécropoles germaniques du massif ardennais, mais, fait plus rare, trois monnaies frappées dans la première moitié $d u v^{e} s$. ont permis de préciser la chronologie de la plupart des tombes (monnaies frappées en 405-420, vers 410-420, 440-450).

Ces développements récents de la recherche ont été diffusés en Allemagne mais n'ont guère eu de retentissements en France jusqu'à ce que Paul Van Ossel en expose un état en 1985 au colloque de la Société française d'étude de la céramique antique en Gaule à Reims ${ }^{14}$. Dans ce même colloque, W. Dijkman présentait les premiers résultats des fouilles de Maastricht ainsi qu'une esquisse de chronologie de la sigillée d'Argonne dans les différents dépôts de la ville. En attendant une étude plus complète qui s'avérera sans doute fondamentale pour notre sujet, il livrait au public le dessin de six molettes nouvelles, toutes inconnues de Chenet, peut-être l'ultime génération de ce type de céramiques $^{15}$.

11 L. Bakker in: J. Metzler, J. Zimmer et L. BAKKer, Ausgrabungen in Echternach, Luxembourg, 1981, en particulier p. 320-331.

12 L. BAKKER, op. cit.

13 J.-P. LÉMANT el alii, Le cimetière el la fortification du Bas-Empire de Vireux-Molhain (département des Ardennes), Römisch-germanisches Zentralmuseum Mainz, 7, Mayence, 1985 , p. $71-75$.

14 P. van Ossei, Céramiques de la fin du ive siècle et du ve siècle en Gaule Belgique, SFECAG, Actes du Congrès de Reims, 1985, p. 63-69.

15 W. Dijkman, La terre sigillée tardive décorée à la molette à motifs chrétiens, trouvée dans la vallée mosane, en particulier à Maastricht (Pays-Bas), ibid., p. 57-6'2. 
Entre-temps, la recherche d'éléments de datation susceptibles d'éclairer les vicissitudes de l'habitat rural et du peuplement dans le Nord de la France ainsi que la publication de la sigillée de VireuxMolhain m'avaient amené à reprendre les publications originales qu'avaient utilisées Unverzagt et Chenet.

Or en lisant l'article de E. Schramm, G. Wolfram et J. B. Keune sur les fouilles du grand amphithéâtre de Metz, les identifications faites par Unverzagt de certains décors reproduits dans les planches finales m'ont paru erronées ${ }^{16}$. Me rendant au musée de Metz, au début de 1985, dans l'espoir incertain de vérifier ce point, j'ai eu la surprise de retrouver conservés les fragments photographiés en 1902 ainsi qu'une bonne centaine d'autres tessons de sigillée décorés à la molette. Le mobilier découvert lors des fouilles de 1902 et 1903 avait été soigneusement déposé au musée et y était resté intact près de quatre-vingts ans malgré les deux guerres mondiales. Conscient de l'intérêt de la collection, le conservateur en chef du musée, Gérard Collot, avait fait nettoyer et inventorier les objets les plus intéressants et notamment les fragments de céramique les mieux conservés ainsi que tous les tessons portant un décor. La collection était considérable, au moins deux fois plus abondante que l'ensemble tardif le plus important publié à ce moment là, celui d'Echternach.

Pour diverses raisons, je me suis limité à l'étude des pièces inventoriées déjà nombreuses. N'ayant pu traiter qu'un aspect très partiel de la collection, j'ai longtemps hésité à ne présenter qu'un inventaire provisoire. Je me suis convaincu de la nécessité de le faire à mesure que, les années passant, il m'est apparu que l'ensemble de Metz tenait une place centrale dans le développement de la sigillée au ve $\mathbf{s}$.

\section{LE GRAND AMPHITHÉÂTRE DE METZ : LES FOUILLES}

Le grand amphithéâtre de Metz a été découvert en 1902 au moment des travaux de construction des gares de voyageurs et de marchandises, plus exactement lors du démantèlement de la redoute du Paté - ou de la Seille - une petite fortification construite en 1736 au sud-est de la ville. L'amphithéâtre édifié semble-t-il, au cours du II $^{\mathrm{e}} \mathrm{s}$., avait été abandonné lors de la construction de l'enceinte du Bas-Empire. Mais les archéologues ont

16 E. Schramm, G. Wolfram, J. B. Keune, Das große römische Amphitheater zu Metz, Jahrbuch der Gesellschaft für Lothringische Geschichte und Altertumskunde, XIV, 1902, p. 340-430, en particulier la planche XXI, no 8 où Unverzagt reconnaissait la molette 82 .

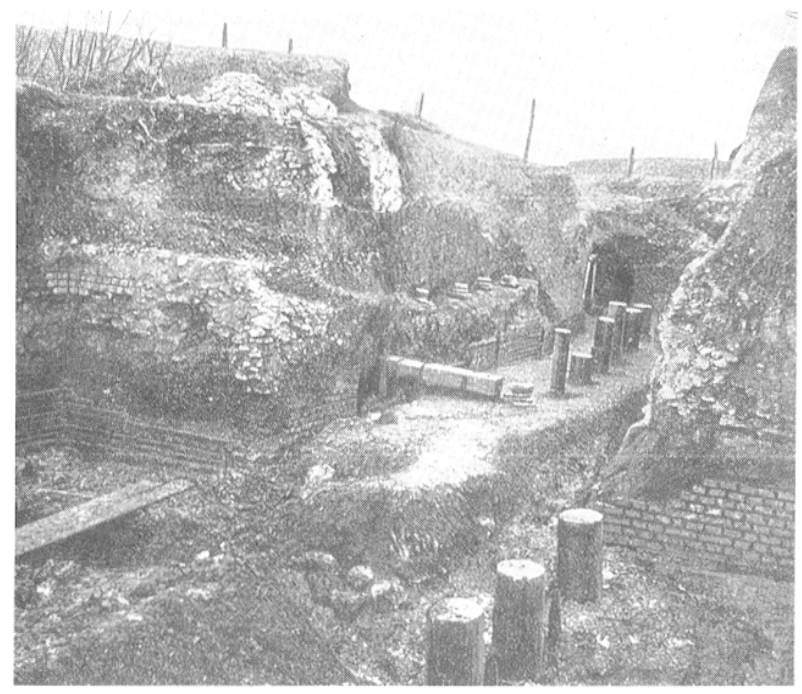

Fig. 1 - La partie nord de la fosse aux machines du grand amphithéâtre de Metz avec ses aménagements tardifs, en cours de dégagement.

retrouvé dans la grande fosse aux machines creusée dans l'arène des aménagements tardifs, avec des colonnes en réemploi, qu'ils ont interprétés comme un édifice de culte paléochrétien, peut-être l'oratoire de saint Clément (fig. 1).

Saint Clément, le fondateur de l'église messine, aurait établi "un oratoire dans les cavernes de l'amphithéâtre ... situé en dehors de la ville" selon une tradition rapportee par Paul Diacre au vill s. La découverte de tituli de tombes chrétiennes et de quelques ossements humains rend l'hypothèse assez plausible ${ }^{17}$. C'est également au milieu de l'édifice tardif et aux alentours immédiats qu'ont été trouvés les centaines de fragments de poterie. Il est assez difficile de restituer leur provenance exacte pour plusieurs raisons.

L'imprécision du rapport est certainement à l'image de la fouille ${ }^{18}$. D'autre part, le fossé interne de la redoute traverse la fosse aux machines en son milieu et les remblais qui en résultent sont venus recouvrir les niveaux plus anciens.

17 L'identification de l'oratoire de saint Clément a été discutée par R. S. Bour qui la conteste tout en admettant "l'existence dans l'amphithéâtre du premier oratoire chrétien $\dot{a}$ Metz», cf. R. S. Bour, Notes sur les églises de Metz antérieures à l'an Mil, Annuaire de la Société d'Histoire et d'Archéologie de la Lorraine, Metz, 38, 1929, p. 573, no 3 et Nancy Gauthier moins réservée, cf. N. Gauthier, L'évangélisation des pays de la Moselle, Rouen, 1980, p. 21. La découverte de tessères de mosaique multicolores dans le remblai implique la présence d'un édifice plus luxueux à proximité de la salle souterraine. 18 L'emploi de l'expression "auf und über dem Fussboden" est révélatrice à cet égard, cf. Е. Гснгамм, G. Wolfram, J. B. Keune, op. cit., p. 352. 
Toutefois, Wolfram et Keune décrivent trois horizons principaux avec, au fond de la partie centrale de la fosse la plus large, une couche de sable boueux épaisse de $1 \mathrm{~m}$, vraisemblablement contemporaine de l'utilisation du monument de jeux, contenant des sigillées plus anciennes ${ }^{19}$.

Plus vers le nord, le sol de l'édifice à colonnes, conservé seulement par endroits, reposait sur une couche de décombres de tuiles et de pierres dont certaines provenaient visiblement de l'amphithéâtre. On a retrouvé dans cette couche de nombreux restes animaux, ossements de boeuf, cerf, ours et des fragments de marbre et de céramique.

Le sol, en calcaire, était recouvert d'une épaisse couche d'incendie composée de bois brûlé, de tuiles, de poteries diverses, ossements animaux, fragments de marbre, peignes en os etc., et, selon G. Wolfram, d'inscriptions chrétiennes. De l'aveu même des auteurs, il n'a pas èté possible de distinguer précisément la couche de destruction elle-même des remblais sous-jacents ou de ceux provenant du creusement du fossé moderne qui la surmontaient ${ }^{20}$. Le seul critère distinctif entre les différents niveaux serait donc, selon Wolfram, la présence ou non d'inscriptions. Malheureusement, le compte rendu de J. B. Keune est moins explicite.

Selon l'interprétation de J. B. Keune, la fosse aux machines aurait connu un premier réaménagement lié à une habitation équipée d'une installation de chauffage dont témoigneraient des restes d'hypocauste et les rejets domestiques. C'est seulement dans un second temps que ce bâtiment aurait été modifié pour servir de lieu de culte. A son avis, le remblai sous le nouveau sol de la fosse n'a pu être mis en place longtemps après 300 .

\section{LE GRAND AMPHITHÉÂTRE : LA SIGILLÉE D'ARGONNE}

L'étude qui suit porte sur près de 300 céramiques différentes. Assez peu fragmentées, elles sont généralement dans un bon état de conservation. Elles n'ont pas subi, de toute évidence, la corrosion si souvent observée dans les sites ardennais. Une grande partie de la sigillée n'en présente pas moins des caractères de dégénérescence dans la qualité d'exécution, la finesse de la pâte et la cuisson. Le vernis n'atteint qu'à de très rares exceptions le lustre des produits classiques d'Argonne. La surface reste mate et la couleur varie d'un rouge orangé à l'ocre ou au brun mat. Manifestement, certaines poteries, beiges ou verdâtres, sont insuffisamment cuites.

19 Ibid., p. 351, note 1.

20 Ibid., p. 352.
Quelques autres, qui ont atteint un fort degré de cuisson, sont beiges. La moitié des vases comporte au cœur de la pâte une zone noire ou foncée.

\section{LES FORMES}

Bien que l'inventaire des formes lisses soit à poursuivre, les pièces recensées offrent déjà un bon échantillon. La forme dominante est de loin le bol Chenet 320 dans son type classique défini par Chenet ou représenté par des variantes tardives plus ou moins carénées. La part des bols carénés ou très évolués atteint environ $1 / 5^{\mathrm{e}} \mathrm{du}$ total.

Viennent ensuite la variante tardive de Chenet 304 (l'assiette Alzei 9/11) et le bol Chenet 324 .

Quelques assiettes et plats Chenet 304 ont été relevés mais ils restent nettement minoritaires par rapport à sa variante tardive. La forme des assiettes Alzei 9/11 est plus ou moins anguleuse (fig. $2, \mathrm{n}^{\circ \mathrm{s}} 9 \mathrm{et}$ 11) et le rebord plus ou moins haut (fig. $2, n^{\circ} 10$ ). Bernhard et Van Ossel ont récemment attiré l'attention sur le type qui n'apparaît que dans les dernières phases d'Alzei ou des camps voisins. La proportion entre les deux formes mérite en tout cas d'être méditée. Il faut ajouter enfin que quelques-unes de ces assiettes portaient un décor de peinture blanche.

Les bols à collerette Chenet 324 présents dans la collection correspondent en fait la plupart du temps à des formes peu "classiques». Quelques-uns portent aussi un décor à la peinture blanche, lignes courbes, rinceaux, palmes ou arbres stylisés.

Plusieurs autres types définis par Chenet (les $\left.\mathrm{n}^{\text {os }} 313,314\right)$ ou l'assiette à collerette bien connue dans le Namurois sont aussi représentés par quelques exemplaires décorés aussi à la peinture blanche. D'autres formes plus rares peuvent être citées pour mémoire, le $n^{\circ} 335$ de Chenet, quelques fragments de cruche, le vase $\mathrm{n}^{\circ} 7583$ dont la forme est attestée dans la dernière phase $\mathrm{d}^{\prime} A l z e i^{21}$, le $\mathrm{n}^{\circ} 7815$, un mortier en sigillée (fig. $\left.2, \mathrm{n}^{0} 14\right)^{22}$ ou encore un mortier en sigillée claire luisante du nord des Alpes, peut-être (fig. 2, $\left.\mathrm{n}^{0} 13\right)^{23}$.

21 J. Oldenstein, op. cil., fig. $2,8$.

22 Une forme semblable est attestée à Huy : C. TrlokinPeters et. D. Marcolungo, Le matériel mérovingien de la rue des Augustins à Huy, Activités 84-85 du SOS Fouilles, 4, 1986, fig. 160,5, p. 202 .

23 Cf. entre autres N. Lambogria, Nuove osservazione sulla "terra sigillata chiara" I, tipi A et B, Revue d'Etudes Ligures, 24, 1958, p. 257-330 et récemment l'article collectif : Céramiques tardives à revêtement argileux des Alpes du Nord et. de la Vallée du Rhône (de Martigny à Vienne), Figlina, 7, 1986 , p. $19-49$. 

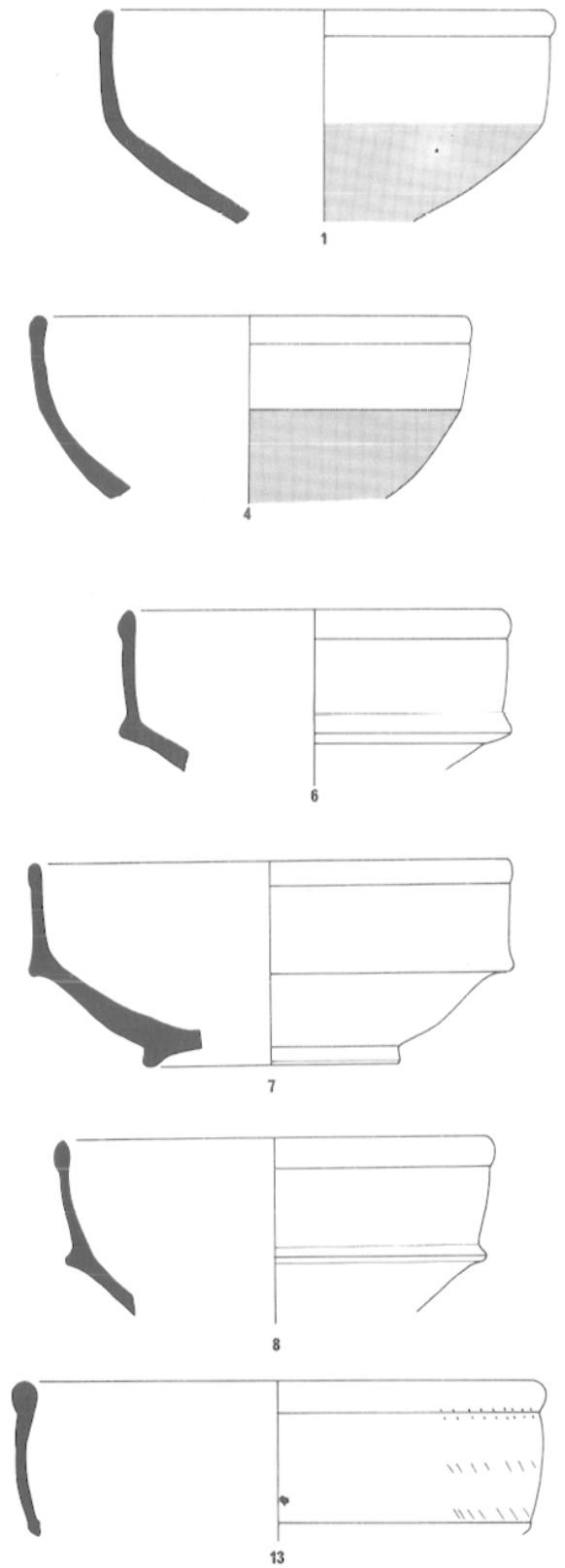

Fig. 2 - Les principaux types de céramique du grand amphithéâtre de Metz: la sigillée. 1 à 12 et 14 : sigillée d'Argonne; 13 : sigillée claire indèterminée.
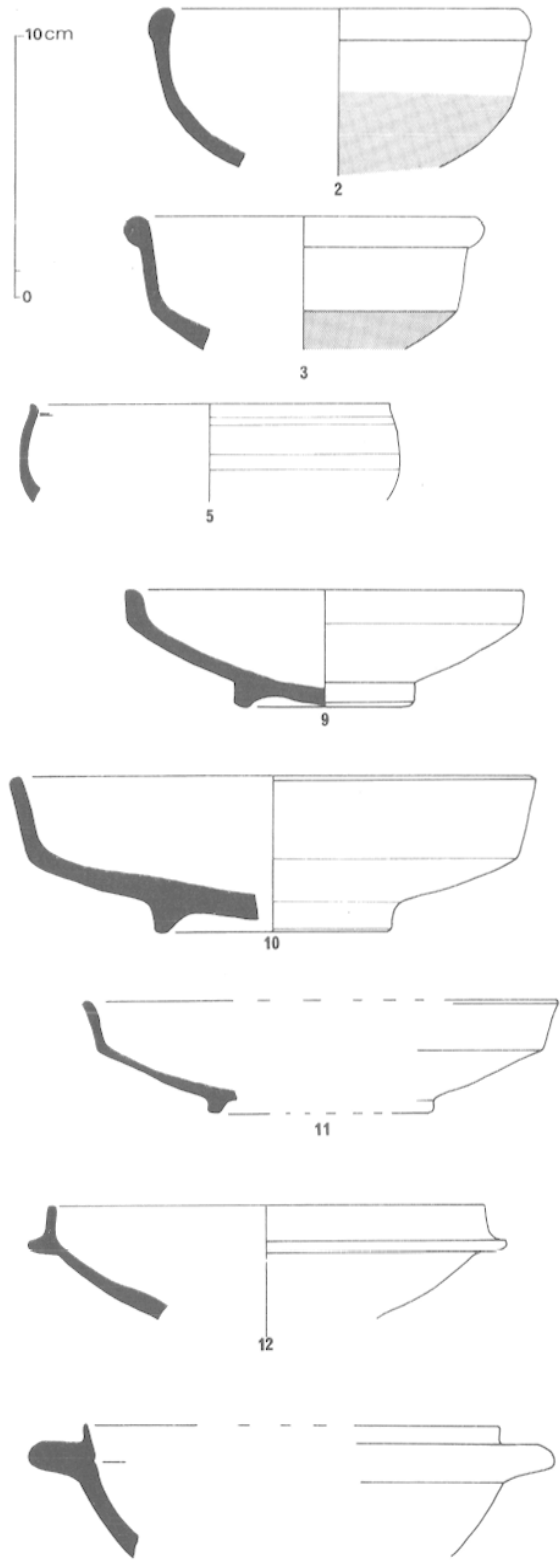

Les autres catégories de céramique s'intègrent parfaitement au corpus des formes tardives, avec de la vaisselle granuleuse du type Mayen, en majorité, d'ailleurs - cruches Alzei 30, pots ovoïdes Alzei 27, jattes Alzei 28 - ou encore avec des mortiers en terre orangée lisse, parfois peints en rouge (fig. 3 , $\mathrm{n}^{\mathrm{os}} 15$ et 16$)^{24}$.

24 Les mortiers de ce type sont connus dans d'autres contextes comparables à Reims, Châlons-sur-Marne ou Trèves.
LA SIGILLÉE DÉCORÉE À LA MOLETTE

Le catalogue qui suit se borne aux pièces inventoriées et quelques autres portant la mention de la date de découverte ${ }^{25}$.

164 fragments ont été examinés correspondant à 128 vases différents. 107 décors ont été identifiés

25 Ces objets portent la mention "amph.» et la date de découverte; cf. infra le catalogue. 

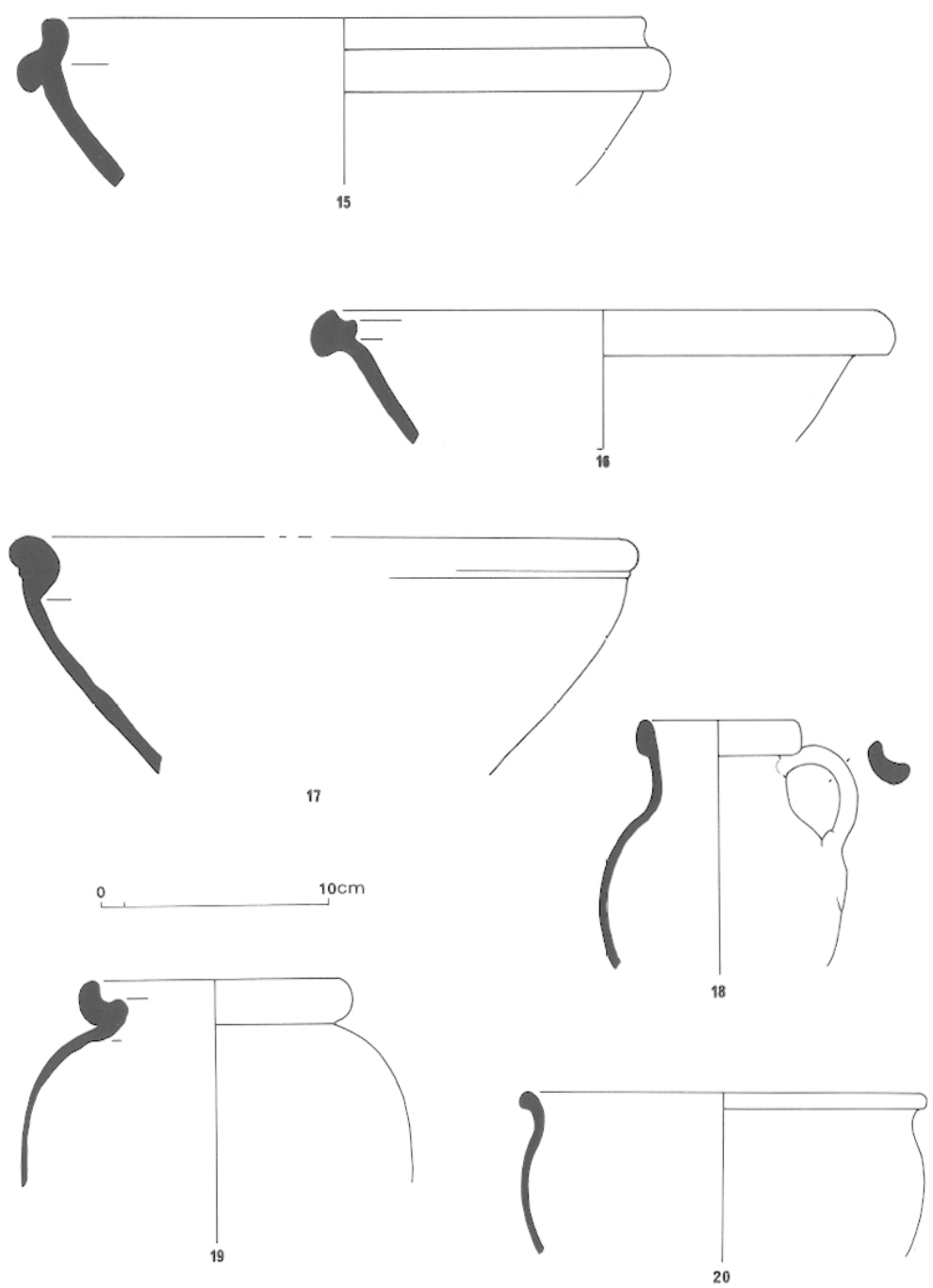

Fig. 3 - Les principaux types de céramique du grand amphithéâtre de Metz : la céramique commune.

avec certitude et 6 avec un certain doute (fig. 4). 8 des fragments reproduits par Schramm, Wolfram et Keune ont été retrouvés (les $n^{\text {os }} 1-3,5-9$ de la planche XXI et 3 à 5 de la planche XXII).

Trois fragments paraissent nettement plus anciens que la majorité du lot. Il s'agit de deux tessons décorés de casiers à hachures obliques attribuables au groupe 3 de Hübener qui s'interrompt peu après $350^{26}\left(\right.$ les $\mathrm{n}^{\text {os }} 10$ et 128) (fig. 5) et d'autre part d'un troisième tesson non retrouvé mais qui est représenté

26 Hübener proposait les années 340-365 pour le groupe 3. Quelques corrections ont été apportées depuis (cf. D. Bayard, A. Ferditire, la céramique sigillée, in: A. Ferdière el alii, Fouille de sauvetage du site gallo-romain de la "Fosse Dieppe" à Dambron (E. \& L.) (2 partie), Revue Archéologique du Loiret, 6, 1980, p. 35-39). dans l'article de $1902^{27}$. Ce dernier est à peine moins ancien que les précédents. Il appartient à un groupe caractéristique de décors, le groupe 2 de Hübener, dont l'existence ne se poursuit pas au-delà des années $370-375^{28}$. Ce sont vraisemblablement les rares représentants qui attestent une occupation de l'amphithéâtre avant le $\mathrm{v}^{\mathrm{e}} \mathrm{s}$. ou la fin du $\mathrm{IV}^{\mathrm{e}} \mathrm{s}$. Hormis ces témoins que l'on qualifiera de résiduels, l'ensemble donne l'impression d'une grande homogénéité. Les 113 décors reconnus ne résultent que de

27 E. Schramm, G. Wolfram, J. B. Keune, op. cit., pl. XXI, 10.

28 Cf. D. Bayard et J. Fournier, Un dépotoir du Ive siècle, rue Blaise-Pascal à Amiens, Cahiers Archéologiques de Picardie, 5, 1978, p. 191-198 et L. Bakker in : J. Metzler, J. Zimmer, L. BaKKer, Ausgrabungen in Echternach, op. cit. 


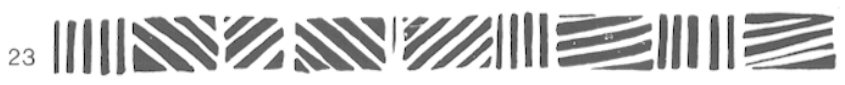

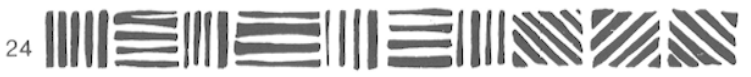

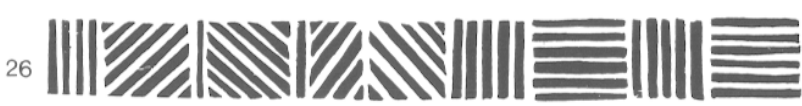

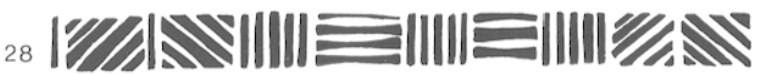

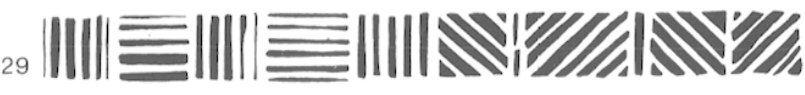

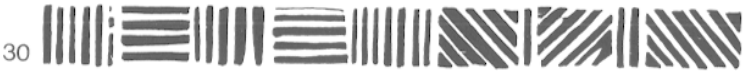

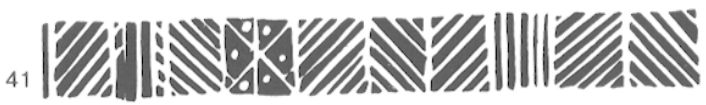

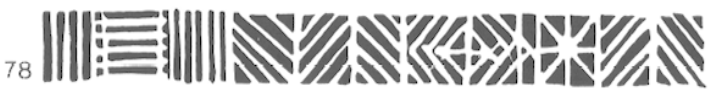

83 $\mathbb{M}$ Y/A

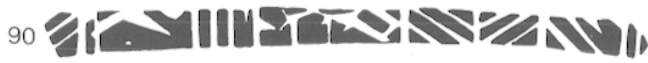

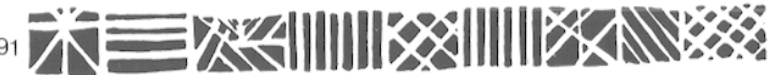

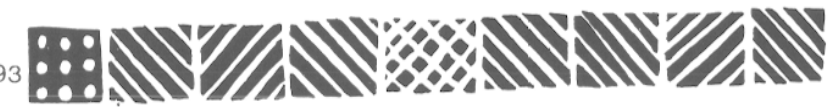

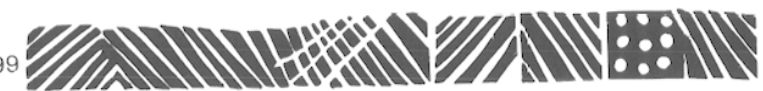

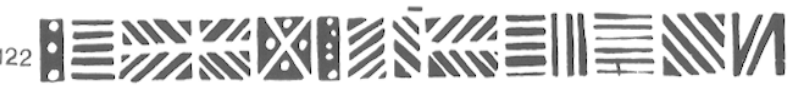

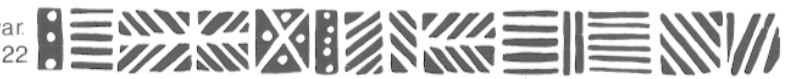

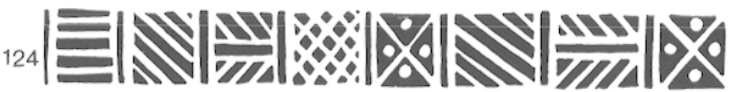

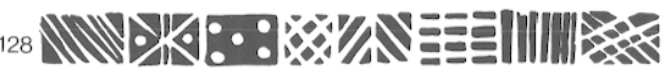

13 2 \%

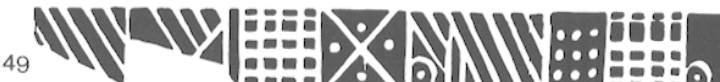

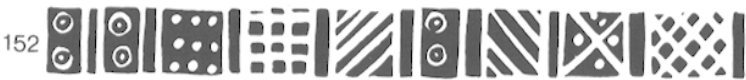

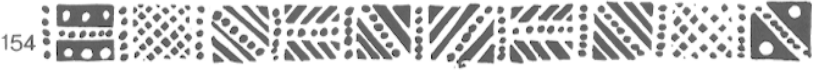

| Z

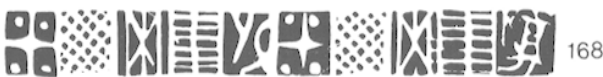

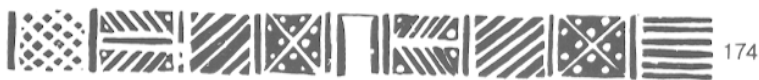

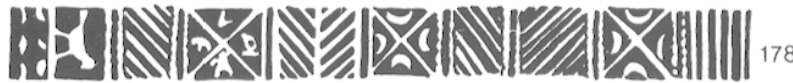

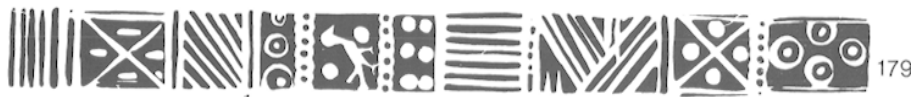

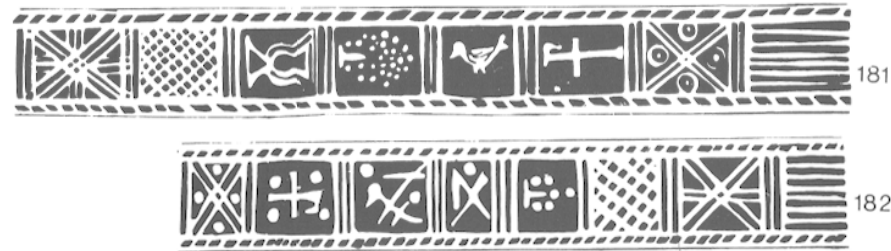

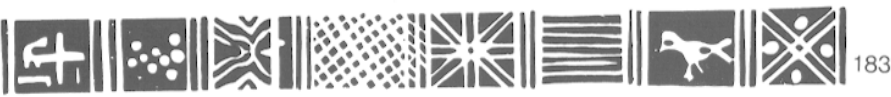

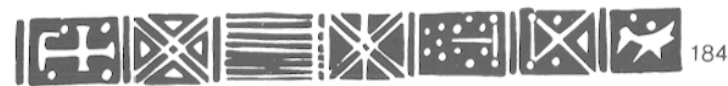

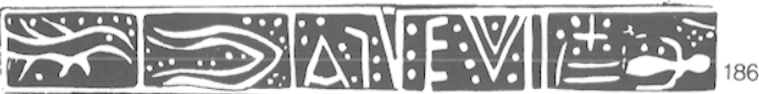

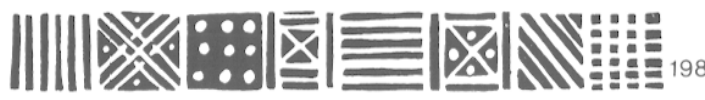

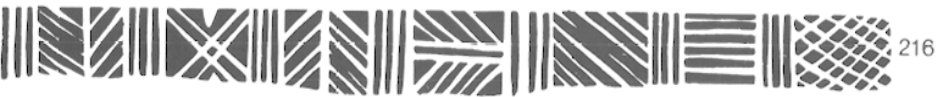

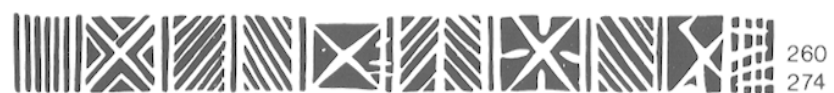

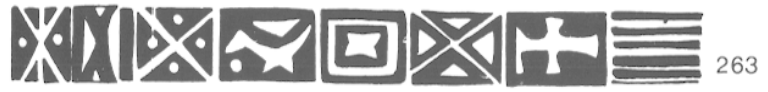

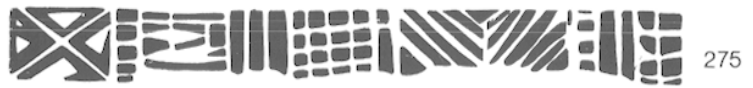

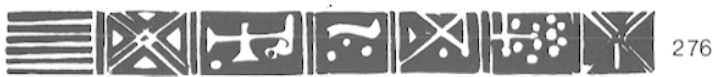

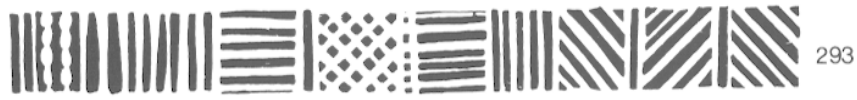

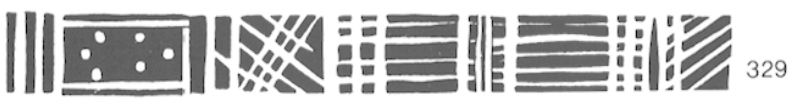

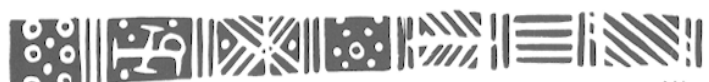

Nicolle 8

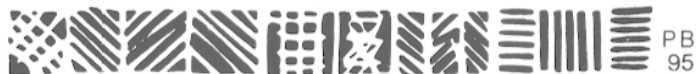

Fig. 4 - Les décors à la molette reconnus dans le grand amphithéâtre de Metz.

Les numéros renvoient au catalogue de Chenet (1941) et aux articles de Nicolle (1962) et Piton, Bayard (1977).

Toutes les molettes sont reproduites grandeur nature. 
50 molettes différentes. La même molette se retrouve couramment sur 3,4 ou 5 vases différents et jusqu'à 7 ou 8 . Une telle concentration se prête à deux explications possibles : elle est due soit à une exceptionnelle longévité des molettes, soit plus vraisemblablement à une forte concentration sur un nombre restreint d'années.

Le faible nombre de molettes inédites confirme cette dernière hypothèse et accrédite l'idée que l'ensemble de Metz reflète en grande partie le corpus en usage à l'époque. Sur les dix molettes qui n'étaient pas connues de Chenet, six ont été signalées depuis, dans des contextes paraissant a priori contemporains de Metz et en premier lieu Echternach. Le nombre de décors réellement nouveaux qu'apporte la collection messine est de quatre $3,5 \%$ du total des décors, $8 \%$ du total des molettes) (fig. 5).

De plus, un grand nombre de molettes de Metz est attesté sur les principaux sites du $\mathbf{v}^{\mathbf{e}} \mathbf{s}$. déjà mentionnés plus haut, les thermes Sainte-Barbe de Trèves, la fortification d'Echternach; elles y constituent d'ailleurs plus de la moitié des collections. Les recoupements entre nos trois contextes concernent le plus souvent des molettes déjà représentées par plusieurs exemplaires à Metz. Quant à celles trouvées dans la couche de destruction d'Alzei, elles sont aussi attestées à Metz.

On reconnaît bien sûr la série des molettes chrétiennes (groupe 8 de Hübener). killes sont presque toutes représentées ici, les $\mathrm{n}^{\text {os }} 181,182,183 \mathrm{et}$ la variante $259,184,186,260$ et sa variante 274,270 , 276 de Chenet. Mais il y en a bien d'autres que l'originalité et l'unité iconographique ne mettent pas aussi bien en évidence que les molettes chrétiennes. Ces dernières ne constituent d'ailleurs qu'une minorité $(18 \%$ des molettes, à peine $17 \%$ des décors reconnus).

Le reste des décors, si l'on reprend la classification de Hübener, se disperse dans les groupes 4, 5, 6 et 7 selon ces proportions :

- groupe 4: $27(25 \%)$;

- groupe $5: 30(28 \%)$;

- groupe 6 : $7(6,5 \%)$;

- groupe $7: 25(23 \%)$;

- groupe $8: 19(17,5 \%)$.

Si l'on suivait l'hypothèse de l'auteur, on obtiendrait une datation de l'ensemble messin de trente à quatre-vingt-cinq ans, entre les années 350375 et $405-435$. La période maximale que devrait faire retenir la prudence est très vaste et n'autorise guère de conclusions. La période minimale au cours de laquelle auraient pu se diffuser les cinq groupes,
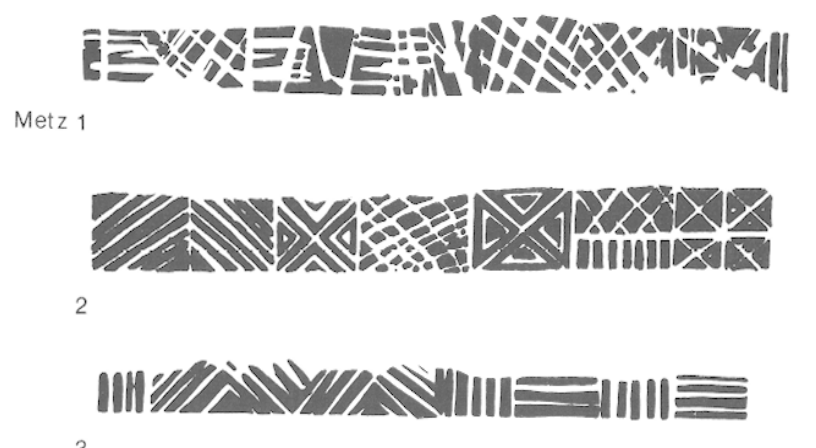

3
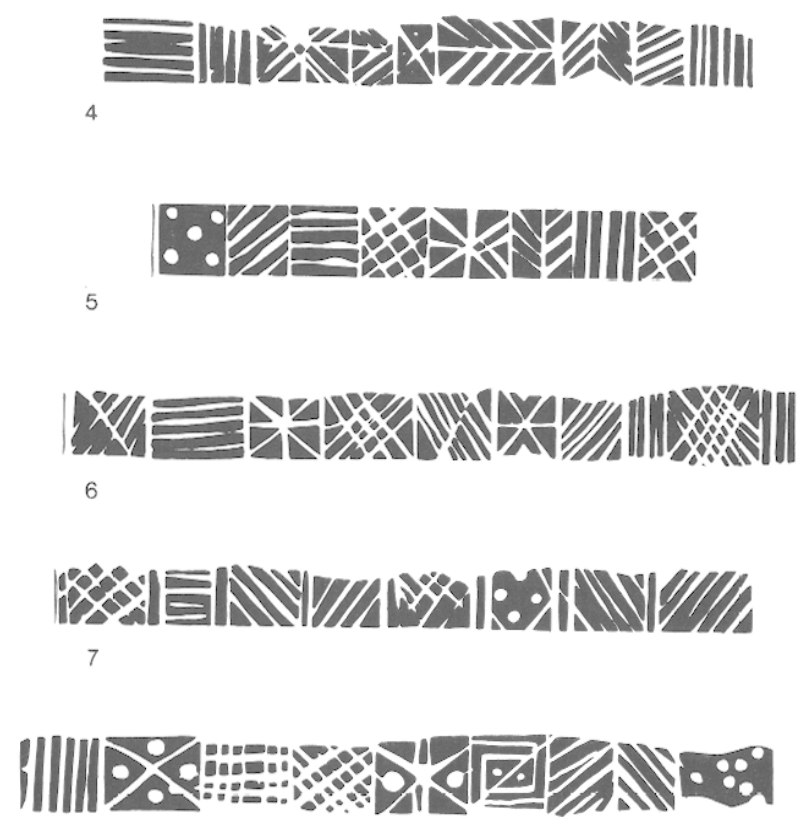

8
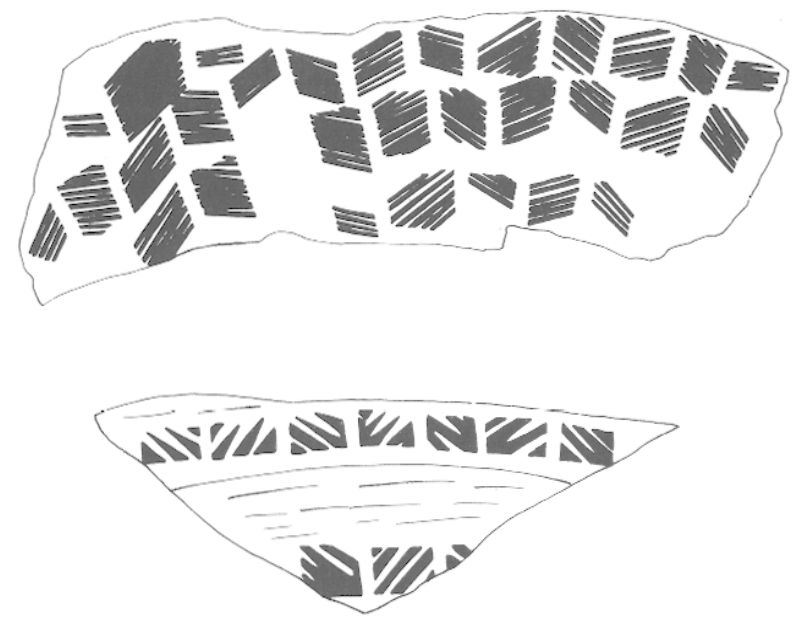

Fig. 5 - En haut, les molettes inédites reconnues dans le grand amphithéâtre de Metz.

En bas, deux des trois fragments de sigillée décorée à la molette datés des deux premiers tiers du IV $\mathrm{I}^{\mathrm{e}} \mathrm{s}$. provenant du grand amphithéâtre de Metz.

entre les années 375 et 405 , ne s'accorde pas avec les datations proposées par MM. Bakker, Bernhard, 
Cüppers et Hüssong, pour les formes lisses Alzei 9/11 par exemple ou les ensembles de référence de Trèves et Echternach. L'impression de départ ne concorde pas avec la chronologie de Hübener et suggère une plus grande concentration de l'ensemble après les années 406 .

Mais, si la plupart des paramètres que nous avons utilisés confirment la datation globale de la collection au ve s., ils ne nous autorisent pas pour autant à assigner la même datation à toutes les pièces. La lecture des conditions de la fouille et de l'enregistrement des données ne peut que nous inciter à la prudence. Le risque de dispersion diachronique d'une minorité de vases est d'autant plus grand que le nombre de fragments est élevé. La question pouvait déjà se poser pour les ensembles de Trèves comptant 20 décors différents ou Echternach, 27 ou 28. Ici avec 50 molettes différentes, elle s'impose. A l'extrême, on peut même se demander si cette homogénéité soupçonnée à Metz ne relève pas de l'illusion. L'image obtenue ne serait pas le reflet d'une seule phase d'occupation, mais de plusieurs successives et différentes.

L'idéal serait de procéder à une analyse détaillée de chacune des molettes retrouvées. Malheureusement, la "carte d'identité» de chaque molette n'est guère explicite. Chacune d'entre elles est connue en cinq ou six exemplaires répartis sur quatre sites en moyenne. Chacun de ces sites ne se prête pas à des commentaires particuliers et la datation en est le plus souvent imprécise.

Rares sont les tombes présentant des associations d'objets significatives qui nous fourniraient des indications plus précises; encore plus rares (une demi-douzaine) celles qui sont datées par des monnaies tardives.

Il faut donc aborder la question autrement et s'interroger sur la nature des sites où chacune des molettes de Metz est signalée, camps du limes, villes, villae ... afin d'en dégager la fréquence. La liste des contextes en corrélation avec l'ensemble du grand amphithéâtre de Metz compte environ 145 noms qui ont été regroupés pour plus de commodité en 17 catégories ou classes:

0 les ateliers d'Argonne

I les villes fortifiées et camps du limes rhénan

II les villes et points fortifiés des secteurs frontaliers de Séquanaise et de Rhétie

III les villes fortifiées du «limes belgicus» auxquelles a été adjoint Alet sur le tractus armoricanus

IV les villes fortifiées de l'intérieur

$\mathrm{V} \quad$ castella et refuges de l'intérieur
VI villae et loci

VII sites ruraux groupés ou indéterminés : vici ou sanctuaires...

VIII nécropoles romaines tardives

(hors Ardennes)

IX nécropoles mérovingiennes (hors Ardennes) (sont incluses celles qui prennent racine dans un noyau de sépultures romaines tardives).

Deux classes rassemblent les sites ardennais qui montrent une grande originalité au cours du $v^{r} s$.

$\mathrm{X}$ les habitats

XI les nécropoles.

Quatre classes regroupent les découvertes effectuées en territoire barbare ou sur ses marges :

XII les habitats en pays alaman-burgonde

XIII les nécropoles en pays alaman-burgonde

XIV les habitats en pays franc-frison

$\mathrm{XV}$ les nécropoles en pays franc-frison.

La représentation de chacune des catégories définies est loin d'être harmonieuse. Elle présente même de fortes anomalies.

La place qu'occupent les camps militaires du limes est considérable, environ $1 / 5^{\circ}$ du total. En comptant l'ensemble des burgi, castella et villes fortifiées des différents secteurs frontaliers, on atteint $1 / 4$ du total. Il est vrai que l'archéologie allemande s'est beaucoup investie depuis le début du siècle dans la recherche sur le limes. Il n'en reste pas moins que nombre de ces sites présentent des points communs avec l'ensemble messin.

La place des villes de l'intérieur, essentiellement en France - dix mentions - est sans doute sousestimée. C'est à peu près la part de la classe $\mathrm{V}$, les castella et refuges de l'intérieur. Que ces fortifications aient laissé quelques traces d'une occupation pendant les troubles du $v^{e} s$. n'est pas pour surprendre.

Plus étonnante par contre, la faible représentation des sites ruraux - villae et vici - mérite que l'on s'y arrête. La liste des villae se limite à cinq ou six et celle des vici à six ou sept. Parmi les villae, deux ont connu une occupation continue, semble-til, jusqu'au $\mathbf{v i}^{e} \mathbf{s}$. et s'intègrent donc sans problème dans la chronologie, Mercin-et-Vaux et Jumel en Picardie. Celle de Vésigneul-sur-Marne a livré, outre la molette 198, un décor chrétien, le n" 182 . Apparemment, seuls deux sites abandonnés à la fin du IV ${ }^{e}$ s. ou peu après se retrouvent dans notre liste : la villa de Rousseloy dans l'Oise avec la molette 93 et la villa de Limé à Pont-d'Ancy dans l'Aisne avec la molette 152. Les sites rassemblés dans la seconde catégorie sont de natures diverses et comprennent 
une grotte à Saint-Moré dans l'Yonne, les fondations d'un four du Haut Moyen Age à La Saulsotte (Aube) et trois vici ou sanctuaires : Morains dans la Marne (Unverzagt, Chenet, abrégé U.C. 26 et 293), Vendeuil-Caply dans l'Oise (encore U.C. 293) et Les Fontaines Salées dans l'Yonne (U.C. 275).

La représentation des cimetières romains tardifs est à l'image des deux classes précédentes et se réduit à trois sites seulement: Cortrat, une nécropole à caractères germaniques du Loiret, Rheingöhnhein et Alzei deux cimetières situés près des camps du même nom au bord du Rhin (molettes 26 et 93$)^{29}$.

Le nombre des correspondances entre l'amphithéâtre de Metz et les sites des Ardennes est très élevé et met en relief les témoins $d u v^{c} \mathbf{s}$., période particulièrement attestée dans le massif ardennais. Les trouvailles faites en domaine germanique, des pays Alamans aux pays Francs ou Frisons, sont assez nombreuses spécialement aux abords du Rhin et de ses principaux affluents.

Enfin dernière anomalie, aucune des molettes de l'amphithéâtre de Metz n'a été reconnue en GrandeBretagne. I a liste des produits argonnais importés dans la grande île n'est pas très longue mais quelques exemplaires ont été recensés par M. Fulford ${ }^{\mathbf{3 0}}$.

Une comparaison de la liste de Metz avec celle obtenue pour un site un peu plus ancien, Altrip, est éloquente et nous convaincra du caractère non fortuit de la distribution de la première. Le choix d'Altrip comme èlément de comparaison s'est imposé pour deux raisons principales. La durée d'occupation du castellum est bien cernée entre $367-370$ et une date antérieure à la fin d'Alzei, peut-être 407-411 ${ }^{31}$. Une garnison de milites Martenses placée sous les ordres du dux Mogontiacensis est attestée à Altrip par la Notitia Dignitatum, probablement entre les années 393 et 407-411 ${ }^{32}$. D'autre part les 17 molettes

29 Cette dernière découverte aurait pu être classée à la limite en $\mathrm{I}$.

30 M. Fulford, Pottery and Britain's Trade in the Late Roman Perind, in : D. P. S. Peacock (dir.), Pottery and Early Commerce. Characterization and Trade in Roman and Later Ceramics, Londres, 1977, p. 39-77.

31 G. Bersu, Das spätrömische Kastell in Altrip, in : Pfalzische Museum, 1928 et G. STEIN, Bericht der römischgermanischen Komission (BRGK), 1968, p. 92 et suiv.

32 II. Nesser.hauf, Die spätrömische Verwaltung der gallisch-germanischen Länder, Abb. Preutz. Akad. Wiss., 1968 $\mathrm{n}^{\circ} 2,40$ p. ; - E. Drмougeot, La Notitia Dignitatum et l'histoire de l'Empire d'Occident au début du ve s., Latomus, XXXIV， 4, 1975, p. 1079-1134; - D. HoffmanN, Das spätrömische Bewegungsheer und die Notilia Dignitatum, Dusseldorf, 1970. Le camp d'Altrip aurait été abandonné lors de l'installation des Burgondes dans la vallée du Rhin soit dès 407 à la suite de l'invasion des Alains-Vandales, soit vers 411 . qui en proviennent sont toutes différentes de celles de Metz, ce qui pourrait laisser penser que le camp est nettement antérieur au dépôt messin.

Sur les 17 molettes publiées par Unverzagt, 14 sont signalées ailleurs qu'à Altrip, dans 61 contextes dont 33 sont absents de la liste de Metz.

Les différences concernant les classes I à V sont minimes. La place des camps militaires y est un peu plus faible, $1 / 5^{\mathrm{e}}$ du total, mais reste prépondérante. La grande différence concerne les sites ruraux qui atteignent entre $1 / 4$ et $1 / 3$ du total, ce qui est en soi plus conforme à la logique : une quinzaine de villae et deux ou trois vici-sanctuaires. Avec les habitats ruraux, se multiplient les cimetières, huit dont trois dans les Ardennes.

La présence des trente-trois sites nouveaux met encore plus en relief les différences fondamentales entre les deux listes.

Celle d'Altrip repose à peu près également sur des sites fortifiés, castella frontaliers et villes de l'intérieur d'une part et des sites ruraux ouverts, habitats et cimetières d'autre part. Celle de Metz s'illustre par un lien extrêmement ténu avec les sites ruraux en dehors des Ardennes, lien qui tient pour une grande part à deux ou trois molettes, qui ont une diffusion d'un type différent. Les molettes 152 et 93 spécialement, retrouvées par deux fois sur des sites ruraux apparemment abandonnés au plus tard au début du $v^{e}$ s., ont une diffusion qui s'apparente également à la liste d'Altrip. Sans préjuger de leur datation, on peut les considérer comme des "maillons faibles» du dépôt du grand amphithéâtre.

Les listes établies à partir des collections des thermes Sainte-Barbe ou d'Echternach sont tout aussi éloquentes que celle de Metz. Les tendances dégagées sont les mêmes et les recoupements si nombreux que le regroupement des trois ensembles est largement justifié. Un bref commentaire des listes de ces deux sites le montre bien et de plus met en évidence la présence là aussi de quelques «maillons faibles».

Sur les vingt molettes des thermes SainteBarbe, douze ont été retrouvées à Metz, les huit autres sont attestées sur cinquante sites représentés pour la plupart dans la liste de Metz. Celle de Trèves ne compte que neuf ou dix sites différents introduits par quatre molettes: une sépulture alamane à Trébur, un castellum du limes rhétique à Kellmünz (U.C. 163), la ville fortifiée de Boulogne-sur-Mer (U.C. 126), les castella de Goudsberg et Bitburg, peut-être la nécropole du castellum d'Oudenbourg (U.C. 108), une sépulture germanique à Herthen (U.C. 106) et enfin une villa en Rhétie à DenningMunich et un castellum de la Bretagne romaine à 
Margidunum (U.C. 58). Des cinq décors, le premier est tout à fait caractéristique du début du $\mathrm{v}^{\mathrm{e}} \mathrm{s}$. et correspond à une des rares lacunes manifestes de Metz. Le dernier, par contre, le seul signalé dans l'île de Bretagne, doit être considéré comme «un maillon faible".

La distribution des molettes 58, 106 et 108 est plus ambiguë. Si U.C. 108 est réellement attestée à Oudenbourg, elle doit être classée, elle aussi parmi les "maillons faibles".

A Echternach, le synchronisme avec Metz apparaît de manière encore plus flagrante qu'à Trèves. Vingt-trois des trente molettes qui en proviennent sont attestées à Metz. Les sept molettes nouvelles ne font apparaître que onze noms nouveaux, dont trois résultent de lacunes manifestes de Metz (molettes 163, déjà citée pour Trèves, et 257 à symboles chrétiens à Bayum aux Pays-Bas).

Les huit autres noms sont introduits dans la liste par les deux molettes U.C. 48 et 82 . La molette 82 est signalée dans les burgi de Zullenstein, situé non loin d'Altrip, et de Rumersheim en Alsace et dans le castrum de Lisieux. La molette 48 , qui n'a d'ailleurs pas été identifiée avec certitude à Echternach, est liée entre autres au castellum d'Altrip. La molette 48 et à un moindre degré U.C. 82 doivent être considérées comme des "maillons faibles».

\section{PRopositions POUR UNE CHRONOLOGIE RELATIVE DE} LA SIGILLÉE D'ARGONNE DÉCORÉE Aं LA MOLETTE DE METZ ET D'AUTRES SITES DE LA FIN DU IV ET DU V $V^{e} S$.

Les réflexions que suscite la confrontation de ces différentes listes nous ont incité à poursuivre l'enquête en l'élargissant progressivement à d'autres contextes comparables à l'ensemble de Metz ou intermédiaires entre Altrip et ce dernier, comme celui d'Alzei. Les données ont été insérées dans un tableau à double entrée permettant à la fois une approche des molettes et de leur répartition et d'autre part des sites et des séries de décors qu'ils ont livrées. La démarche n'est pas originale et s'apparente aux méthodes mises en application avec succès par P. Périn et R. Legoux ${ }^{33}$. La grille de départ a été bâtie autour des deux ensembles de Metz et Altrip, en agglomérant au premier les molettes d'Echternach et des thermes Sainte-Barbe de Trèves, puis au second les décors attestés à Alzei. A l'intérieur de cette trame les molettes sont classées par leur

33 P. PÉrin avec annexe de R. Legoux, La datation des tombes mérovingiennes. Historique. Méthodes. Applications, Genève, 1980. numéro d'ordre dans le catalogue de Chenet. Leur position a cependant été modifiée en fonction des critères suivants :

- critères techniques: qualité de la cuisson (présence éventuelle d'une âme sombre dans la pâte);

- critères typologiques: forme Chenet 320 classique ou carénée;

- anomalies de la répartition par rapport à l'ensemble d'origine ("maillons faibles» ou intermédiaires).

Le classement qui est présenté dans le tableau (cf. p. 302) résulte d'un compromis entre plusieurs solutions qui diffèrent dans le détail mais qui aboutissent toutes à une répartition en trois phases ou horizons. Les divergences concernent les marges et interférences de ces horizons ou bien l'amorce d'éventuelles phases intermédiaires encore trop peu documentées.

La phase 1, que nous pourrions appeler horizon d'Altrip, doit regrouper en réalité beaucoup plus de décors que ceux qui ont été retenus ici ${ }^{34}$. Elle est constituée pour le moment de trente-trois molettes, les quatorze exploitables d'Altrip et dix-huit d'Alzei. Les "maillons faibles» des ensembles d'Echternach, de Metz et des thermes Sainte-Barbe de Trèves ont été classés parmi ces dernières (les $\mathrm{n}^{\mathrm{os}} 58,108,152$, 79, 82 et 93). Mais cette solution peut être contestée puisqu'elle ne se fonde que sur le hasard des répartitions, notamment pour la molette 93 qui présente les traces d'une cuisson caractéristique de la phase 2 (fig. 6).

La phase 2 est bâtie essentiellement autour des molettes de Metz et d'Alzei et s'achève avec les derniers témoins attestés dans le camp, avant les molettes chrétiennes. Elle compte environ trentesept molettes (fig. 7).

La phase 2 est marquée par des renouvellements dans la technique, la typologie et le choix des ateliers mais ces transformations se sont opérées progressivement et inégalement, semble-t-il, suivant les ateliers. La limite avec la phase 1 est très floue et n'est soulignée par aucune différence technique ou iconographique. Elle a été fixée à l'aide de la seule analyse

34 Il est certain que la grille serait déjà beaucoup plus complète si j'avais pu intégrer les molettes d'Altrip non publiées par Unverzagt. H. BERNHARD a compté au musée de Spire 76 décors différents provenant d'Altrip au lieu des 19 publiès par Unverzagt; cf. H. Bernhard, Die spätrömischen Burgi von Bad Dükheim-Ungstein und Eisenberg, op. cit., p. 51. Ces fragments sont actuellement en cours d'étude par M. L. Bakker. 


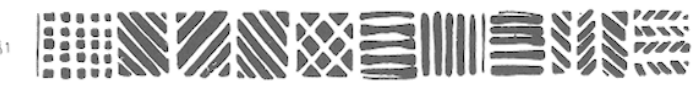

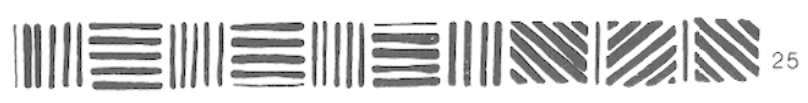

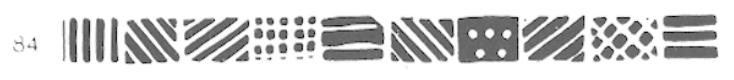

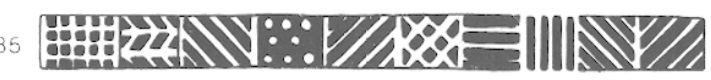

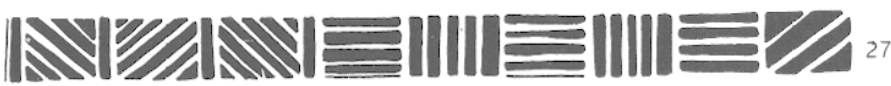

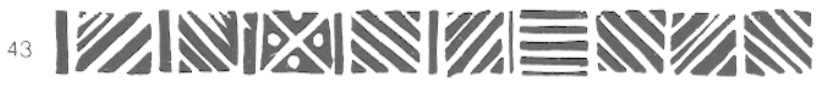

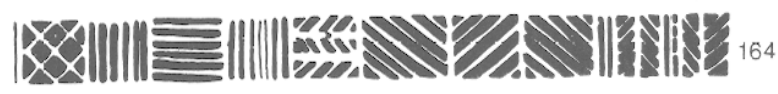

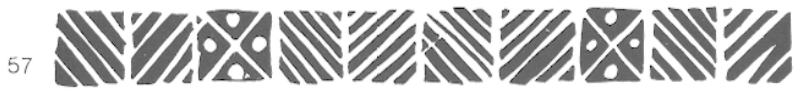

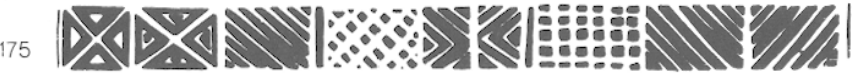

" "

".

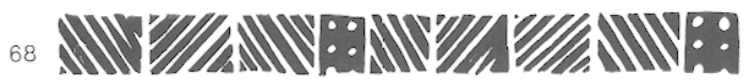

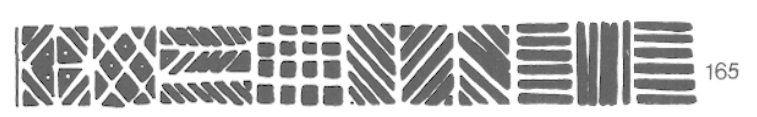

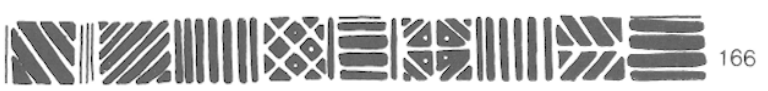

$\mathbb{N} / \mathbf{A} \mathbb{N}|||||| \mid$

$72\left[\begin{array}{ll}0 & 0 \\ 0 & 0\end{array}\right]$ N

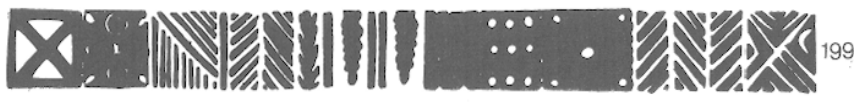

:

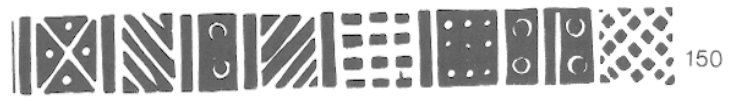

93 :0:

WAY

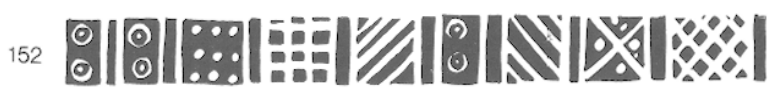

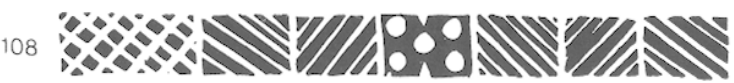

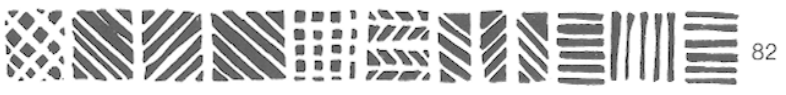

26

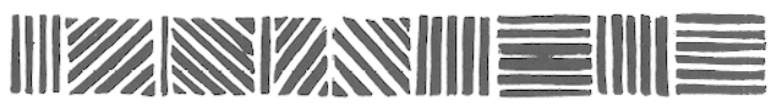

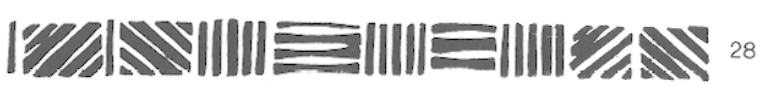

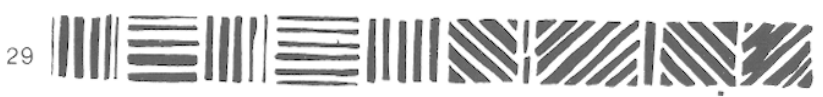

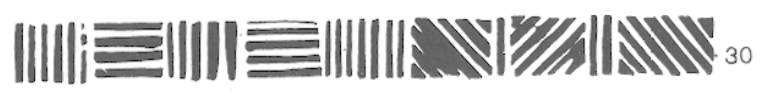

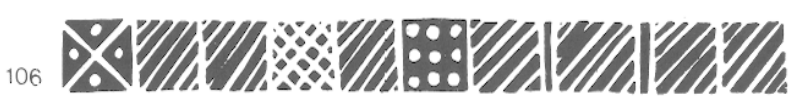

UANB:

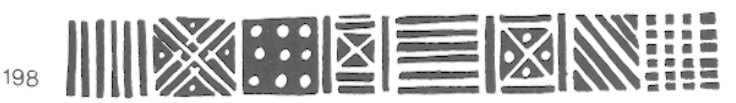

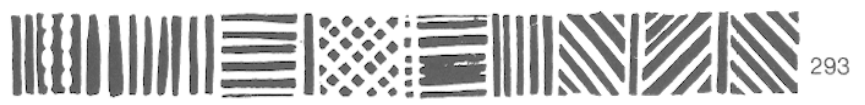

Fig. 6 - Quelques décors à la molette de la phase 1 et décors de la phase 2 assurant la transition avec la phase 1 (en bas). Les cinq décors du milieu sont probablement à rattacher à la phase 1 . 


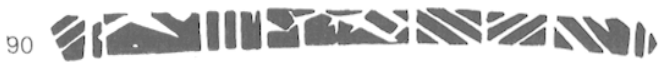
95 ${ }_{10}$ U

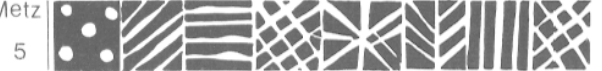

${ }_{24}\|\|\|\equiv\|\|\equiv\|\|\equiv\| \mathbb{E} \mathbb{E} / \mathbb{A}$

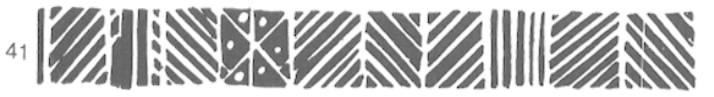

\section{"}

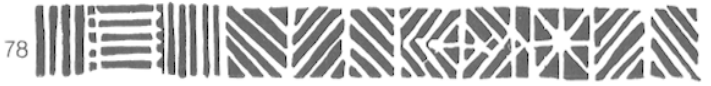

,

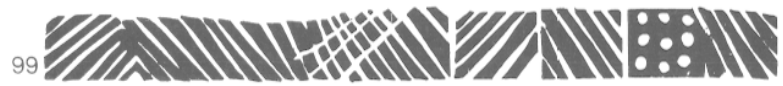

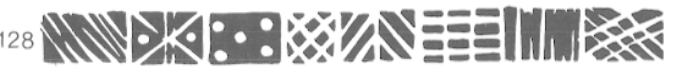

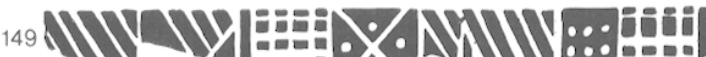

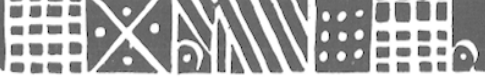

|

NV/.

* N N

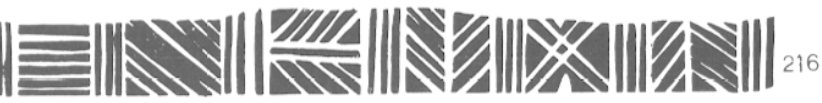

NUUA:

:

:

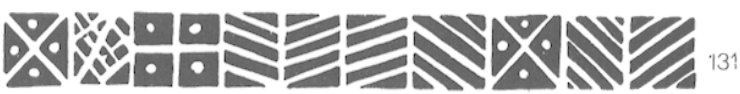

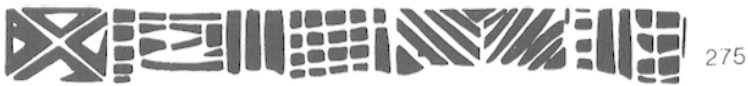

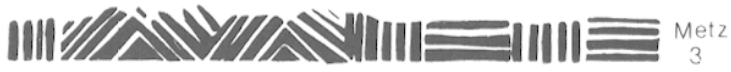

|||||=||||||

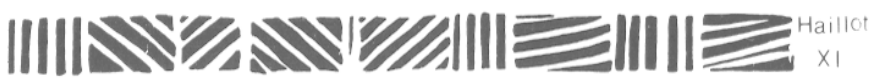

:

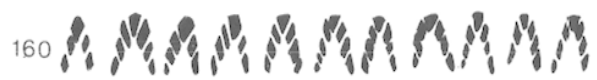

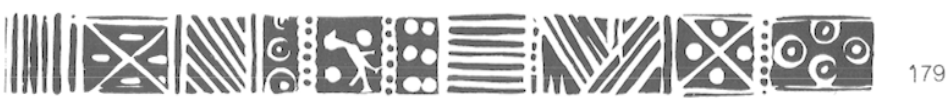

"10 骂:

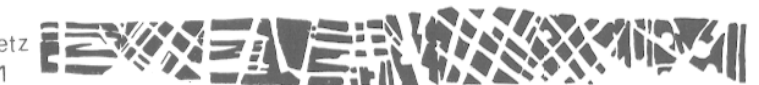

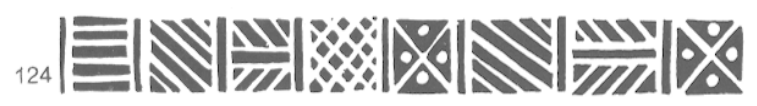

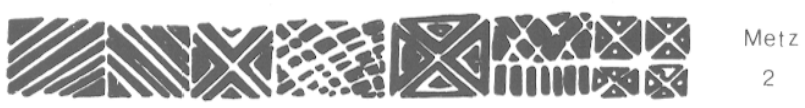

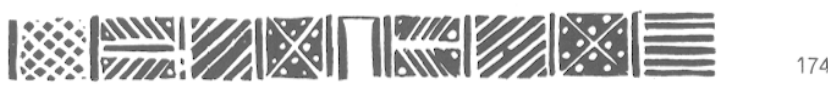

Fig. 7 - Décors à la molette de la phase 2. Les cinq décors du bas assurent probablement la transition avec la phase 3. 


\section{${ }^{200.274}$}

r.

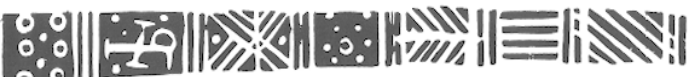
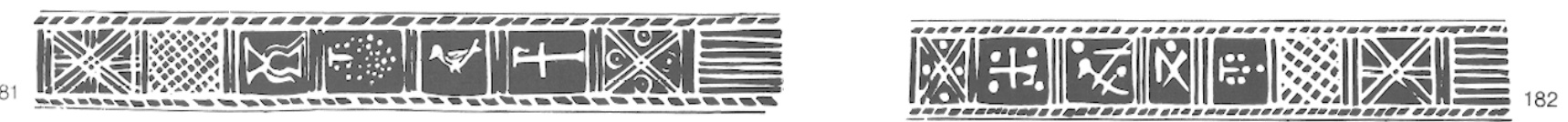
183.259||c|||

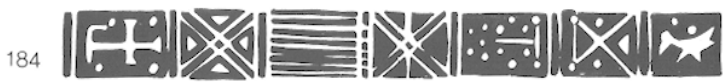

:

:

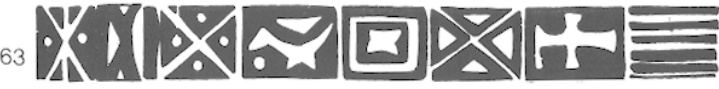

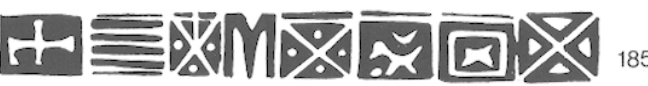

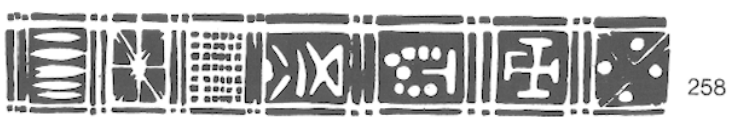

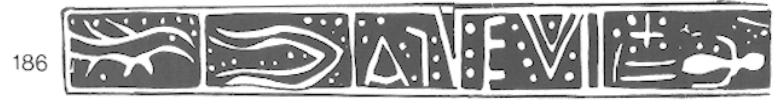

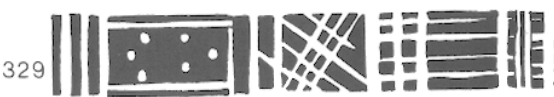

w I|l||-

"

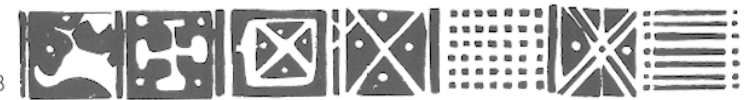

M4

(6)

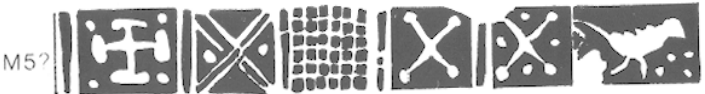

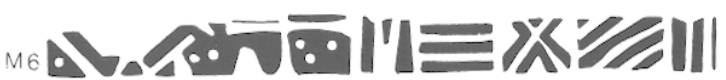

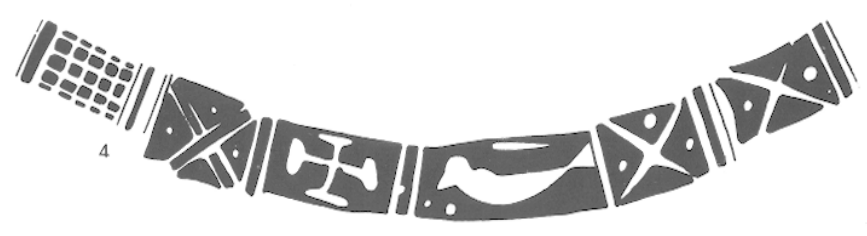

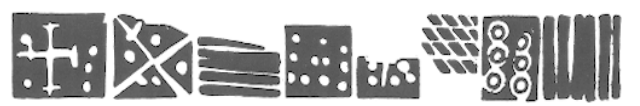

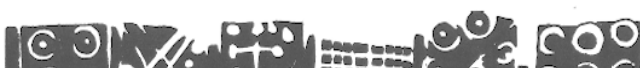

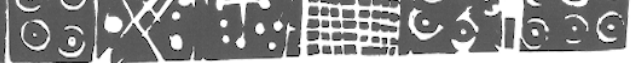
2.1. \&.○.

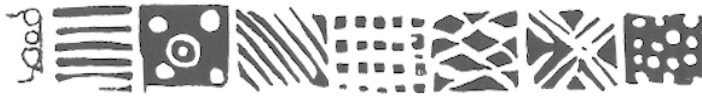

Fig. 8 - En haut, décors à la molette de la phase 3. Les numéros renvoient au catalogue de Chenet (1941) et à l'article de Nicolle (1962).

En bas, décor's a la molette de la phase 4 . Les $\mathrm{n}^{\mathrm{ox}} 1$ à 4 renvoient aux $\mathrm{n}^{\mathrm{os}} 180-182,191$ de l'annexe 2 , les lettres $M$ et $T$ aux découvertes de Maastricht (Dijkman, 1985, no 190 de l'annexe 2) et de Trivières (Faider-Feytmans, 1970, no 199 de l'annexe 2). 
de la répartition. La phase 2 se compose de trois ou quatre groupes. Dans le premier, se retrouve une série de molettes caractéristiques de la phase 2 mais qui sont associées sporadiquement à des sites plutôt caractéristiques de la phase 1 . Elles assurent la transition entre la phase 1 et la phase 2 (il s'agit des molettes 106 ou 108, 26, 28, 29, 30, 126, 198, 293). La molette 293 est assez caractéristique à cet égard et offre tous les signes d'une utilisation prolongée. Le cœur de la phase 2 se divise en deux ou trois catégories définies par des critères techniques et typologiques : d'abord le passage d'une cuisson du type traditionnel à une cuisson d'un type nouveau, c'est du moins ce que suggère l'apparition de plus en plus systématique d'un cœur plus sombre dans la pâte qui peut varier du rose foncé au noir ${ }^{35}$. Le deuxième critère est le développement de la variante tardive du Chenet 320, la forme carénée, qui s'applique en général à des poteries cuites en mode 2 . Mais, là aussi, le passage paraît tout à fait progressif. D'ailleurs, la détection du nouveau mode de cuisson n'est pas toujours évidente, la réoxydation ayant pu gagner complètement la partie du vase conservée. En tout cas, les caractères de la pâte et l'apparition de la forme carénée ne peuvent servir de critères chronologiques exclusifs. Les molettes 178 et 179 qui font partie des décors les plus récents de la phase 2 ornent souvent des vases de facture très classique dont la caractéristique principale est la faible cuisson.

Il est possible de cerner dans la phase 2 un groupe de molettes tardives telles que U.C. 178 et 179 mais aussi les ${ }^{\text {os }} 131,154$ et peut-être le $n^{\circ} 23$ qui répond au double critère technique et typologique défini plus haut.

Il existe en outre six ou sept molettes qui associent ces mêmes caractères, mais dont les anomalies dans la répartition posent des problèmes d'interprétation. Elles sont absentes d'Alzei et de la plupart des camps du limes. Pour les molettes 124, 168,174 et Metz 2 bien documentées, l'anomalie paraît manifeste. Pour U.C. 260 et sa variante 274, toutes deux ornées d'une colombe stylisée, 275 et Metz 1, il s'agit plus d'une impression que d'une constatation objective. Faut-il voir dans ce petit groupe un stade final de la phase 2 assurant une transition avec la phase 3 ? L'hypothèse aurait le mérite de faire l'économie d'un hiatus intermédiaire. Elle demande toutefois à être confirmée à l'avenir.

35 Des vases portant les mêmes décors ont pu être cuits très différemment. Cela s'explique facilement par la durée de vie des molettes qui a pu atteindre plusieurs décennies et l'irrégularité des cuissons.
La phase 3 est représentée par douze molettes dont onze chrétiennes ${ }^{36}$ (fig. 8). Les molettes 183 et 259 sont si proches qu'elles ont été considérées ici comme des variantes d'un seul décor. La phase 3 se distingue parfaitement à la fois par son unité iconographique et la répartition de ses molettes qui se démarque nettement de celle de la phase précédente. Les tendances techniques et typologiques esquissées auparavant se sont développées ici. Il est admis que ces molettès sont issues de l'atelier de ChâtelChéhéry.

Le décor de la molette U.C. 329 rompt complètement avec le reste du groupe. D'autre part, sa présence dans des sites très tardifs, trois cimetières mérovingiens, incite à la placer parmi les tous derniers exemplaires de sigillée décorée de l'amphithéâtre de Metz. Le décor ainsi que le type des vases qui le portent sont si particuliers, qu'il faut bien se demander si la molette 329 ne serait pas l'élément précurseur d'une quatrième phase inconnue à Metz, mais attestée sur d'autres sites tardifs comme Maastricht.

La phase 4. L'existence de poteries aux formes très évoluées trouvées régulièrement dans les nécropoles ardennaises a été bien mise en évidence par Dasnoy. La présence de décors dérivés des molettes chrétiennes inconnues de Chenet a été soulignée plus récemment par Wautelet et à nouveau par Dijk$\operatorname{man}^{37}$. Une douzaine de molettes ont été identifiées, mais le corpus est loin d'être complet (fig. 8). La mauvaise conservation des vases de cette phase, spécialement dans les terrains acides des Ardennes, rend leur lecture assez difficile. Mais, contrairement à une opinion répandue, la gravure est encore très détaillée et somme toute de bonne qualité. En dehors d'une ou deux molettes au décor géométrique (Mézières tombe 119 et peut-être Trivières IV), elles comportent systématiquement un ou deux symboles chrétiens, la croix et la colombe.

\section{Propositions pour UNE CHRONOLOGIE ABSolue DE L'ENSEMBLE DE METZ}

Comme il est apparu au fur et à mesure de l'exposé des données, la chronologie de l'ensemble de

36 Il y a 12 molettes chrétiennes si l'on compte U.C. 260 et sa variante 274 dans la phase 3 . Ce nombre peut varier encore si l'on considère à la suite de L. Bakker que la molette Nicolle $n^{\circ} 8$ n'est qu'une variante de U.C. 173 cf. L. BAKKER, Ein Grab des Frühen 5 Jahrhunderts aus Bornheim-Widdig (Rhein-Sieg-Kreis), Bonner Jahrbücher, 1977, p. 605-610.

37 Y. Wautelet, op. cit.; - W. Dijkman, op. cit. 
Metz est indissociable de celle des quatre phases distinguées. Aussi, après un rappel des éléments de datation propres au grand amphithéâtre, verronsnous comment s'intègrent dans notre tableau les contextes dont la chronologie est la mieux assurée : les sépultures et les camps d'Altrip et d'Alzei.

\section{LES DONNÉES DE LA FOUILLE}

D'après l'article de 1902 , la stratigraphie de la fosse aux machines se composait de trois niveaux principaux. Le plus profond, qui a été atteint à l'aplomb du fossé interne de la redoute, contenait, selon Keune, de la céramique plus ancienne ${ }^{38}$. Le remblai de démolition établi sous le sol de la salle aux colonnes, comme les débris d'incendie qui le surmontaient, contenait aussi de la céramique et des ossements animaux. Mais Keune indique que les archéologues n'ont pu vérifier si les poteries recueillies provenaient du remblai sous le sol ou des décombres incendiés ${ }^{39}$. Seconde source de confusion, le remblai d'incendie remanié par endroits et mêlé aux terres provenant du creusement du fossé moderne. Enfin, on ne sait rien des fouilles qui se sont poursuivies en 1903, après la publication de l'article, au sud du fossé et, au nord, à l'extérieur de la fosse.

D'après les monnaies et les tuiles estampillées, Keune pensait que le remblai sous le sol n'avait pas été mis en place très longtemps après 300 . Mais la série monétaire se limite à une dizaine de pièces dont seulement trois $\mathrm{du} \mathrm{IV}^{\mathrm{e}} \mathrm{s}$. sont lisibles : deux de l'époque constantinienne et une frappée au nom de Gratien (367-383). L'argument numismatique apparaît bien fragile. Le remplissage de la fosse aux machines, ainsi que d'autres zones non localisées, ont livré une dizaine de tuiles estampillées dont quatre portaient les noms ADIVTEC/E], ARTICIANVS, CONCORDIVS, [AN]TIOLVS. La signature la plus connue, celle d'Adiutex, était attestée à SaintPierre-aux-Nonnains à Metz, sur l'Herapel, à Niederjeutz et en particulier dans les édifices impériaux de Trèves ${ }^{40}$. Pour cettc raison, Keune la considérait comme datant des années 310 . La datation vers 370 400 , que vient de proposer X. Delestre pour la construction de la basilique Saint-Pierre-aux-Nonnains, datation fondée en partie sur des analyses

38 E. Schramm, G. Wolfram, J. B. Keune, op. cil., p. 362 , note 1 . Seul un fragment décoré portait des traces très nettes de surcuisson.

39 Il s'agit probablement, de la sigillée à décors moulés du Ilaut-Empire reproduite dans l'ouvrage de E. Schramm, G. Wolfram, J. B. Keune, op. cit., pl. XXII, fig. 6-9.

40 Ibid., p. 392-394. archéomagnétiques, va plutôt à l'encontre de l'hypothèse de Keune, même si elle ne s'applique pas formellement à des tuiles portant la marque d'Adiutex ${ }^{41}$. Faut-il adopter dans ces conditions la datation de Keune et mettre en relation le remblai inférieur avec les trois décors à la molette plus anciens? Une datation plus récente serait tout aussi vraisemblable, dans ce cas, une partie au moins de l'ensemble des céramiques tardives pourrait provenir du remblai.

Le reste du mobilier, dont on ignore tout autant le contexte, date apparemment du $\mathrm{v}^{\mathrm{e}} \mathrm{s}$. La figure 49 page 420 de l'article sur le grand amphithéâtre de Metz montre un cornet en verre conique qui ressemble à des exemplaires de la première moitié du $\mathrm{v}^{\mathrm{e}} \mathrm{s}$., comme ceux des tombes 44 de Vireux-Molhain, 11 de Haillot ou aux fragments découverts récemment dans les niveaux les plus récents d'Alzei ${ }^{42}$. Les verreries de la planche XXII présentent également des caractères plus tardifs du milieu du ve au $\mathbf{v i}^{e} \mathrm{~s}$. $\mathrm{Au}$ milieu des nombreux objets en os et en corne, fusaïoles, poinçons, lissoirs, les peignes triangulaires ou bifides peuvent appartenir aux $\mathrm{IV}^{\mathrm{e}}$, $\mathrm{v}^{\mathrm{e}}$ et $\mathrm{VI}^{\mathrm{e}} \mathrm{s} .{ }^{43}$.

Le matériel qui se prête le mieux à la discussion est la série d'inscriptions paléochrétiennes trouvées en 1902 et 1903 dans l'amphithéâtre. Pour N. Gauthier, qui les a réétudiés, ces tituli ne semblent pas antérieurs au milieu du $\mathrm{v}^{\mathrm{e}} \mathrm{s}^{44}$. La première pièce $(R I C G, \mathrm{I}, 254)$ trouvée au nord du fossé moderne est originale et pose des problèmes d'interprétation particuliers. La datation proposée, à partir du $\mathrm{VII}^{\mathrm{e}} \mathrm{s}$., ne repose pas sur des bases aussi

41 X. Delfestre, Saint-Pierre-aux-Nonnains, une nouvelle datation par l'archéomagnétisme, Les Cahiers Lorrains, juin 1982, no 2, p. 195-198. La datation des estampilles sur tuile est encore aujourd'hui imprécise sinon incertaine, cf. II. von Petrikovits, Fortifications in the North-Western Roman Empire from the Third to the Fifth Centuries A. D., Journal of Roman Studies, 61, 1971, p. 182-184 et H. J. KAN, Römische Ziegelstempel in trierer Privatssamlungen, Trierer Zeitschrift, 43-44, 1980-81, p. 301 et suiv.

42 J.-P. LÉmant, op. cit., fig. 40, p. 43 ; - J. Breuer H. Roosens, op. cit., p. 217 , fig. 12,5 ; - H. Bernhard, Zur spätantiken Besiedlung im Alzeyer Raum, op. cit., fig. 7, p. 140.

43 Les peignes triangulaires sont surtout attestés dans des contextes des dernières années du ive $s$. et des deux premiers tiers du ve s., cf. entre autres H. W. Böнмe, Germanische Grabfunde des 4. bis 5. Jahrunderts zwischen Unterer Flbe und Loire, Studien zur Chronologie und Bevölkerungsgeschichte, Münchner Beiträge zur Vor- und Frühgeschichte, 19, 1974, p. 122-125.

44 N. Gauthier, Première Belgique, in: H. I. Marrou (dir.), Recueil des inscriptions chrétiennes de la Gaule (RICG), Paris, 1975, p. $576 s q . ;-N$. Gauthier n'a pas repris dans son inventaire les fragments nos $2,3,7$ et 8 de Keune (E. Schramm, G. Wolfram, J. B. Keune, op. cil., p. 384-390). 
solides que les pierres suivantes. La seconde provient vraisemblablement du couloir nord de la construction enterrée, selon Keune, et porte des figurations chrétiennes assez banales (rinceaux et pampres) ainsi qu'une colombe.

La suivante, trouvée dans la terre en dehors du monument enterré, a cependant été endommagée par le feu. Elle est ornée d'une colombe perchée sur une branche tenant dans son bec un rameau. La quatrième (RICG, I, 252) trouvée au sud du fossé interne de la redoute, ne semble pas remonter audelà de la seconde moitié du v ves., selon N. Gauthier, et serait plus vraisemblablement du vir ${ }^{\mathrm{e}} \mathrm{s}$.

La cinquième, trouvée au sud du fossé (RICG, I, 251), présente un double vulgarisme difficilement envisageable avant les années 430-450. L'inscription $\mathrm{n}^{\circ} 6$, trouvée en août 1902 , est accolée à une palme, symbole qui ne paraît pas attesté à 'Trèves avant la seconde moitié du $\mathrm{v}^{\mathrm{e}} \mathrm{s}$.

Les restitutions que propose Keune pour la septième inscription n'appellent pas de commentaire particulier. Le dernier fragment trouvé pendant l'été 1902, se réduit à deux lettres identifiables.

Aucune des inscriptions n'a été trouvée en place. L'endroit précis de la découverte n'est d'ailleurs mentionné par Keune que deux fois, l'une à l'intérieur du monument, une autre à l'extérieur au nord-est. Wolfram assure, quant à lui, que les inscriptions trouvées dans le monument enterré proviennent du remblai d'incendie. Un détail qui a son importance plaide en faveur de son hypothèse. Trois et peut-être quatre des sept fragments ont été endommagés par le feu, y compris le $n^{\circ} 3$ trouvé à l'extérieur. Risquons-nous à penser que ces quatre pierres, sinon les sept, étaient initialement dans le même secteur et qu'elles ont brûlé dans le même incendie, peut-être celui dont les décombres sont venus condamner le monument enterré.

Les archéologues messins proposaient la date de 451 pour la destruction de "l'oratoire». Le premier argument était qu'aucune céramique postérieure à l'époque romaine n'avait été trouvée dans les travaux de l'amphithéâtre. Nous n'avons effectivement retrouvé dans l'abondant matériel déposé au musée de Metz aucune trace de céramique du Haut Moyen Age, poteries biconiques ou vaisselle usuelle, que l'on sait identifier aujourd'hui, dans le Nord de la France.

Le second argument était d'ordre historique. Grégoire de Tours écrit dans l'Historia Francorum que les Huns ont enlevé la ville de Metz la veille de Pâques 451, ont tout brûlé, excepté l'oratoire de saint Étienne. La prise de Metz est confirmée par
Hydace, un contemporain ${ }^{45}$. Si l'importance de l'événement doit retenir toute notre attention et si l'on doit envisager éventuellement la destruction de l'édifice tardif de l'amphithéâtre, rien n'interdit de penser que la vie ait repris après le raid d'Attila. D'autres destructions ont pu marquer le destin de Metz dans les années qui ont suivi. Vers 440, Trèves avait déjà été prise quatre fois selon Salvien et, selon des historiens modernes, l'aurait été une nouvelle fois en 456 par les Francs ${ }^{46}$. La date de 451 demeure une hypothèse sérieuse mais la possibilité d'une destruction définitive plus tardive, dans la seconde moitié $d u v^{e}$ s., qui serait plus conforme aux conclusions de l'analyse épigraphique, n'est pas exclue.

\section{L'APPORT DES MOBILIERS FUNÉRAIRES}

Utilisées avec circonspection, les informations que nous offrent les sépultures constituent de véritables points d'ancrage. Parmi les molettes retenues dans notre tableau, près de 50 sont attestées dans des nécropoles. Si, la plupart du temps, on ignore les coordonnées de la tombe ou la composition du mobilier funéraire, ce que l'on sait de l'évolution des rites funéraires sert de critère chronologique.

Dans le Nord de la Gaule, le dépôt de mobilier disparaît généralement des nécropoles rurales dans la seconde moitié du IV ${ }^{r}$ s. Seules les nécropoles présentant des caractères germaniques font exception ct elles montrent même une tendance inverse jusque dans les années $400^{47}$. Au-delà du début du v"s., le massif ardennais et à un moindre degré les contrées au nord de la Somme maintiennent le dépôt de mobilier dans les sépultures jusqu'à l'époque mérovingienne. Dans l'ensemble, la chronologie suggérée par notre tableau reste conforme à ce schéma.

Plus précisément, une trentaine de molettes bénéficient d'un contexte plus clairement défini. Pour la phase 1, toutes les molettes trouvées en contexte funéraire sont associées à du mobilier de la

45 Grégoire de Tours, Historiae Francorum, II, 6 ; Hydace, Chronique: M.G.II. A.A. XI, n' 150, p. 26 et aussi Prosper Tiro, Chronique, M.G.II. A.A. IX, n' 1364, p. 481.

46 Salvien, De Gubernatione Dei, M.G.H. A.A., I. 1 (éd. C. Hat.M), Berlin, 1877, p. 1-108; sur les vicissitudes de Trèves au ve s., voir la dernière mise au point de Hans Hubert Anton, Trier von der römischen zur fränkischen Herrschaft, Francia, 12, 1984, p. 3-52.

47 Cf. en particulier II. W. Bӧнмғ, Germanische Grabfunde, op. cit. 
fin $d u \quad V^{e} s$. et des premières années du $v^{e} s$. La molette 68, l'une des plus largement diffusées, est attestée dans trois tombes des Ardennes, à Jamiolle, à côté d'un mobilier typique des années 400 . A Vireux-Molhain, dans la tombe 12, elle était associée à un solidus frappé entre 405 et 420 el à un riche mobilier contemporain. Non loin de là, la tombe 22 qui a livré le même décor, semble un peu plus ancienne.

La molette 57 est également attestée trois fois, dans des sépultures des Ardennes belges. Le contexte de la première, à Spontin, est perdu. A Flavion, dans la tombe A, la sigillée était accompagnée d'un salus Reipublicae frappé en 388 et à Furfooz, dans la tombe 13, d'une monnaie de l'usurpateur Eugène (392-394).

La molette 109 trouvée à Vron dans la Somme serait selon le fouilleur, Cl. Seillier, à dater des années $400^{48}$. Les autres molettes ont été trouvées dans des contextes plus anciens, de l'époque valentinienne ou théodosienne, ou sont moins bien documentées ${ }^{49}$.

Dans la phase 2, douze molettes sont signalées dans des sépultures. Sur le Rhin, près du castellum de Gelduba, le vaste cimetière de Krefeld-Gellep a livré dans la tombe 2344 , avec la molette 29 , une boucle de ceinture à décor animalier et à plaque fixe que l'on date de la première moitié du $\mathbf{v}^{\mathrm{c}} \mathbf{s} .{ }^{50}$. Dans les Ardennes, Dasnoy signale la molette 26 dans une Lombe des environs de 400 à Rochefort ${ }^{51}$.

Une troisième molette à décor géométrique, la molette 23, a vraisemblablement été utilisée très longtemps. Elle est attestée à Cortrat (Loiret) et à Oyes (Marne). A Cortrat, la tombe 26, comme plusieurs autres de ce petit cimetière, contenait des objets de type germanique, en particulier une paire de fibules que Böhme place dans sa phase II (vers $380-420)$, ce que ne contredit pas le reste du mobilier $^{52}$. Le bol 85713 du musée de Saint-Germain-

48 Claude Srit.ims prépare actuellement la publication du cimetière de Vron. La nécropole a déjà fait l'objet de plusieurs articles : voir en dernier lieu, Cl. Seillier, Développement topographique et caractères généraux de la nécropole de Vron (Somme), Archéologie Médiévale, 16, 1986, p. 7-32.

49 Entre autres à Oudenbourg (molette 107 ou 108), Vieux Mont, MAN, no 13708.

50 R. Pirting, Das römisch-fränkische Gräberfeld von Krefeld-Gellep 1964-1965, Römisch-Germanische Kommission des Deutschen Archäologischen Instituts, 10, Berlin, 1979, p. 34 et pl. 10 .

51 R. DASnoy, Le cimetière du Corbois à Rochefort (ve-vir siècles), Namurcum, XL, 1968, p. 1-14.

52 A. France-Lanord, Un cimetière de Lètes à Cortrat (Loiret), Revue Archéologique, 1963, p. 15 ; - H. W. Вӧнме, Germanische Grabfunde, op. cil., p. 312-314, pl. 118-119.
en-Laye trouvé à Oyes présente des signes très nets de dégénérescence. Le cimetière d'Oyes n'a d'ailleurs livré aucun indice d'une utilisation antérieure à la fin du $v^{e} s .{ }^{53}$.

Dans un article concernant les origines de l'église Saint-Piat de Tournai, H. Roosens reproduit le dessin de quelques objets trouvés dans une tombe d'Harmignies. Le décor que porte le bol en sigillée ressemble étrangement à la molette 131 de Chenet ${ }^{54}$. Une hache profilée ainsi qu'un petit bol biconique décoré au poinçon qui ne sauraient être tous deux antérieurs à la seconde moitié sinon la fin $d u v^{e} s$. l'accompagnaient.

Les découvertes du monde alaman sont à utiliser avec une grande prudence. Le mobilier est parfois équivoque de sorte que les datations proposées peuvent varier considérablement. D'autre part, la rareté de la sigillée romaine puis sa disparition ont entraîné une prolongation exceptionnelle de l'utilisation de certains vases. La molette 106 est signalée à Herthen, la molette U.C. 163 à Trébur, 162 à Untertürkheim $^{55}, 178$ à Weilbach dans la seconde moitié du ve $\mathrm{s}^{56}$ et récemment une variante de la molette 154 a été reconnue à Dettingen ${ }^{57}$.

La nécropole de Vireux-Molhain offre des données solides. La richesse exceptionnelle des sépultu-

53 MAN, no 85713.

54 H. Roosens, Les sépultures paléochrétiennes, in: Le sous-sol archéologique de l'église Saint-Pial à Tournai, Archaeologia Belgica, 222, 1980, p. 57 et 58. Est-ce le même vase que celui décrit par Wautelet pour la tombe 45 (Y. WAutelet, L'important problème de la "pseudo-sigillée", op. cit., p. 41)?

55 A Ilerten, tombe 41, cf. F. Garscha, Die Alamannen in Südbaden, Katalog der Grabfunde, Berlin, 1970, pl. 51 ; - R. Roeren, Zur Archäologie und Geschichte Südwestdeutschlands ins 3 . bis 5. Jahrhunderts n. chr., Jahrbuch des römisch-germanischen Zentralmuseums Mainz, 7, 1960, p. 214294 ; - J. Mol.Ler, Katalog der Grabfunde aus Völkerwanderungs- und Merovingerzeit in südmainischen Hessen (Starkenburg), Römisch-Germanische Kommission des Deutschen Archäologischen Instituts, II, 1987, pl. 103, no 8 ; - pour la datation voir également L. BAKKER in: J. METzLER, J. Zimmer et L. BAKKer, Ausgrabungen in Echternach, op. cit., p. 320 , note 251 et B. Kaschau, Der Runde Berg bei Urach II. Die dreihscheibenkeramik aus den Plangrabungen 1, Sigmaringen, 1976 .

56 L. Bakker, in: J. Metzler, J. Zimmer, L. BAKKER, op. cit., p. 320 , note 251 ; - H. SchopPa, Die fränkischen Friedhöfe von Weilbach - Maintaunaskreis, 1959, p. $59, \mathrm{pl}$. 19. Dans la tombe 13 le vase portant la molette 178 est associè à un petit bol biconique à rainures de la seconde moitié du ve $\mathbf{s}$.

57 D. Rosenstock, Zwei völkerwanderungszeitliche Körpergräber aus Dettingen, Gde Karlstein-a-Main, Ldks Aschaffenburg, Unterfranken, Bayerische Vorgeschichtsblätler, 52, 1987, p. 105-131. 
res a permis de restituer le développement $d u$ cimetière depuis un noyau central fondé dans le dernier quart du $\mathrm{IV}^{\mathrm{e}} \mathrm{s}$, , avec un développement progressif vers la périphérie, essentiellement vers le nord et le sud. Dans la partie sud, une dizaine de sépultures ont été creusées à la suite de l'incinération $n^{\circ} 12$ déjà mentionnée, datée de 405-420. Ces tombes sont à peu près sûrement datées, entre 405 et le milieu du $v^{e} s$. qui marque le terme de la nécropole. La découverte dans l'une d'elles d'un argenteus frappé à Trèves à la titulature de Théodose II vers 440-450 le confirme.

En progressant vers l'extérieur à partir de la tombe 12 , c'est-à-dire vers le terme de la nécropole, ont été trouvés trois bols en sigillée, respectivement décorés de la molette 163 dans la tombe 19 , puis de la molette 154 , avec un mobilier encore typiquement romain tardif, couteau et hache massive, dans la tombe 41 , et enfin à la limite extérieure, dans la tombe 44 , de la molette 178 avec une petite boucle à plaque fixe et un fer de hache légèrement profilé.

La tombe 833 de Rhenen (Pays-Bas) associe une fois encore une molette de la phase 2 avec une boucle à plaque fixe. La tombe de Rhenen qui a livré un mobilier assez riche est datée par Ypey et Böhme de la première moitié $\mathrm{du} \mathbf{v}^{\mathrm{e}} \mathbf{s} .{ }^{\mathbf{5 8}}$.

Le groupe des molettes qui assure semble-t-il, la transition entre les phases 2 et 3, est illustré par une découverte tout à fait intéressante. La nécropole de Haillot, fouillée en 1920, a livré seize tombes bien datées de la seconde moitié du $\mathbf{v}^{\mathrm{e}}$ s. et une autre, la tombe XI, dont le mobilier offre un certain contraste avec le reste de la nécropole et qui, pour cette raison, a été placée prudemment dans le deuxième quart du $\mathbf{V}^{\mathrm{e}} \mathrm{s}$. Son mobilier se compose d'un cornet conique en verre, de deux plats en sigillée, un de la forme Chenet 304, le second, un peu plus évolué, qui serait à classer dans le type Alzei 9/11, et de deux bols en sigillée Chenet 320 ornés de la molette 124 et d'un décor géométrique apparemment inédit ${ }^{59}$. Le mobilier métallique pris séparément serait à placer vers le milieu du $v^{e} \mathbf{s}$. La boucle à plaque fixe appartient à la Stufe III de Böhme, apparemment antérieure au milieu du siècle, alors que le ferret ne trouve de parallèle qu'avec la tombe 43 de Krefeld-Gellep, qui

58 J. YPEY, La chronologie du cimetière franc de Rhenen (Pays-Bas, province d'Utrecht), Problèmes de chronologie relative el absolue concernant les cimetières mérovingiens entre Loire et Rhin, Paris, 1978, p. 89-127; - H.W. Вӧнме, Germanische Grabfunde, op. cit. p. 270, pl. 63.

59 D'après le dessin proposé par les auteurs, le décor du vase ressemble à une molette reconnue à Bavay: la molette inédite 98 . est de la seconde moitié ou du milieu du v"s. au plus tôt $^{60}$. La hache, déjà très évoluée, ferait penser plutôt à la seconde moitié de ce siècle.

Un bol décoré de la molette $\mathrm{n}^{\circ} 2$ de Metz, classée elle aussi dans ce petit groupe de transition, a été trouvé en deux fragments dans deux sépultures voisines de la nécropole de Bulles dans l'Oise. Il s'agit vraisemblablement d'un cas de réemploi. Même en admettant que ces tombes soient parmi les plus anciennes du cimetière, on ne saurait remonter, de l'avis du fouilleur, René Legoux, en deçà des deux dernières décennies du v $\mathrm{v}^{e} \mathbf{s}^{61}$.

Une grande partie des molettes de la phase 3 est issue de découvertes funéraires, effectuées dans les Ardennes. Mais, comme celle de Bulles (Oise), d'autres nécropoles mérovingiennes du Bassin parisien en ont livré sporadiquement. La valeur de ces découvertes est inégale. Le contexte précis est inconnu le plus souvent et il est difficile dans les autres cas d'apprécier la contemporanéité des pièces. Les cas de réemploi sont fréquents dans les tombes mérovingiennes. Le meilleur exemple est celui de la tombe 178 de Lavoye où le défunt avait été inhumé avec une boucle de ceinture à ardillon scutiforme caractéristique du $\mathrm{vI}^{\circ} \mathrm{s}$. et un demi-bol en sigillée portant la molette 184 . Les deux tombes de Bornheim-Widdig et de Dieue-sur-Meuse indiquent tout au moins qu'une partie des molettes chrétiennes sont encore contemporaines d'un faciès romain tardif que l'on hésite habituellement à placer après le milieu du $\mathrm{v}^{\mathrm{e}} \mathrm{s}^{62}$. Les découvertes de Haillot confirment la fréquence de l'association entre les décors chrétiens et les bassins en bronze à bords perlés. La tombe III apporte une nuance tardive avec la présence d'une boucle en bronze à ardillon à base élargie et non plus l'habituelle plaque-boucle à décor animalier ${ }^{63}$. I a tombe 128 de la nécropole Saint-Victor à Huy correspond elle aussi à un faciès romain tardif ${ }^{64}$.

Les molettes chrétiennes connues dans des contextes plus tardifs nettement mérovingiens doivent être considérées le plus souvent comme des cas

60 Cf. R. Pirling, op. cit. et II. W. Böнmf, op. cit.

61 R. Legoux, in: P. Périn, La datation des tombes mérovingiennes, op. cit., p. 309, note 9 et p. 312 . Il convient de noter à l'encontre de l'hypothèse de R. Legoux, que l'on ne dispose d'aucun élément objectif qui interdise de faire remonter les tombes les plus anciennes au-delà des années 480 .

62 C. H.W. Böнмe, op. cit.

63 J. Breuer et H. Roosens, le cimetière franc de Haillot, op. cit., p. 200.

64 J. Docquier, R. Bit, Nécropole de Saint-Victor à Huy, La civilisation mérovingienne dans le bassin de la Meuse, Études et Recherches Archéologiques de l'Université de Liège (ERAUL), 1986, p. 195-209, pl. 2. 
de réemploi. Ainsi à Pry (Belgique), la molette 183259 est associée dans la tombe 47 à une hache profilée des années 500 et dans la tombe 59 à une boucle cloisonnée décorée de filigranes qui ne saurait être antérieure à la fin du ve s., sinon au début du siècle suivant. L'apparition dans les parties anciennes de certaines nécropoles mérovingiennes de molettes de la phase 4 et de la molette U.C. 329, élément de transition plausible entre les phases 3 et 4 , suggère une antériorité de la phase 3 au développement des nouvelles "nécropoles à rangées". U.C. 329 est signalée à Moreuil (Somme), Neuville-sur-Escaut (Nord) et Trivières (Belgique). A Neuville-surEscaut, dans la tombe 27, la molette 329 est associée à du mobilier postérieur aux années 500 . De toute manière, la nécropole ne semble pas antérieure au dernier quart du $\mathbf{v}^{\mathrm{e}} \mathrm{s}^{65}$.

Le cimetière de Trivières qui ne débute apparemment pas avant la fin $d u v^{e} s$. a livré en outre trois molettes de la phase 4 et aucune de la phase précédente. L'une d'entre elles est connue également dans les cimetières de Concevreux et de SaintSauveur en Picardie ${ }^{66}$. Il existe des décors de la phase 4 dans les cimetières d'Éprave, Merlemont dans les Ardennes belges ${ }^{67}$.

Toutefois, la relative fréquence des molettes chrétiennes et d'U.C. 329 dans des cimetières mérovingiens situés au sud de la Somme va à l'encontre d'un écart chronologique trop important entre la fin de la phase 3 et l'implantation des tombes les plus anciennes. Il est admis généralement que la multiplication des "cimetières à rangées" est consécutive à la conquête de Clovis ${ }^{68}$. Malheureusement, il est impossible de préciser aujourd'hui si les vases découverts à Nesle-Hodeng (Seine-Maritime), Oyes ou Péronne

65 G. Hantute avec les contributions de J. Brondiaux et Cl. Seillier, Le cimetière mérovingien de Neuville-sur-Escaut (Nord) ve-Vre siècles, Septentrion, 12-13 et musée de Ienain, 1989. La tombe 27 contenait un bol biconique décoré à la molette el un fer de lance à douille ouverte (renseignement Cl. Seillier).

66 Les deux nécropoles ne paraissent pas antérieures à la fin du ve s. sinon le début du siècle suivant (renseignements T. Berredjeb pour Saint-Sauveur) et pour Concevreux, cf. J. Pit.oy, Études sur d'anciens lieux de sépulture dans l'A isne, 3, 1912 et La Picardie, berceau de la France, Clovis el les derniers romains, Catalogue d'exposition, Amiens, 1986, p. 157-159 ou p. 189.

67 Y. Wautei.et, L'important problème de la «pseudosigillée", op. cit.

68 W. Menghin, Das Schwert im frühen Mittelalter, Stuttgart, 1983, p. 57 ou P. PÉrin, Trois tombes de chefs du début de la période mérovingienne : les sépultures 66,68 et 74 de la nécropole de Mézières (Ardennes), Bulletin de la Société Archéologique Champenoise, 1972, 4, p. 3-70.
(Somme) appartenaient bien à des tombes de l'horizon A-B-C (vers 480-530) ou à un éventuel noyau antérieur comme il en a été observé parfois ${ }^{69}$. La tombe de Sablonnières à Fère-en-Tardenois (Aisne) pourrait faire partie de ces rares cas ${ }^{70}$.

L'étude des mobiliers funéraires met en lumière une certaine coincidence entre les phases définies pour la sigillée et les Stufen proposées par W. Böhme pour le mobilier métallique. Les molettes de la phase 1 se rencontrent non seulement dans des sépultures "germaniques" caractéristiques de la Stufe I (vers 350-400) mais aussi au cours de la Stufe II (vers 380-420).

La molette 114-340 confirme que la phase 1 se prolonge au moins jusqu'à la fin de la première décennie du $v^{e} \mathrm{~s}$. La molette 114-340, non reprise dans le tableau mais qui s'apparente par sa distribution aux molettes de la phase 1 , a été reconnue à Vieuxville (Belgique) dans une tombe enfouie peu après $411^{71}$. Les dates généralement acceptées pour l'abandon du castellum d'Altrip (Rhénanie-Palatinat, RFA), vers 407-411, vont dans le même sens : une extinction de la phase 1 dans les années de la grande invasion des Alains et Vandales.

Les molettes de la phase 2 correspondent presque exclusivement à la Stufe III de Böhme (vers 400450). Les molettes intermédiaires ont pu apparaître dès la première décennie du siècle. Les autres sont certainement postérieures. Seule, la molette U.C. 23 est associée à un mobilier classé dans la Stufe II à Cortrat, mais Böhme fait poursuivre cet horizon jusqu'aux années 420 .

La phase 3 se situe manifestement à l'articulation des faciès romains tardifs et de faciès plus évolués, mérovingiens ou "prémérovingiens".

69 F. VAllet, A propos des tombes à épées d'apparat de la Rue-Saint-Pierre (Oise) et d'Arcy-Sainte-Restitue (Aisne), Revue Archéologique de Picardie, 1988, 3-4, p. 45-55.

70 La tombe de Sablonnières n'a livré que deux objets : le bol en sigillée et une coupe en verre à bords coupés.

71 J. Breuer, II. Roosens, op. cit. D'autres mulettes comme la série U.C. 151, 169, 199, 256 comportant des symboles astrologiques sont attestées dans les dernières années du ive s. ou au début du ve $s$., datation qui coïncide avec celle des gemmes et tables d'incantation séthiéniques portant des signes comparables (vers 390-420), cf. G. ChENET, La céramique gallo-romaine d'Argonne, op. cit., p. 111-120. Pour la datation de U.C. 169 , cf. R. Christlein, Grabfunde des 5. Jahrhunderts von Frikingen, Ortsteil Bruckfelden, Kreis Uberlingen, Fundberichte aus Baden-Würtemberg, 1974, 1, p. 565-572. La molette 224 à toutes les chances, elle aussi, d'appartenir au tournant des ive et $v^{e} s$. Il est probable que son utilisation se soit poursuivie sous la forme d'une variante, U.C. 149, après la première décennie du $\mathrm{v}^{\mathrm{e}} \mathrm{s}$. Enfin la distribution de cette série de décors est conforme aux tendances reconnues dans la phase 1 . 
La tombe de Dieue (Meuse) implique que la phase 3 débute avant l'extinction de la Stufe III de Böhme et la modification des faciès funéraires. Ce dernier la place vers le milieu du v $\mathrm{v}^{\mathrm{s}}{ }^{72}$. Se poursuitelle au-delà, comme le suggèrent les trouvailles de Haillot? Nous ne disposons pour le vérifier, d'aucun jalon sûr, avant les années 480 . La chronologie de la phase 4 apparaît tout aussi floue. Elle semble globalement contemporaine de la phase A-B-C de Legoux et Périn (vers 480-530).

\section{La discussion autour de LA FIN D'Alzei}

En l'absence de données d'origine funéraire suffisamment fiables, la discussion autour de la fin d'Alzei apparaît fondamentale pour préciser la limite entre nos phases 2 et 3 . Comme nous l'avons vu plus haut, Unverzagt mettait en relation, dans ses derniers articles, l'occupation tardive du castellum avec l'installation des Burgondes sur le Rhin en Germanie I vers $413^{73}$. De la même façon, l'abandon du camp lui paraissait contemporain soit d'une des campagnes d'Aetius contre les Francs en 428 ou $432^{74}$, soit de l'écrasement des Burgondes sous les coups conjugués d'Aetius et des Huns en 436 et de leur départ pour la Sapaudia en $\mathbf{4 4 3} 3^{\mathbf{7 5}}$.

Tout en adoptant une position plus réservée visà-vis des textes, Bernhard aboutit à une date assez semblable. Même si les découvertes d'Oldenstein compliquent encore davantage la question, il paraît raisonnable de penser que le matériel le plus tardif du camp, en l'occurrence les quelques tessons d'assiette Alzei 9/11 et de plat à collerette, n'est pas antérieur aux deux monnaies les plus récentes frappées sous Valentinien III (425-455). La fin d'Alzei et a fortiori celle des deux burgi voisins de BadDürkheim et surtout Eisenberg où ces types céramiques sont plus abondants (près de $50 \%$ ) n'est probablement pas antérieure aux années 430 . Et rien n'interdit de repousser encore plus loin leur

72 H.W. Böнme, op. cit. "Le milieu du ve s." n'est ici qu'une estimation qui ne doit pas être prise à la lettre. Cette approximation semble correspondre davantage aux années 460 qu'aux années 450.

73 W. Unverzagt, Zur zeitsbestimmung des Kastells Alzei, op. cit. et ID., Neue Ausgrabungen im Römerkastell Alzei (Rheinhessen), BRGK, 1968-1970, p. 83.

74 Prosper D'Aquitaine, M.G.H. A.A. IX, 1298 , p. 472 : "Pars Galliarum propinqua Rheno quam Franci possidendam occupaverant, Aetii comitis armis recepta".

75 Hydace, Chronique, M.G.H. A.A. XI, 96-98: Prosper, 1322, Hydace, Chronique, 108-110. date d'abandon, jusqu'aux années 436 ou 443 par exemple ${ }^{76}$.

S'il existe réellement une période de transition, entre nos phases 2 et 3 , assurée par les molettes 124, $168,174,260$ et Metz 2, les années 440 constitueraient un terminus posl quem tout à fait acceptable pour le début de notre phase 3 .

\section{Valeur chronologigue de l'iconographie des} MOLETTES CHRÉTIENNES

Dernier argument en faveur d'une datation de la phase 3 vers le milieu du $v^{r} s$. : l'iconographie des molettes chrétiennes. Les molettes de la phase 3 sont ornées de symboles christiques mêlés aux décors géométriques traditionnels. Le choix des symboles utilisés ici et dans l'épigraphie funéraire montre une similitude remarquable. Comme sur les inscriptions, les motifs sont peu variés, cinq ou six tout au plus : la colombe, la croix monogrammatique, le vase, la grappe de raisin, le poisson et plus tard dans la phase 4, la croix.

Grâce aux travaux de Le Blant poursuivis par l'équipe du RICG, qui ont défini l'évolution des formulaires et de l'iconographie au cours du v"s., l'épigraphie chrétienne offre une chronologie détaillée de l'apparition des différents symboles ${ }^{77}$.

La colombe comme la grappe de raisin sont fréquemment représentées dès le $\mathrm{IV}^{\mathrm{r}} \mathrm{s}$. La croix monogrammatique est banale elle aussi mais comporte plusieurs variantes. Le plus souvent la boucle du $\mathrm{P}$ se prolonge par une courbe tournée vers l'extérieur de façon à former un R. A Trèves, dans l'orbite culturelle de laquelle se situait l'Argonne, $\mathrm{N}$. Gauthier voit un stade antérieur avec un $R$ seulement ébauché, qui apparaitrait assez tôt dans le $\mathrm{v}^{\mathrm{e}} \mathrm{s}$. Les croix monogrammatiques représentées sur la sigillée seraient plutôt de ce type. Selon

76 Rien n'oblige à faire de ces dates des terminus a quo de l'occupation du camp. D'ailleurs, si la silique trouvée vers 1960 se rattache bien aux émissions d'argent que J. Lafaurie a mises en évidence à Trèves vers 445-455, il faudrait encore repousser le terme de l'occupation d'Alzei jusque vers le milieu du siècle, cf. J. Lafaurie, Monnaies d'argent franques trouvées à Envermeu (Seine-Maritime) (v' siècle), Centenaire de l'Abbé Cochet, Actes du colloque international d'Archéologie, 1975, Rouen, 1978, p. 477-487. Je tiens à remercier M. Lafaurie de ses précisions sur les monnaies d'Alzei.

77 E. Le Blant, Inscriptions chrétiennes de la Gaule antérieure au vIIIe siècle, Paris, 1856, 1865 ; - ID., Nouveau recueil d'inscriptions chrétiennes de la Gaule, Paris, 1892, en particulier tableau p. II; - N. GauthIfr, Première Belgique, in : H. I. Marrou (dir.), RICG, Paris, 1975, p. 37-59; F. Descomaf, Viennoise du Nord, in: H. I. Marrou (dir.), RICG, Paris, 1985, p. 75 et suiv. 
N. Gauthier, les rares croix comportant un RHÔ clairement distinct, comme sur la molette $\mathrm{n}^{0} 8$ de Nicolle, sont inconnues à Trèves des ateliers du Ive et de la première moitié du $v^{e} s$.

Le vase n'apparaît sur une inscription datée en Gaule qu'en 438, mais serait adopté à Trèves avant le gel des formulaires, c'est-à-dire avant le milieu du siècle. Le chrisme qui tient une si grande place dans les inscriptions $d u$ Ive $^{\text {e }}$ et du début du $\mathrm{v}^{\mathrm{e}} \mathrm{s}$. n'est apparemment pas représenté sur nos molettes. Il tombe en désuétude en Gaule à partir de la fin du $\mathrm{v}^{\mathrm{e}} \mathrm{s}$. Une autre absence à remarquer est celle de la croix latine simple qui n'apparaît que sur les molettes de la phase 4. Sur les inscriptions, la croix latine supplante le chrisme dans la seconde moitié du $v^{c} s$. (première inscription datée en 448).

Unverzagt a évoqué depuis longtemps les problèmes d'interprétation que soulevait la molette 186. Elle figure un oiseau, un poisson, quelques lettres, qu'Unverzagt rapprochait d'une inscription EUSTACHIOS imprimée sur une céramique paléochrétienne de Bordeaux, et un homme couché surmonté d'une croix. D'un simple point de vue chronologique, la croix et le poisson nous orienteraient vers la seconde moitié du $v^{e} s$. Le poisson, un des plus anciens symboles chrétiens, ne fait qu'une timide apparition en Gaule et la date fort tardive de sa représentation sur une inscription datée en 478 doit être prise à titre indicatif.

Les décors à la peinture blanche appliqués sur la vaisselle lisse ou ornée se rattachent également en partie au répertoire chrétien. La palme notamment est parfois représentée. Elle n'est attestée en Gaule sur une inscription qu'à partir de 444 (pas avant le milieu du siècle à Trèves).

Même s'il ne faut pas accorder le même poids à l'iconographie et à d'autres arguments plus archéologiques, les similitudes entre le répertoire épigraphique et celui de la sigillée d'Argonne sont troublantes et confirment l'usage des symboles chrétiens utilisés par les potiers argonnais à partir des années 440-450.

En définitive, il semble bien que l'ensemble de l'amphithéâtre de Metz se soit constitué pendant la première moitié $d u \mathbf{v}^{\mathrm{e}} \mathrm{s}$. Les témoins les plus anciens comme la molette 152 sont peut-être antérieurs à l'invasion de 406 mais la quasi-totalité du lot est postérieure à la première décennie du $\mathrm{v}^{\mathrm{c}} \mathrm{s} .{ }^{78}$.

Divers indices suggèrent même une intensification de l'approvisionnement dans les années qui ont

78 Le vase orné de la molette 152 est manifestement, parmi l'ensemble de Metz, le fragment qui se rapproche le plus des productions classiques du Ive $\mathbf{s}$. par sa cuisson, son vernis et son lustre. précédé l'apparition de la phase 3 , à la fin de l'horizon Alzei et un peu après, peut-être autour des années $430-440^{79}$.

Quant à la datation des dernières sigillées présentes sur le site, comme U. C. 329, plusieurs solutions peuvent être choisies sans qu'il existe réellement d'argument décisif en faveur de l'une ou l'autre. Le choix dépend des réponses que l'on voudra bien donner à quelques questions restées non résolues pour le moment et en particulier celle-ci : l'édifice souterrain a-t-il disparu lors du raid de 451 ou a-t-il connu des réaménagements postérieurs? Cette seconde solution s'accorderait davantage avec l'analyse des inscriptions paléochrétiennes ou même avec l'étude des décors de la sigillée d'Argonne.

LA SIGILLÉE D'ARGONNE DANS LA GAULE DU V'S. : LES ENSEIGNEMENTS APPORTÉS PAR L'ENSEMBLE DU GRAND AMPHITHÉÂTRE DE METZ

La chronologie de l'ensemble de Metz et, audelà, celle que nous proposons pour la sigillée du $\mathrm{v}^{\prime \prime} \mathrm{s}$. est fondée en grande partie sur l'étude de sa distribution dans le nord de la Gaule. Afin de valider nos hypothèses, il conviendrait de les confronter, par un juste retour des choses, aux données locales. Mais un tel travail dépasserait de loin le cadre de cet article. De plus, il ne nous appartient pas de porter un jugement, qui serait hâtif et insuffisamment. fondé, sur la datation de ces sites. Les quelques remarques qui suivent se borneront à commenter l'évolution de la sigillée d'Argonne et sa diffusion au cours du $\mathrm{v}^{\mathrm{c}} \mathrm{s}$. et de mettre en lumière ici et là les principales contradictions de datations habituellement avancées (fig. 9).

La première remarque concerne les événements de 406-407 et leurs conséquences. Contrairement à ce que pensait Chenet, la grande invasion des Alains et des Vandales n'a pas entrainé la fermeture des ateliers de potiers d'Argonne. Celui de la clairière des Nllicux à Vauquois, qui était l'un des plus importants sinon le principal d'Argonne à la fin du IV' s., a très probablement continué à fonctionner après la première décennie du $v^{e} s .{ }^{80}$. C'est du moins ce que

79 La forte proportion d'assiettes Alzei 9/11 plaide mème pour une faible coïncidence chronologique des deux collections de Metz et Alzei.

80 C'est ce qu'ont amplement démontré les recherches menées par Marc Feller depuis près de quatre ans; cf. M. Feller et G. Poplineau, Ateliers de céramique galloromaine d'Argonne : préalables méthodologiques, Les Cahiers Lorrains, p. 173-180. 


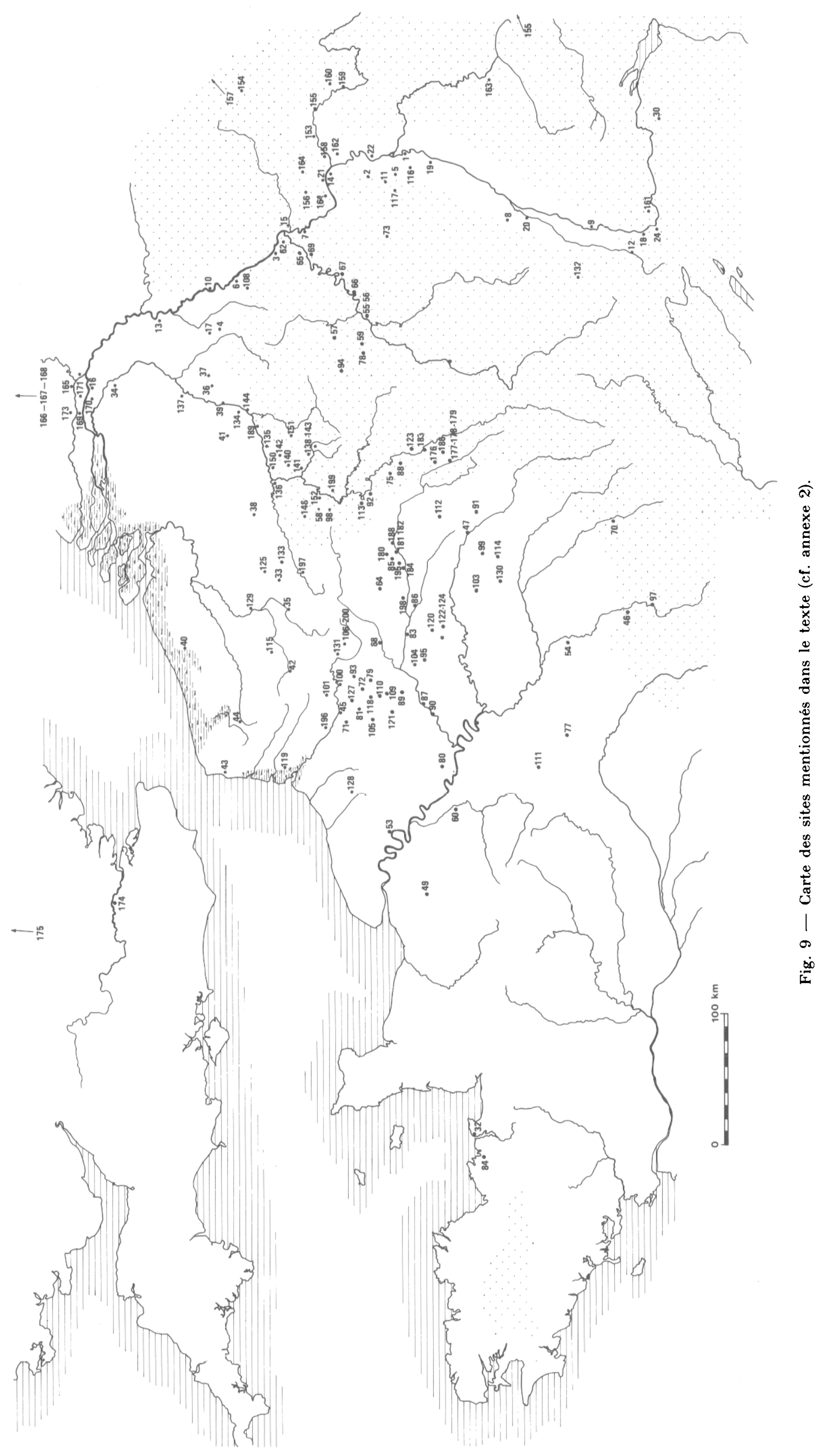




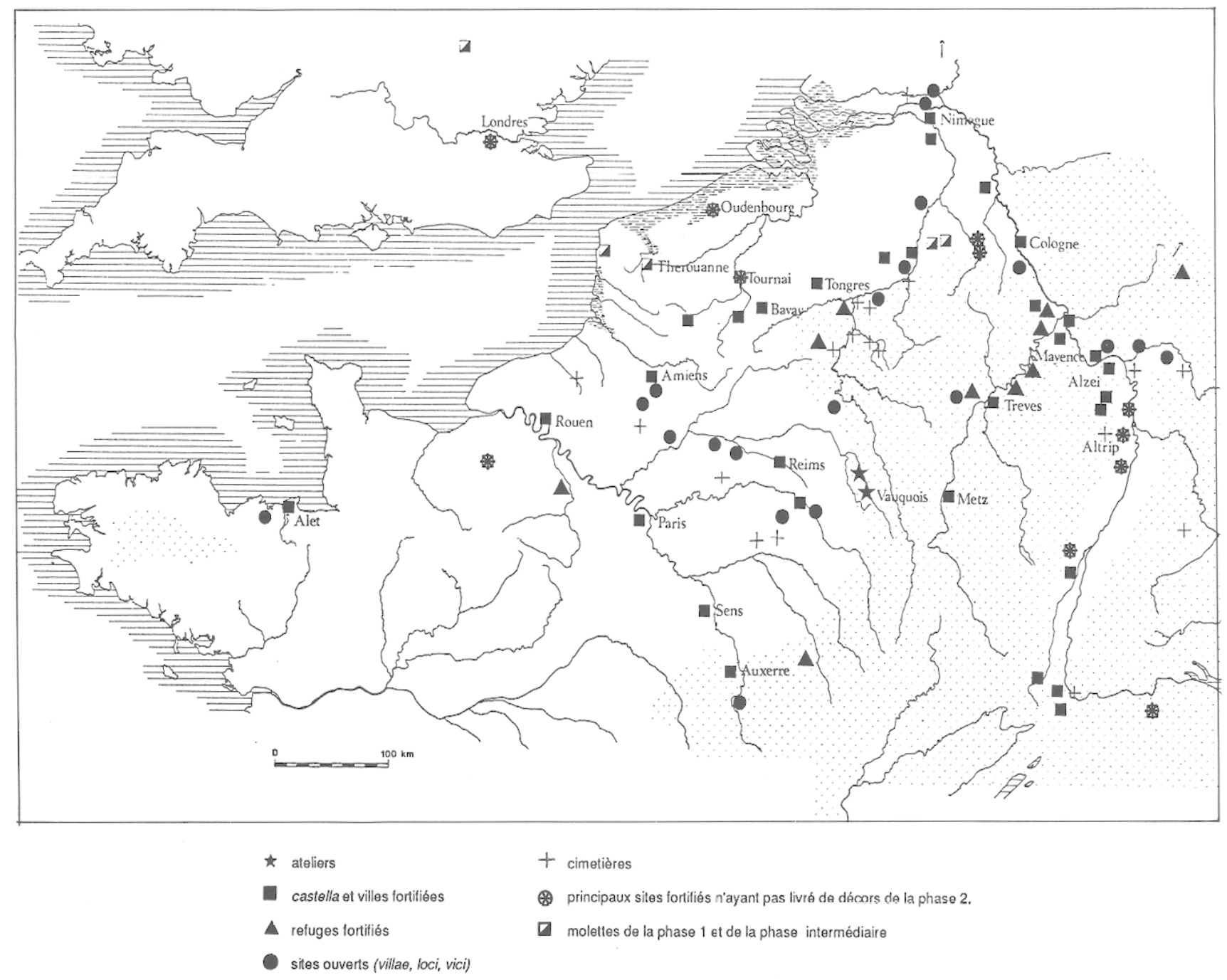

Fig. 10 - Carte de répartition des décors de la phase 2.

suggère la liste des molettes qui y sont attestées par Chenet. C'est curieusement au cours de ces années troublées qu'apparaît un nouvel atelier, tout juste repéré par Chenet, au Pont des Quatre Enfants (commune d'Avocourt). La molette la plus ancienne parmi les sept ou huit qui y sont bien attestées, U. C. 114-340, était utilisée autour des années 410 .

Les différences se font sentir de manière plus nette pour la cuisson de la céramique. Mais en l'absence d'observations précises, il est délicat de les interpréter. Du simple point de vue descriptif, l'évolution se marque par deux étapes. Dans un premier temps, après les années 400 , les poteries devenues poreuses résistent moins bien à l'acidité des sols. Puis, apparaissent des pâtes comportant un cœur plus foncé variant du rose foncé au noir. L'hypothèse la plus séduisante serait de supposer que les potiers d'Argonne, ne parvenant plus à mener la cuisson de la céramique à une température suffisante dans les fours à atmosphère oxydante, ont fini par modifier leurs techniques et leurs fours ou sont passés progressivement à des fours différents du type réducteur-oxydant (mode $\mathrm{B}$ ).

$\mathrm{Si}$ la situation ne semble pas radicalement différente dans les ateliers, la diffusion s'est, par contre, trouvée profondément altérée au début de la phase 2, c'est-à-dire vers 410. La distribution des molettes de la phase 1 , également répartie entre sites fortifiés et sites ouverts, devient par la suite extrêmement déséquilibrée avec la disparition de la plupart des sites ruraux (fig. 10).

Seulement deux ou trois villae sont attestées au cours de la phase 2, cinq ou six avec les "maillons faibles". Nous avons vu à propos de la liste de Metz que la part des vici et sanctuaires était comparable. De toute ćvidence, les campagnes ont souffert de la 
grande invasion de 407 qui s'est prolongée dans l'Ouest de la Gaule jusqu'en 409. Mais, de là à conclure que les villae et vici ont été massivement abandonnés pendant ces années éprouvantes, il y a un pas que nous ne franchirons pas. L'échantillon disponible n'est certes pas représentatif. La carence des fouilles de villae, les difficultés d'évaluation des niveaux les plus récents, en général disparus dans les labours, les handicaps sont suffisants pour qu'on se garde d'apporter une réponse péremptoire à la question des désertions. D'autre part, de légères différences de distribution observables sur ces dix ou douze sites suggèrent un processus plus complexe pour lequel on mesure mal la part de l'effondrement des réseaux commerciaux et celle des désertions. Deux vici notamment, ont livré des molettes qualifiées de "maillons intermédiaires" qui ne sont pas formellement attestées avant 406 , mais qui se retrouvent sporadiquement dans des contextes clos au début du $\mathrm{v}^{\prime \prime} \mathrm{s}$.

D'ailleurs, l'apparition exclusive aux côtés de molettes de la phase 1 , de ces maillons intermédiaires, décors géométriques simples (U.C. 26, 28, 29, 30, 293) et quelques autres, ne s'observe pour le moment que dans trois ou quatre catégories de sites : les deux vici de Morains (Marne) et Vendeuil-Caply (Oise), un cimetière en Rhénanie, quelques points fortifiés du limes rhétique et deux ou trois villes du nord-ouest de la Gaule. Là encore, l'interprétation des données s'avère extrêmement délicate.

L'étude des vicissitudes du limes en Séquanaise et dans les provinces de Rhétie I et II incite à donner une valeur chronologique à l'apparition de ces "maillons intermédiaires". Selon Émilienne Demougeot, la réorganisation de la frontière rhénane par Stilichon en 396 s'est traduite par l'évacuation de nombreuses garnisons du limes dans le ressort du duc de Mayence (Bad-Kreuznach, Alzei) et surtout en Séquanaise où la Notitia Dignitatum ne mentionne plus que la petite garnison de Besançon. La défense du secteur aurait été assurée par une petite armée régionale de comilatenses autour du comte de Strasbourg. L'étude convaincante de Pekari sur le monnayage du castrum Vindonissense à Windish, et plus généralement les conclusions de Stähelin sur les camps suisses aboutissent à la même conclusion, une évacuation générale des garnisons vers 396-400. Il est à noter que les décors attestés sur les sites militaires en Suisse aussi bien à Windish, qu'à Schur, Schaan, Zürich, sont tous de la phase $1^{\mathbf{8 1}}$.

81 Cf. T. Pekari, Die Fundmünzen von Vindonissa, 1971 et plus généralement F. Stafhel. römischer Zeit, 1948, p. 318 et suiv.
Émilienne Demougeot adopte une position plus nuancée pour les garnisons de Rhétie. Certes, Stilichon y a prélevé de nombreux détachements pour combattre, en 402, l'invasion de Radagaise en Italie. Mais comme le précise la Notitia Dignitatum, le duc de Rhétie dispose encore de vingt et un numeri et trois escadrons de cavalerie, répartis sur les grandes routes alpines vers l'Italie. Or, contrairement à la partie suisse du limes rhénan, la Rhétie a livré quelques décors de la phase 2. Plusieurs ensembles se terminent d'ailleurs par les molettes «intermédiaires" 26 et 293 (le Goldberg près de Türkheim, le Moosberg de Murnau et peut-être le Lorenzberg à Epfach $)^{82}$. Il est possible que ces molettes particulières aient été diffusées dès la période transitoire entre les phases 1 et 2 , dans la première décennie du $\mathrm{v}^{\mathrm{e}} \mathrm{s}$.

Toutefois, l'exemple d'Arras incite encore une fois à la prudence. Trois villes du Nord de la Gaule se distinguaient dans notre liste par l'absence d'échantillons de la phase 2 à l'exception de «maillons intermédiaires». Toutes trois ont pourtant fait l'objet de fouilles ces dernières années, à l'emplacement ou près du groupe épiscopal - en général le secteur le plus propice à la découverte d'éléments tardifs à Boulogne et à Thérouanne, un peu plus loin à Arras mais toujours dans le castrum. L'absence de témoins de la phase 2 sur ces sites semblait devoir être imputée aux conséquences de la grande invasion de 407 qui a durement touché la région ${ }^{83}$. L'identification toute récente à Arras de deux tessons de la phase 2, ornés semble-t-il de la molette 154 (hors contexte) et de la molette 178 recueillie dans une tranchée de récupération montre la fragilité de l'argument a silentio. Cette découverte rapproche la datation de la fin d'Arras tout au moins, de celle de Bavay et des fortifications du "limes belgicus».

La phase 2 est largement représentée dans les camps du limes rhénan depuis Illzach au sud jusqu'à Nimègue. L'indication n'est pas nouvelle. Différents auteurs ont souligné ces dernières années la poursui-

82 D. HoffmanN, Das spätrömische Bewegungsheer und die Notitia Dignitatum, op. cit.; - E. Demougeot, La Notitia Dignitatum, op. cit., p. 1079-1134 et K. ReINDEL, in : Verhandl. des historisch. Vereins Oberpfalz und Regensburg, 106, 1966, p. 23-41. A Epfach, la molette 149 qui n'a pas été rattachée au groupe intermédiaire est aussi signalée. La molette 149 ne constitue probablement qu'une variante de U.C. 224 antérieure à la phase 2 et peut être, à la limite, rangée aux côtés des molettes intermédiaires.

83 Cf. Је́́ồe, Epistulae ad Ageruchiam, 123, 15 : "La très puissante ville de Reims, Amiens, Arras, Les Morins ces plus lointains des hommes, Tournai, Spire, Strasbourg sont transférés en Germanie». Gf. sur ce point F. Vercauteren, Note sur la ruine des villes de la Gaule, Mélanges Bidez, Bruxelles, 1934, p. 955-963. 
te dans ces camps d'une occupation militaire ou civile, au-delà de 406-407. La situation d'Altrip est en fin de compte assez originale. C'est le seul camp dont l'abandon vers 407-411 soit aujourd'hui admis. Sa localisation sur les bords mêmes du Rhin, en plein cœur de la zone attribuée aux Burgondes en 411 n'est peut-être pas sans rapport avec l'évacuation ${ }^{84}$.

Le camp de Zullenstein qui occupe la même situation qu'Altrip a livré ces dernières années une série de molettes comparables à celles d'Altrip si l'on en juge d'après la publication préliminaire. Il sera intéressant de confronter les deux ensembles.

La phase 2 est aussi représentée dans d'autres dispositifs frontaliers, sur le "limes belgicus" et le tractus armoricanus. La présence de molettes 122, $163,178,179$ à Bavay ou à Tongres va à l'encontre des hypothèses retenues sur l'abandon de ces villes ${ }^{85}$. A Bavay, seize molettes de la phase 2 ont été reconnues (cinq molettes intermédiaires sur trentesix vases différents et huit molettes bien caractéristiques de la phase 2 sur seize vases). J. Gricourt avait déjà souligné en son temps la mauvaise qualité et la cuisson particulière de certains fragments qu'il hésitait à situer au-delà du début du ve $\mathrm{v}^{\mathbf{8}}{ }^{86}$. Même si la fréquence des décors de la phase 2 est moins forte en dehors des molettes intermédiaires, il est clair que la vie a continué dans le castrum jusqu'aux années 430 peut-être ${ }^{87}$. Les indices sont moins forts à Tongres, mais les fouilles à l'intérieur de l'enceinte tardive sont restées plus limitées. La phase 2 est quand même attestée par vingt-trois fragments dont quatorze sont décorés par six molettes caractéristiques de la phase 2. Un second argument qui

84 Les Burgondes y étaient installés en tout cas en 413 selon Prosper d'Aquitaine (Prosper, 1250, M.G.H. A.A. IX, p. 467: «Burgundiones partem Galliae propinquam Rheno obtinuerunt»); - cf. P. WACKWITZ, Gab es ein Burgunderreich in Worms? Der Wormsgau Beihefte, 20, 1964 et pour la région d'Alzei, cf. II. Bernhard, Zur Spätantiken Besiedlung im Alzeier Raum, op. cit.

85 Pour les positions antérieures, cf. W. Vanvinckenroye, Tongeren romeinse stadt, Tongres, 1975, p. $81 \mathrm{sq}$. (résumé en français) "le déclin définitif de la ville doit s'être produit, croit-on, au cours des années durant lesquelles les usurpateurs Constantin III et Jovin arrivèrent au pouvoir. Des bandes de guerriers francs ont alors certainement pillé la ville une dernière fois".

86 J. Gricourt, D. Piton et D. Bayard, La sigillée d'Argonne décorée à la molette à Bavay (Nord), Cahiers Archéologiques de Picardie, 4, 1977, p. 205-219; J. Gricourt, La terre sigillée argonnaise du Ive siècle décorée à la molette à Bavai (Nord), Gallia, 8, 1950, p. 55-76.

87 Il est vrai que la ville ne parait pas avoir livré de sigillée comportant une âme noire dans la pâte, contrairement à Bavay. Je remercie MM. Vanderhoeven et Vanvinckenroye de leur accueil au Musée de Tongres. confirme une occupation de la ville au cours des trois premières décennies $d u v^{e} s$. est la découverte de plusieurs garnitures de ceinturon appartenant indubitablement à la Stufe III de Böhme ${ }^{88}$. D'autres découvertes moins nombreuses ou incomplètement publiées témoignent d'une diffusion de la sigillée d'Argonne au cours de la phase 2 dans les camps jalonnant le limes belgicus, à Famars, Liberchies, Maastricht, Cuijk.

La cité d'Alet (Saint-Malo, Ille-et-Vilaine) est le seul point du tractus armoricanus où la sigillée d'Argonne ait été publiée. Elle provient pour la plus grande partie d'un grand bâtiment construit vers 380 que Loïc Langouët identifie aux principia de la garnison de milites Martenses signalée par la Notitia Dignitatum. La phase 2 y est représentée par une demi-douzaine de fragments. Il ne s'agit assurément pas des molettes les plus récentes de la phase 2. Mais on compte cependant U.C. 126 deux fois et U.C. 163, signalée dans la couche d'incendie du camp d'Alzei ou dans la tombe 19 de VireuxMolhain, donc après 405.

Sans intervenir dans le débat sur l'organisation du tractus armoricanus et le maintien éventuel de ses garnisons jusque vers 417 , force est de reconnaître que la communauté civile ou militaire d'Alet recevait encore de la sigillée d'Argonne, dans la deuxième ou la troisième décennie du $\mathrm{v}^{\mathrm{e}} \mathrm{s} .{ }^{89}$.

Avant que ne se termine la phase 2, avant l'abandon d'Alzei, apparaissent les signes d'un renouvellement des formes et des décors en Argonne. Le plat Chenet 304 donne naissance à une variante aux bords plus élevés, les types Alzei 9 et surtout 11 . Le type 304 se poursuit sous une forme plus réduite et plus creuse. Le bol Chenet 320 comporte parfois une variété à carène plus vive. Une forme nouvelle est introduite avec un plat ou un couvercle à collerette. C'est à la même époque que les potiers argonnais commencent à orner les vases lisses et parfois même les bols décorés à la molette de motifs de peinture blanche. Les molettes 178 et 179 figurant une colombe et considérées comme les prototypes des molettes chrétiennes appartiennent à cette généra-

88 II. W. Вӧнме, op. cit., p. 301-302, pl. 106.

89 E. Stein, Histoire du Bas-Empire (éd. J. Palanque), 1959, p. 249 et suiv.; selon cet auteur, le tractus armoricanus aurait été rétabli par Constance en 417 en vue d'une reconquête de la Bretagne; - E. Demougeot, La Notitia Dignitatum, op. cit.; - D.A. White, Litus Saxonicum, Madison, Wisconsin, 1961, p. 67 et dernièrement S. Joнnson, Channel Commands in the Notitia, in: R. GoodburN, Ph. Bartholomew, Aspects of the Notitia Dignitatum, BAR, 15,1976, p. $81-102$. 
tion. A part les deux molettes 178-179, qui ont pu être utilisées au Pont des Quatre Enfants, ces innovations ne semblent pas le fait des ateliers de Vauquois-Cheppy (Meuse), mais plutôt de ChâtelChéhéry. Les quelques molettes attestées seulement dans cet atelier, fort mal connu au demeurant, laissent supposer un fonctionnement de l'officine avant la fin de la phase 2.

La fin de la phase 2 est accompagnée de modifications importantes de sa zone de diffusion. La sigillée disparaît alors de la plupart des camps rhénans. Les quelques molettes classées dans le groupe intermédiaire 2-3 se rencontrent encore sur la Moselle et jusqu'à Andernach. Plus tard, les deux sigillées décorées de Bornheim-Widdig près de Bonn, Rumersheim en Alsace, et sans doute quelques autres exemplaires lisses comme à Krefeld-Gellep indiquent que les échanges ne se sont pas totalement interrompus avec la Rhénanie ${ }^{80}$. Mais ces trouvailles ne constituent que des exceptions. Les années 450 marquent le terme du commerce de la sigillée d'Argonne vers les camps rhénans et au-delà vers le pays alaman. Les imitations en rolgestrichene Keramik de l'Eifel, qui ont pu se substituer un certain temps aux produits argonnais sur le Rhin moyen, n'alimentent plus qu'un circuit limité à l'échelle régionale $^{91}$. On s'interroge sur les raisons de la fermeture des marchés rhénans à la sigillée d'Argonne. Est-elle due à la simple concurrence de la céramique régionale ou à la disparition d'une clientèle suffisante? Les archéologues allemands qui ont mis l'accent ces dernières années sur les signes de continuité dans l'occupation des castella du Rhin au cours du $\mathbf{v}^{\mathrm{e}} \mathbf{s}$. admettent toutefois que les indices d'une occupation militaire se raréfient considérablement au début du siècle ${ }^{92}$. Y a-t-il un lien entre les deux phénomènes?

90 En particulier, dans la tombe $\mathbf{4 3}$ datée du milieu du siècle ou peu après, ou la tombe 59 de Herten. Malheureusement, la datation des vases lisses s'avère bien incertaine. J'ignore si les exemplaires de la région de Mayence, très tardifs, sont encore en sigillée d'Argonne ou s'il s'agit d'imitations de l'Eifel. Je ne suis pas sûr que l'appellation rotgestrichene Keramik s'applique bien toujours à des imitations, par exemple à Biblis ou Mainz-Fithen : cf. J. Moller, op. cit., note 55, pl. 119 ou, Bericht des staatlichen Amtes für Vor- und Frühgeschichte Mainz, Mainzer Zeitschrift, 71-72, 1976-77, p. 302, fig. 51 et Mainzer Zeitschrift, 73-74, 19781979, p. 357.

91 La rotgestrichene Keramik n'est guère attestée avec certitude que dans le Palatinat et la moyenne vallée du Rhin de Worms à Andernach et autour de Mayence (cf. K. BöHNer, Die Fränkischer Altertumer des trierer Landes, op. cit., note 1 , p. 35-63)

92 H. von Petrikovits, Das Fortleben römischen
C'est à la même époque que la sigillée d'Argonne disparaît des points fortifiés du "limes belgicus", castra de Bavay, Tongres, Arras, castella de Famars, Liberchies et Cuijk. La question de la fin de l'approvisionnement en sigillée se pose dans ce secteur dans les mêmes termes qu'en Rhénanie, sauf qu'elle ne se trouve pas compliquée par l'apparition d'un produit de substitution. Ici la coïncidence avec l'avance des Francs Saliens, attestés vers 448 chez les Atrebates, est frappante ${ }^{93}$.

Vers le milieu du $v^{e}$ s., la sigillée d'Argonne constitue encore l'essentiel de la vaisselle fine dans les villes du Bassin parisien, à Amiens, Rouen, Paris, Sens, Auxerre, Châlons-sur-Marne, Metz ou même Trèves (fig. 11). A l'instar de beaucoup d'autres industries "d'art", la sigillée étale désormais de manière ostentatoire une iconographie d'inspiration chrétienne : signe manifeste de l'imprégnation du christianisme dans les esprits. On ignore en revanche si le phénomène ne concerne que les villes ou également les campagnes. Notre méconnaissance du monde rural au ve $\mathrm{s}$. est telle qu'il nous est interdit de répondre un tant soit peu à cette question.

Il est frappant en tout cas que la diffusion de cette vaisselle romaine et chrétienne se limite aux régions encore bien contrôlées par les autorités romaines (en l'occurrence par Aetius ou Aegidius), à l'exception du sillon mosan qui commence à devenir alors l'un des principaux axes commerciaux de la Gaule.

Les molettes de la phase 3 se retrouvent en pays franc le long de la Meuse et jusqu'en Frise. Le contraste est saisissant avec les pays alamans où les traces d'un commerce avec l'Argonne deviennent extrêmement ténues après la phase $2^{94}$.

La phase 3 se poursuit certainement au-delà du milieu du ve $s$. (jusque 460 ? ou 470 ?). Mais au-delà, la connexion avec les décors de la phase 4 n'apparaît pas de manière évidente.

Les différences de contextes habituels entre les fragments portant des décors des deux phases sont

Städte am Rhein und Donau, Studien $z u$ den Anfängen des europäischen Städlwesens Vorträge und Forschungen, 4, 1958,63 p. ou récemment L. BАKKER, Römerzeit, in: H.H. Wegner, Bericht zur Archäologie an Mittelrhein und Mosel, 1, Trèves, 1987, p. 41-47.

93 Sidoine Apollinarre, Panégyrique de Majorien, carmen V., v. 212 (éd. A. Loyes) I, C.V.F., 1960-1970. Pour Loyen, l'événement du vicus Helena se situerait entre 446 et 451 et E. Will retient la date de c. 448, cf. E. WIL, Remarques sur la fin de la domination romaine dans le Nord de la Gaule, Revue du Nord, 48, 1966, p. 517-534.

94 Seuls les vases de Rumersheim et de Herthen (t. 59) attestent le maintien de quelques liens vers le milieu ou dans la seconde moitié du ve $\mathbf{s}$. 


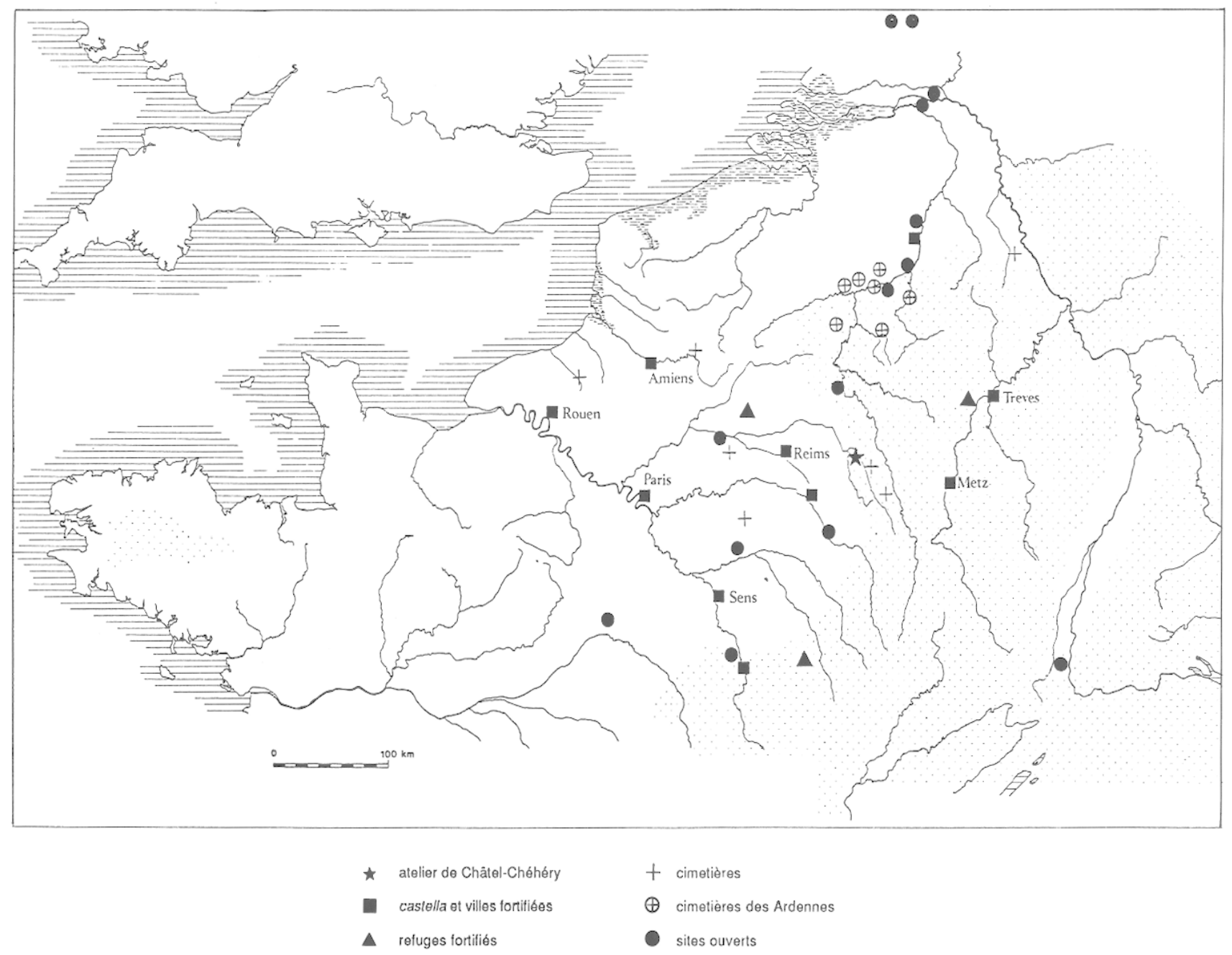

Fig. 11 - Carte de répartition des décors de la phase 3. Les castella du limes rhénan n'ont pas livré de décors de la phase 3.

telles qu'il faut bien envisager l'hypothèse d'une rupture.

La molette U.C. 329 est actuellement le seul maillon intermédiaire possible. Les sigillées tardives décorées de molettes de la phase 4 ne se rencontrent que dans des contextes nettement mérovingiens, au cours de la phase $\mathrm{A}-\mathrm{B}-\mathrm{C}$ de Périn (vers 480-530). Elles sont issues très probablement d'un autre atelier que Châtel-Chéhéry, sans doute dans la même région d'Argonne, entre Aisne et Meuse ${ }^{95}$. La phase 3 est peut-être suivie d'une interruption momentanée du

95 Les premières analyses qui ont pu être effectuées sur des fragments de la phase 4 et des échantillons recueillis à Chatel-Chéhéry montrent des compositions assez proches. Signalons enfin qu'un tesson décoré d'une molette de la phase 4 a été trouvé sur le site de Châtel-Chéhéry. décor à la molette, la production de vases lisses se poursuivant jusqu'à la phase suivante.

La carte de répartition des décors de la phase 4 (grosso modo contemporaine de Clovis et de ses fils) est assez étonnante (fig. 12). L'aire de diffusion s'est encore un peu restreinte à l'ouest et au sud. Elle ne dépasse plus le cours de la Seine ou de la Marne. Mais surtout elle délaisse désormais toutes les régions situées à l'est de la Meuse, dont Metz et Trèves, jusqu'alors les principaux débouchés de l'Argonne avec Reims.

Le faible nombre des trouvailles rend prématurée toute interprétation de ces lacunes. Faut-il rappeler que les neuf fragments du nord de la France ne sont connus que depuis trois ou quatre ans? Il est tout à fait possible que le vide observable actuellement, en Lorraine par exemple, se comble dans les prochaines années. Des vases lisses en sigillée tardive, recueillis dans des nécropoles de la région de Metz attestent des contacts avec l'Argonne entre le 


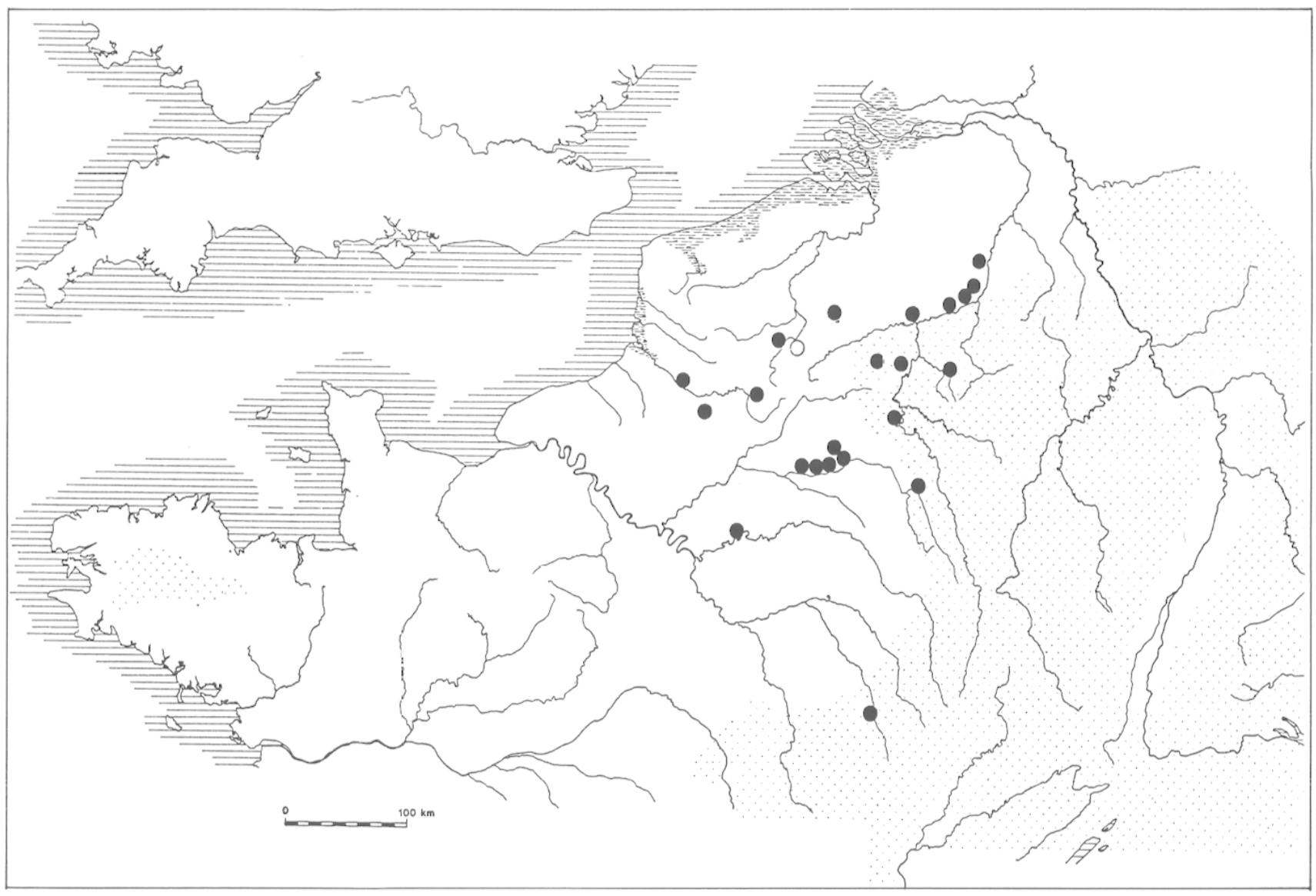

Fig. 12 - Carte de répartition des décors de la phase 4.

milieu du $v^{e}$ s. et le milieu du siècle suivant ${ }^{96}$. Sontils antérieurs, contemporains ou même postérieurs aux décors de la phase 4 ?

Néanmoins, les axes privilégiés de distribution des productions d'Argonne sont, vers 500, les deux vallées de l'Aisne et de la Meuse. Les vases lisses, bols Chenet 320 à carène, plat-couvercles à

96 Cl. Joly, M. WAGner, Époque mérovingienne, Calalogues des collections archéologiques des musées de Metz, p. 26 (Métrich à Koenigsmacker) plus près d'Argonne cf. J. Gunllaume, La nécropole d'Abainville, Bulletin de liaison de l'Association Française d'Archéologie Mérovingienne, 12, $1988-X^{e}$ journées internationales d'Archéologie mérovingienne, Meiz (20-23 octobre 1988), 1988, p. 59-64. collerette, bols Alzei 11, s'y rencontrent couramment jusqu'au milieu du vi ${ }^{e} \mathrm{~s}$. au moins ${ }^{97}$. Dernier témoin de l'Antiquité dans le Nord de la Gaule, la sigillée d'Argonne perdure jusqu'en pleine époque mérovingienne et côtoie pendant près d'un siècle les nouvelles productions céramiques issues d'un répertoire différent d'inspiration germanique.

\section{Didier BAYARD}

97 Cf. les multiples publications de R. Dasnoy, notamment R. Dasnoy, Quelques tombes du cimetière de Pry ..., op. cit. Les fouilles récentes de la vallée de l'Aisne confirment amplement les conclusions de R. Dasnoy. 


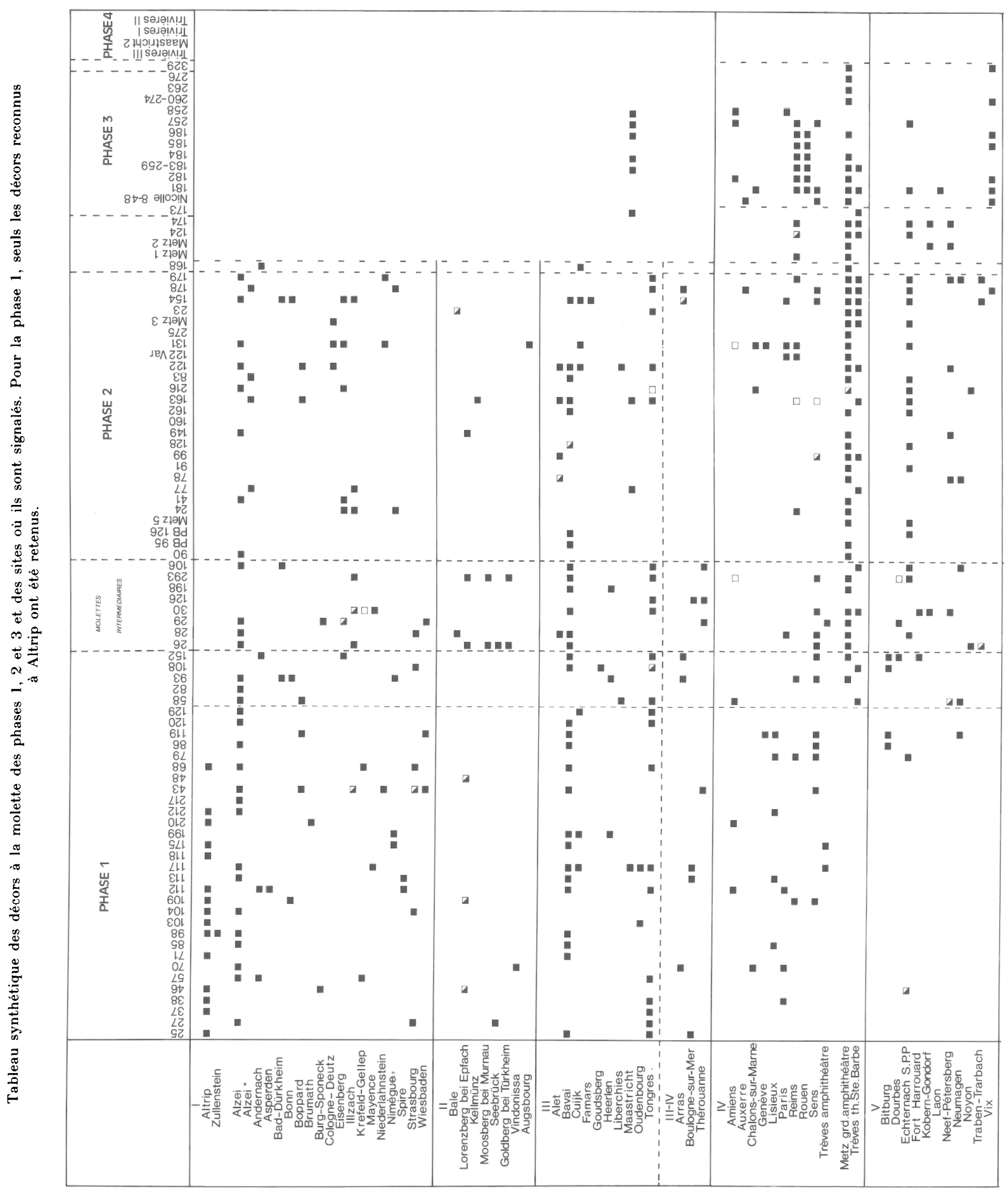




\section{ANNEXE 1}

\section{Catalogue}

Les fragments étudiés ici portent des indications diverses, soit un numéro d'inventaire pour la plupart, soit la date de la découverte pour les fragments supplémentaires retrouvés par M. Coudrot et qui n'avaient pas encore été inventoriés. Seule la série T13 A suivie d'un numéro était accessible au public avant ces dernières années. Ce sont ces tessons qui ont été reproduits dans la publication de 1902.

La description des fragments a été restreinte aux indications les plus importantes : deux ou trois termes pour l'examen de la pâte et de la surface, en fonction de l'existence éventuelle d'un cœur plus sombre ou d'anomalies manifestes. La partie conservée du vase est précisée dans la mesure où le cœur sombre est d'autant plus visible que l'on se rapproche $d u$ fond. Les fragments reproduits dans l'article de 1902 sont signalés (cf. E. Schramm, G. Wolfram, J. B. Keune, Das große römische Amphitheater zu Metz, op. cit.). Enfin, la plupart des identifications ont été établies à partir du catalogue d'Unverzagt complété par Chenet (abréviation U.C. suivie du numéro de la molette). Sur les huit molettes "inédites", en réalité, quatre ont déjà èté trouvées sur d'autres sites, mais n'ont pas toujours été reconnues comme telles. Nous avons préféré leur garder l'appellation Metz suivie du numéro d'ordre.

$\mathrm{N}^{\circ} 1$ (inv. T13 A9)

fragment de panse de bol Chenet 320 , pâte homogène orangée, vernis légèrement métallescent, décoré de la molette U.C. 30 (reproduit pl. XXII, fig. 5).

$\mathrm{N}^{\circ} 2$ (inv. T13 A10)

morceau de panse de bol Chenet 320 caréné, pâte orangée à cœur noir, surface mate ocre à brun, décoré de la molette U.C. 276 (reproduit pl. XXI, fig. 3).

$\mathrm{N}^{\circ} 3$ (inv. T13 A11)

morceau de panse de bol Chenet 320, pâte à cœur noir, vernis mat rouge orangé, décoré de la molette U.C. 181 (reproduit pl. XXI, fig. 9).

$\mathrm{N}^{\circ} 4$ (inv. T13 A12)

grand fragment de bol Chenet 320 , décoré de la molette U.C. 174 (reproduit pl. XXI, fig. 2).

$\mathrm{N}^{\circ} 5$ (inv. T13 A13)

morceau de panse de bol Chenet 320 , pâtè à cœur noir, surface mate ocre à brun, décoré de la molette U.C. 263. No 6 (inv. T13 A14)

morceau de bol Chenet 320, pâte orangée à cœur noir, surface mate ocre à brun, décoré de la molette U.C. 182 (reproduit pl. XXII, fig. 3).

No 7 (inv. T13 A15)

fragment de panse de bol Chenet 320, pâte à cœur noir, surface mate ocre à brun, décoré de la molette U.C. 186 .
$\mathrm{N}^{\circ} 8$ (inv. T13 A16 et très probablement les fragments inventoriés $6455,6456,6459$ et 7503 )

fragments d'un bol Chenet 320 à légère carène, pâte orangée comportant une âme un peu plus foncée, surface mate orangé à ocre, décoré de la molette U.C. 186.

$N^{\circ} 9$ (inv. T13 Al7 peut-être avec le $n^{\circ} 7470$ ) morceau de bol Chenet 320, pâte orangée à cœur noir, surface mate ocre à brun, décoré de la molette U.C. 83 (reproduit pl. XXI, fig. 1).

$\mathrm{N}^{\circ} 10$ (inv. T13 A19)

petit morceau de panse de bol Chenet 320 usé, abîmé et ayant subi l'action du feu, décoré d'une molette non identifiée attribuable au groupe 3 de W. Hübener (reproduit pl. XXI, fig. 7).

$\mathrm{N}^{\circ} 11$ (inv. T13 A34 et 7506)

grands fragments d'un bol Chenet 320 , pâte homogène orangée, vernis mat rouge à orangé, décoré de la molette Piton-Bayard 95 (reproduit pl. XXI, fig. 8).

$\mathrm{N}^{\circ} 12$ (inv. 6403)

morceau de fond, pâte à cœur noir, surface mate ocre à brun, décoré de la molette U.C. 174 inversée.

$\mathrm{N}^{\circ} 13$ (inv. 6404)

morceau de fond à la pâte orangée homogène, vernis mat rouge orangé, décoré de la molette U.C. 26 inversée.

$\mathrm{N}^{\circ} 14$ (inv. 6405 et 6431 )

deux morceaux d'un bol Chenet 320 à la pâte orangée homogène, vernis mat usé rouge orangé, décoré de la molette U.C. 41 inversée.

$\mathrm{N}^{\circ} 15$ (inv. 6406)

grand fragment d'un bol Chenet 320 caréné, pâte orangée à cœur noir, surface mate rouge orangé, décoré de la molette U.C. 23 inversée.

$\mathrm{N}^{\circ} 16$ (inv. 6407 avec peut-être le $\mathrm{n}^{\circ} 6458$ ) morceau de fond d'un bol Chenet 320 au profil très évolué, pâte beige avec un cœur un peu plus sombre, surface beige clair, décoré de la molette U.C. 174 inversée.

$\mathrm{N}^{\circ} 17$ (inv. 6408 et peut-être 7500 )

morceaux de panse et de fond d'un bol Chenet 320, pâte rouge orangé avec un cœur noir pour le deuxième tessòn, surface mate rouge orangé, décoré de la molette U.C. 128.

$\mathrm{N}^{\circ} 18$ (inv. 6409)

morceau de col d'un bol Chenet 320 , pâte homogène orangée, surface mate rouge orangé, décoré de la molette U.C. 128 inversée. 
$\mathrm{N}^{\circ} 19$ (inv. 6410 et 7517 )

grande partie d'un bol Chenet 320 , pâte rouge orangé homogène, surface orangée très clair, décoré de la molette U.C. 162 inversée.

$\mathrm{N}^{\circ} 20$ (inv. 6411)

morceau de col et de panse d'un bol Chenet 320, pâte orangée à cœur noir, surface mate variant du rouge orangé à l'ocre rouge, décoré de la molette U.C. 23.

$\mathrm{N}^{\circ} 21$ (inv. 6412)

morceau de fond d'un bol Chenet 320, pâte à cœur noir, surface variant du brun au noir, orné de la molette U.C. 198 .

$\mathrm{N}^{\circ} 22$ (inv. 6413)

morceau de fond de bol Chenet 320, pâte orangée comportant une âme plus sombre, surface mate usée rouge orangé, décoré de la molette U.C. 149 inversée.

$\mathrm{N}^{\circ} 23$ (inv. 6414)

morceau de panse de bol Chenet 320, pâte comportant une âme plus sombre, surface mate beige clair, décoré de la molette U.C. 78.

$\mathrm{N}^{\circ} 24$ (inv. 6415 et 6426 )

morceau de col et de panse de bol orangé, légèrement brillant, décoré de la molette U.C. 28 ou U.C. 29.

$\mathrm{N}^{\circ} 25$ (inv. 6416)

fragment de bol Chenet 320, pâte rouge orangé homogène, surface mate rouge orangé, décoré de la molette U.C. 91 inversée.

$\mathrm{N}^{\circ} 26$ (inv. 6417)

morceau de panse de bol Chenet 320, pâte micacée orangée, vernis mat rouge orangé, décoré de la molette U.C. 178.

$N^{\circ} 27$ (inv. 6418)

morceau de col de bol Chenet 320, pâte homogène orangée, surface mate rouge orangé, décor non identifié.

$\mathrm{N}^{\circ} 28$ (inv. 6419)

morceau de panse de bol Chenet 320 à carène vive, pâte homogène rouge orangé, vernis rouge orangé légèrement brillant, décoré de la molette U.C. 124 inversée.

$\mathrm{N}^{\circ} 29$ (inv. 6420 et 7475 )

morceaux de bol Chenet 320 peu cuit, pâte orangée comportant une âme plus sombre, décoré de la molette U.C. 259.

$\mathrm{N}^{\circ} 30$ (inv. 6421 et 6433 )

morceaux d'un bol Chenet 320, pâte homogène orangée, surface mate ocre rouge, décoré de la molette U.C. 293 inversée.

$\mathrm{N}^{\circ} 31$ (inv. 6422)

fragment de col de bol Chenet 320 caréné, pâte comportant une âme plus sombre, surface mate rouge orangé, décor non identifié.

$\mathrm{N}^{\circ} 32$ (inv. 6423)

morceau de panse fortement cuit, pâte et surface beiges, décoré d'une molette géométrique non identifiée du type U.C. 24-28.

$\mathrm{N}^{\circ} 33$ (inv. 6424)

morceau de bol et de panse d'un bol Chenet 320 faiblement caréné rouge orangé mat, décoré d'une molette inédite (Metz 1). Cette molette a déjà été découverte à Huy, site de Batta et à Jumel.

$\mathrm{N}^{\circ} 34$ (inv. 6425)

morceau de fond d'un bol Chenet 320 caréné, pâte à cœur noir, surface mate rouge orangé, décoré d'une molette inédite (Metz 2). Cette molette a été reconnue en fait, à Bulles, Kobern-Gondorf et Neef-Petersberg. $\mathrm{N}^{\circ} 35$ (inv. 6427)

morceau de col d'un bol Chenet 320, pâte homogène rouge orangé, surface mate rouge orangé, décor non identifié.

$\mathrm{N}^{\circ} 36$ (inv. 6428)

morceau de panse de bol Chenet 320 caréné, pâte comportant un cœur noir, surface mate rouge orangé, décoré de la molette U.C. 174.

№ 37 (inv. 6429)

morceau de panse de bol Chenet 320 , pâte comportant une tranche noire, surface mate rouge orangé, décoré de la molette U.C. 41 inversée.

No 38 (inv. 6430)

morceau de panse et de col de bol Chenet 320 légèrement caréné, rouge orangé homogène, décoré probablement de la molette U.C. 178 sans certitude.

$\mathrm{N}^{0} 39$ (inv. 6432 et 7471)

morceaux d'un bol Chenet 320, pâte homogène orangée, surface ocre rouge, décoré de la molette U.C. 293 inversée.

$\mathrm{N}^{\circ} 40$ (inv. 6434 et 6435 )

morceaux de bol Chenet 320, pâte comportant une âme noire, surface orangé à ocre rouge, décoré de la molette U.C. 99 inversée.

$\mathrm{N}^{\circ} 41$ (inv. 6436 et 6464 )

fragments de bol Chenet 320, pâte homogène orangée, surface mate rouge orangé, décoré de la molette U.C. 23.

$\mathrm{N}^{\circ} 42$ (inv. 6437)

fragment de bol Chenet 320, pâte homogène orangée, surface mate ocre rouge à brun, décoré de la molette U.C. 182 .

$\mathrm{N}^{\circ} 43$ (inv. 6438)

morceau de panse et de col de bol Chenet 320 caréné, pâte et surface rouge orangé, décor non identifié.

$\mathrm{N}^{\circ} 44$ (inv. 6439 et 6449 )

fragments de bol Chenet 320 caréné, pâte homogène orangée, surface mate rouge orangé à ocre, décoré de la molette U.C. 131.

$\mathrm{N}^{\circ} 45$ (inv. 6440)

morceau de panse et de fond de bol Chenet 320, pâte comportant un cœur noir, surface mate ocre à brun, décoré d'une molette inédite (Metz 3). La molette Metz 3 est attestée aux thermes Sainte-Barbe de Trèves, à Echternach et Cologne-Deutz.

$\mathrm{N}^{\circ} 46$ (inv. 6441)

morceau de fond de bol Chenet 320 , pâte comportant un cœur noir, surface mate rouge orangé, décorć de la molette U.C. 41 inversée. 
$\mathrm{N}^{\circ} 47$ (inv. 6442)

morceau de panse de bol Chenet 320 , pâte gris-vert à beige, décoré peut-être de la molette U.C. 41 sans certitude.

$\mathrm{N}^{\circ} 48$ (inv. 6443)

morceau de panse de bol Chenet 320 , pâte orangée comportant une âme un peu plus sombre, surface orangé très clair, décoré de la molette U.C. 274.

$N^{\circ} 49$ (inv. 6444)

morceau de panse de bol Chenet 320 , pâte comportant un cœur noir, vernis légèrement brillant rouge orangé, décoré de la molette U.C. 274.

$\mathrm{N}^{\circ} 50$ (inv. 6445)

morceau de panse de bol Chenet 320 , pâte comportant un cœur noir, surface assez brillante rouge orangé, décoré de la molette U.C. 274.

$N^{\circ} 51$ (inv. 6446 et 7511 )

morceaux de bol Chenet 320 caréné, pâte comportant un cour noir, surface brun-noir, décoré de la molette inédite Metz 2.

$\mathrm{N}^{\circ} 52$ (inv. 6447 et 6448 )

morceaux de panse de bol Chenet 320 caréné, pâte comportant un cœur noir, surface mate rouge à ocre, décoré de la molette U.C. 131.

$\mathrm{N}^{\circ} 53$ (inv. 6450 et 6454 )

morceaux de bol Chenet 320 , pâte homogène orangée, surface mate rouge orangé, décoré de la molette U.C. 154 .

$\mathrm{N}^{\circ} 54$ (inv. 645l)

morceau de panse de bol Chenet 320 , pâte homogène orangée, surface male rouge orangé, décoré de la molette U.C. 154 inversée.

$\mathrm{N}^{\circ} 55$ (inv. 6452)

morceau de panse de bol Chenet 320 caréné, pâte comportant un cour noir, surface mate rouge orangé, décoré de la molette U.C. 154.

$\mathrm{N}^{\circ} 56$ (inv. 6453)

morceau de panse de bol Chenet 320 caréné, pâte homogène orangée, surface mate rouge orangé, décoré de la molette U.C. 154 inversée.

No 57 (inv. 6457)

col de bol Chenet 320 au profil très évolué, pâte micacée beige à coeur légèrement gris, décoré d'une molette géométrique du type U.C. 24-28 non identifiée.

$\mathrm{N}^{\circ} 58$ (inv. 6458, peut-être le même vase que 6407) fragment de panse d'un bol Chenet 320 sans certitude, pâte comportant une légère âme plus foncée, vernis inexistant, décoré de la molette U.C. 174 inversée.

$\mathrm{N}^{\circ} 59$ (inv. 6460)

morceau de panse et de col de bol Chenet 320 , pâte comportant une âme un peu plus foncée, surface mate ocre-rouge à brun, décoré d'une légère variante de la molette U.C. 260.

No 60 (inv. 6461)

morceau de panse et de col de bol Chenet 320 ? pâte homogène, vernis brillant rouge orangé, décoré de la molette U.C. 41 inversée.
$\mathrm{N}^{0} 61$ (inv. 6462)

morceau de panse de bol Chenet 320, pâte comportant un cœur noir, surface mate rouge orangé, décoré de la molette U.C. 23 inversée.

$\mathrm{N}^{\circ} 62$ (inv. 6463)

morceau de panse et de col de bol Chenet 320 caréné, pâte très cuite beige, surface mate ocre à brun, décoré de la molette U.C. 23.

$\mathrm{N}^{\circ} 63$ (inv. 6465)

morceau de panse de bol Chenet 320 , décoré d'une molette inédite (Metz 4).

$\mathrm{N}^{\circ} 64$ (inv. 6466,6471 et $6471 \mathrm{~b}$ )

fragments de bol Chenet 320 , pâte homogène, surface mate rouge orangé, décoré d'une molette inédite (Metz 5). La molette Metz 5 est attestée à Echternach et à la clairière des Allieux à Vauquois.

$\mathrm{N}^{\circ} 65$ (inv. 6467)

fond de bol Chenet 320 , pâte homogène, surface mate rouge orangé, décoré de la molette U.C. 293.

$\mathrm{N}^{\circ} 66$ (inv. 6468)

morceau de fond de bol Chenet 320, pâte comportant un cœur noir, surface rouge orangé à ocre, décoré de la molette U.C. 184 inversée.

$\mathrm{N}^{\circ} 67$ (inv. 6469)

morceau de fond de bol Chenet 320 , pâte homogène orangée, surface mate rouge orangé, décoré de la molette U.C. 28.

$\mathrm{N}^{\circ} 68$ (inv. 6472)

morceau de fond de bol Chenet 320 , pâte homogène, surface mate rouge orangé, décor non identifié.

$\mathrm{N}^{\circ} 69$ (inv. 6919)

morceau de panse et de col de bol Chenet 320, pâte comportant un cœur noir, surface mate ocre à brun, décoré de la molette U.C. 276.

$\mathrm{N}^{\circ} 70$ (inv. 6920,7502 et 7463 )

fragments de bol Chenet 320, pâte peu cuite beige clair surface mate ocre rouge à brun, décoré de la molette U.C. 168 inversée.

$\mathrm{N}^{\circ} 71$ (inv. 7400)

morceau de panse et de fond de bol Chenet 320 , pâte comportant une âme un peu plus sombre, surface mate rouge orangé, décoré de la molette $n^{\circ} 48$ de Nicolle (cf. Nicolle, 1962).

$\mathrm{N}^{\circ} 72$ (inv. 7442)

morceau de fond de bol Chenet 320, pâte comportant un cœur noir, surface mate ocre à brun, décoré de la molette U.C. 183-259.

$\mathrm{N}^{\mathrm{o}} 73$ (inv. 7464)

fragment de bol Chenet 320 caréné, pâte comportant une âme un peu plus sombre, surface mate rouge orangé, décoré de la molette U.C. 131 .

$\mathrm{N}^{\mathrm{o}} 74$ (inv. 7465)

plusieurs fragments de bol Chenet 320 , pâte comportant une âme plus sombre, surface mate rouge orangé, décoré de la molette U.C. 23.

$\mathrm{N}^{\circ} 75$ (inv. 7466)

morceau de fond de bol Chenet 320, pâte homogène, 
surface mate rouge orangé, décoré d'une variante de la molette U.C. 122 .

$\mathrm{N}^{\circ} 76$ (inv. 7467)

morceau de panse et de fond de bol Chenet 320, pâte homogène surface mate rouge orangé, décoré de la même molette que le fragment prćcédent.

$\mathrm{N}^{\circ} 77$ (inv. 7468)

morceau de panse de bol Chenet 320 , pâte comportant une âme un peu plus sombre, surface mate rouge orangé, décoré de la molette U.C. 174.

$\mathrm{N}^{\circ} 78$ (inv. 7469)

fragments de bol Chenet 320 , pâte comportant un cœur noir, surface mate rouge à brun, décoré de la molette U.C. 83.

$\mathrm{N}^{\circ} 79$ (inv. 7470 peut-être le même vase que T13 A17) morceau de panse de bol Chenet 320 , pâte comportant un cœur noir, surface mate ocre à brun, décoré de la molette U.C. 83.

$\mathrm{N}^{\circ} 80$ (inv. 7472)

morceau de fond de bol Chenet 320, pâte comportant un cœur noir, surface mate ocre à brun, décoré de la molette U.C. 93 inversée.

$\mathrm{N}^{\circ} 81$ (inv. 7473)

fragment de bol Chenet. 320 légèrement caréné, pâte comportant un cœur noir, surface mate rouge orangé, décoré d'une molette inédite (Metz 6).

$\mathrm{N}^{\circ} 82$ (inv. 7474)

2 fragments de bol Chenet 320, pâte rouge, surface brillante ocre à brun, décoré de la même molette Metz 6 mais inversée.

\section{$\mathrm{N}^{\circ} 83$ (inv. 7499)}

morceau de panse de bol Chenet 320 caréné, pâte micacée comportant une âme un peu plus sombre, surface mate ocre à brun, décoré d'une molette non identifiée.

$\mathrm{N}^{\circ} 84$ (inv. 7501)

morceau de fond de bol Chenet 320 , pâte beige à violet, surface d'aspect métallescent, décoré de la molette U.C. 174 inversée.

$\mathrm{N}^{\circ} 85$ (inv. 7504)

morceau de fond de bol Chenet 320 caréné, pâte comportant un cœur noir, surface mate ocre à brun, décoré d'une légère variante de la molette U.C. 260 .

$\mathrm{N}^{0} 86$ (inv. 7505)

morceau de panse d'un bol Chenet 320 à carène très vive, pâte orangée comportant une âme rouge à noir, surface mate rouge orangé, décoré de la molette U.C. 122 .

$\mathrm{N}^{\circ} 87$ (inv. 7507)

morceau de fond de bol Chenet 320 , pâte comportant un cœur noir, surface mate ocre à brun, décoré de la molette U.C. 24.

$\mathrm{N}^{\circ} 88$ (inv. 7508)

morceau de panse de bol Chenet 320 , pâte homogène orangée, surface mate rouge orangé, décoré de la molette U.C. 29
$\mathrm{N}^{\circ} 89$ (inv. 7509)

morceau de panse de bol Chenet 320, pâte homogène, surface mate rouge orangé, décoré de la molette U.C. 23 sans certitude.

$\mathrm{N}^{\circ} 90$ (inv. 7510)

morceau de panse de bol Chenet 320 , pâte beige clair, vernis beige clair, décoré de la molette U.C. 24 sans certitude.

$\mathrm{N}^{\circ} 91$ (inv. 7512 et un fragment non inventorié portant l'indication amph. 27-3-03 N.O. ausserhalb)

fragment de bol Chenet 320 , pâte homogène, surface mate rouge orangé à brun, décoré d'une molette inédite (Metz 7).

$\mathrm{N}^{\circ} 92$ (inv. 7513)

fragment de bol Chenet 320 , très peu cuit, pâte orangée farineuse et poreuse, décoré de la molette U.C. 179.

$\mathrm{N}^{\circ} 93$ (inv. 7514)

fragment de bol Chenet 320 , pâte homogène, surface mate rouge orangé, décoré d'une molette inédite (Metz 8).

$\mathrm{N}^{\circ} 94$ (inv. 7515)

fragment de bol Chenet 320 peu cuit, surface mate ocre à brun, décoré de la molette U.C. 149.

$\mathrm{N}^{\circ} 95$ (inv. 7516)

morceau de col d'un bol Chenet 320 caréné, pâte comportant un cœur noir, surface mate rouge orangé, décoré probablement de la molette U.C. 181.

No 96 (inv. 7518)

morceau de col de bol Chenet 320 caréné, pâte homogène orangée, surface mate rouge orangé, décoré, d'une molette non identifiée.

No 97 (inv. 7519)

morceau de col de bol Chenet 320, pâte homogène et surface mate rouge orangé, décoré d'une molette non identifiée.

$\mathrm{N}^{\circ} 98$ (inv. 7520)

morceau de col de bol Chenet 320 , pâte beige peu cuite, décor non identifié.

$\mathrm{N}^{\circ} 99$ (inv. 7582)

morceau de panse de bol Chenet 320, pâte comportant un cour noir, surface mate rouge orangé, décoré de la molette U.C. 83 inversée.

$\mathrm{N}^{\circ} 100$ (inv. 7605)

2 fragments d'un bol Chenet 320 déformé, manifestement surcuit, surface brun à noir, décoré de la molette U.C. 23.

$\mathrm{N}^{\circ} 101$ (inv. 7784)

morceau de panse de bol Chenet 320 , pâte comportant une âme un peu plus sombre, surface mate rouge orangé, décoré de la molette U.C. 41 inversée.

$\mathrm{N}^{\circ} 102$ (inv. 7785)

morceau de fond et de panse de bol Chenet 320, pâte homogène orangée, surface mate rouge orangé, décoré de la molette U.C. 293 inversée.

$\mathrm{N}^{\circ} 103$ (inv. 7804)

morceau de fond de bol Chenet 320, pâte homogène 
orangée, surface mate rouge orangé, décoré de la molette U.C. 91 inversée.

\section{$\mathrm{N}^{\circ} 104$ (inv. 7805)}

morceau de fond de bol Chenet 320 peu cuit, surface très claire, décor non identifié.

$\mathrm{N}^{\mathrm{o}} 105$ (inv. 7818)

fragment de bol Chenet 320, pâte comportant une âme un peu plus sombre, surface mate rouge orangé, décor non identifiè.

$\mathrm{N}^{\circ} 106$ (non inventorié, portant l'indication L.P. 8/8.02) morceau de panse de bol Chenet 320 caréné, pâte homogène, surface mate ocre à brun, décoré de la molette U.C. 131 sans certitude.

$N^{0} 107$ (non inventorié, portant l'indication L.P. 8/8.02) morceau de panse et de fond de bol Chenet 320 , pâte comportant des grains calcaires, surface mate rouge orangé, décoré de la molette U.C. 41 inversée.

$\mathrm{N}^{\circ} 108$ (non inventorié portant l'indication Amph. 26/1/03)

moitié du fond d'un bol Chenet 320 , pâte comportant un cœur noir, surface rouge orangé à brun suivant les endroits, décoré de la molette U.C. 28.

$\mathrm{N}^{\circ} 109$ (non inventorié portant l'indication Amph. $10 / 2 / 03)$

morceau de panse de bol Chenet 320 , pâte comportant une âme un peu plus sombre, surface mate rouge orangé, décoré de la molette U.C. 28.

$\mathrm{N}^{0} 110$ (non inventorié portant l'indication Amph. $31 / 3 / 03)$

fragment de bol Chenet 320 , pâte orangé clair comportant une âme un peu plus sombre, surface orangé très pâle à beige clair, décoré de la molette U.C. 24 .

$\mathrm{N}^{0} 111$ (non inventorié portant l'indication 1903 Amph.)

morceau de panse de bol Chenet 320 , pâte brune avec quelques grosses inclusions, surface mate ocre à brun, décoré de la molette U.C. 24 inversée.

$N^{\circ} 112$ (non inventoriés portant l'indication Amph. 1903)

5 fragments recollant d'un bol Chenet 320 , peut cuit, pâte orangée poreuse, surface orangé très clair, décoré de la molette U.C. 216.

$\mathrm{N}^{\mathrm{o}} 113$ (non inventorié portant l'indication 26/1/03) fond de bol Chenet 320 , pâte noire, surface mate beige clair à brun, décoré de la molette U.C. 275 inversée.

$N^{o} 114$ (non inventorié portant l'indication Amph. 1903)

morceau de fond de bol Chenet 320, pâte grise, surface ocre rouge, décoré de la molette U.C. 90.

$N^{\circ} 115$ (non inventorié portant l'indication Amph. 26/1/03)

morceau de fond de bol Chenet 320 , pâte fine homogène orangée, surface mate rouge orangé à ocre, décoré de la molette U.C. 131.

$\mathrm{N}^{\circ} 116$ (non inventoriés portant l'indication Amph. $10 / 2 / 03)$

2 fragments de bol Chenet 320, pâte comportant un cœur noir, surface externe orangée, décoré de la molette U.C. 41 .
No 117 (non inventorié portant l'indication Amph. 26/1/03)

grand morceau de bol Chenet 320, pâte comportant un cœur noir, surface mate rouge orangé, décoré de la molette U.C. 293 variante inversée.

$\mathrm{N}^{\circ} 118$ (non inventoriè portant l'indication Amph. 1903)

fragment de bol Chenet 320 , pâte brune litée, surface mate usée brun, décoré de la molette U.C. 293 inversée. № 119 (non inventorié portant l'indication Amph. $19 / 1 / 03)$

fragment de bol Chenet 320 , pâte rouge foncé très cuite, surface mate rouge brique, décoré de la molette U.C. 293.

$N^{\circ} 120$ (non inventorié portant l'indication Amph. 1903)

morceau de panse de bol Chenet 320, pâte comportant un cœur noir, surface mate rouge orangé à ocre, décoré de la molette U.C. 83 inversée.

$N^{\circ} 121$ (non inventoriés portant l'indication Amph.)

3 grands fragments d'un bol Chenet 320 caréné peu cuit, surface mate rouge orangé, décoré de la molette U.C. 152.

$\mathrm{N}^{0} 122$ (non inventorié portant l'indication Amph. 1903)

fragment de bol Chenet 320, pâte comportant un cœur noir, surface mate très usée brun laissant apparaitre des particules calcaires, décoré de la molette U.C. 329.

$N^{\circ} 123$ (non inventorité portant l'indication Amph. 26/1/03)

petit tesson, pâte bcige, surface beige, décoré de la molette U.C. 168 inversée.

$N^{\circ} 124$ (non inventorié portant l'indication Amph. 26/1/03)

grand morceau de panse de bol Chenet 320 , pâte orangée comportant une âme un peu plus sombre, surface mate rouge orangé à ocre, décoré de la molette U.C. 154 inversée.

$\mathrm{N}^{\circ} 125$ (non inventorié portant l'indication Amph. 1903)

gros morceau de bol Chenet 320, pâte comportant une âme un peu plus sombre, surface mate rouge à ocre, décoré de la molette U.C. 183-259.

$N^{\circ} 126$ (non inventorié portant l'indication Amph. 1903)

gros morceau de bol Chenet 320, pâte fine comportant une âme un peu plus sombre, surface mate rouge orangé à ocre, décoré de la molette U.C. 260 variante.

$N^{\circ} 127$ (non inventorié portant l'indication Amph. 19/1/03)

morceau de fond de bol Chenet 320, pâte comportant un cœur noir, surface complètement noire, décoré de la molette U.C. 184.

$N^{\circ} 128$ (non inventorié portant l'indication Amph. 1903)

fond de bol Chenet 320, pâte litée orangée, décoré d'une molette non identifiée attribuable au groupe 3 de W. Hübener. 


\section{ANNEXE 2}

LISTE DES SITES AYANT LIVRÉ DES DÉCORS RETENUS DANS NOTRE TABLEAU

I Les villes fortifiées et camps du limes rhénan

1 Altrip (Rhénanie-Palatinat, RFA)

Alta Ripa, castellum rhénan

U.C. $25,37,38,46,71,98,103,104,109,112,118,175$, $210,212,68$

G. Bersu, Das spätrömische Kastell in Altrip, in : Pfalzische Museum, 1928.

2 Alzei (Rhénanie-Palatinat, RFA)

Alteium, castellum rhénan

U.C. $27,57,70,85,98,104,113,117,212,217,43,68$, $86,120,129,58,82,93,26,29,106,90,28,41,149,216$, $122,131,154,179$ (4 molettes de la couche d'incendie des casernes ouest à ajouter à la liste : U.C. $77,83,163$, 178)

W. Unverzagt, Die Keramik des Kastells Alzei (Rheinhessen), Francfort-sur-le-Main, 1916;--- ID., Zur Zeitbestimmung des Kastells Alzei (Rheinhessen), Germania, 13, 1929, p. 177-187.

\section{2b Alzei}

Cimetière

U.C. 26

W. Unverzagt, Terra Sigillata mit Rädchenverzierun, Francfort-sur-le-Main, 1919.

3 Andernach (Rhénanie-Palatinat, RFA)

Anlunnacum, castellum rhénan

U.C. 57, $112,152,168 \ldots$

W. UNVERzaGt, 1919.

4 Asperden (Rhénanie-Westphalie, RFA)

Burgus de l'arrière-pays de Cologne U.C. 112

H. Hinz, I. Hömberg, Ausgrabung eines spätrömischen Burgus in Asperden, Kreis Kleve, Beiträge zur Archäologie des römischen Rheinlands, Rheinische Ausgrabungen, 3, 1968, p. 167-212.

5 Bad-Dürkheim (Rhénanie-Palatinat, RFA)

Burgus rhénan proche d'Alzei

U.C. $93,106,154 \ldots$

H. Bernhard, Die spätrömischen Burgi von Bad Dürkheim-Ungstein und Eisenberg. Eine Untersuchung zum spätantiken Siedlungswesen in ausgewählten Teilgebieten der Pfalz, Saalburg Jahrbuch, Bericht des Saalburg Museums, 37, 1981, p. 23-85.
6 Bonn (Rhénanie-Westphalie, RFA)

Bonna, castrum sur le Rhin

U.C. $109,93,154 \ldots$

UnverzaGt, 1919; - W. Hübener, Eine Studie zur spätrömischen Rädchensigillata (Argonnensigillata), Bonner Jahrbücher, 168, 1968, p. 240-298.

7 Boppard (Rhénanie-Palatinat, RFA)

Bodobriga, castellum rhénan

U.C. $43,119,58,163,122 \ldots$

HÜBENER, 1968.

8 Brumath (Bas-Rhin)

Brocomagus, castrum

U.C. $210 \ldots$

Unverzagt, 1919; -- G. Cinenet, la céramique gallo-romaine d'Argonne du IV siècle el la lerre sigillée décorée à la molelle, Mâcon, 1941.

9 Burg Sponeck (Bade-Wurtemberg, RFA)

Fortification rhénane

U.C. 46,29

R.M. SwoворA, Eine spätrömische Anlage auf der Burg Sponek, Gemarkung Jechtingen, Kreis Emmendingen, Fundberichte aus Baden-Würtemberg, 4, 1979, p. 316-343.

10 Cologne-Deutz (Rhénanie-Westphalie, RFA)

Divitia, castellum sur la rive droite du Rhin

U.C. 122, 131, Metz $3 \ldots$

Hübener, 1968; - L. Bakker in: Metzler, Zimmer, Bakker, Ausgrabungen in Echternach, Luxembourg, 1981.

11 Eisenberg (Rhénanie-P'alatinat, RFA)

Burgus rhénan proche d'Alzei

U.C. $152,29(?), 24,41,216,131,154 \ldots$

Bernhard, 1981.

12 Illzach (Haut-Rhin)

Uruncis? castellum? sur l'Ill

U.C. 43 (?), 26, 30 (?), 293, 24, 77, $154 \ldots$

R. Schweitzer, Contribution à l'étude de la céramique du Bas-Empire, Bulletin du Musée Historique de Mulhouse, 84, 1977, p. 65-76.

13 Krefeld-Gellep (Rhénanie-Westphalie, RFA)

Gelduba, caslellum rhénan

U.C. $57,68,30$ (var.) 
I. PaAR, Ch. B. Rüger, Kastell Gelduba, Beiträge zur Archäologie des römischen Rheinlands, 1971, p. 242-339.

\section{3b Krefeld-Gellep}

Cimetière

U.C. 29, inédite var. de U.C. 30

R. PIRling, Das römisch-fränkische Gräberfeld von Krefeld-Gellep 1964-1965, Römisch-Germanische Kommission des Deutschen Archäologischen Instituts, 10, Berlin, 1979, p. 34 et pl. 10.

14 Mayence (Rhénanie-Palatinat, RFA)

Mogontiacum, ville fortifiée sur le Rhin

U.C. $117,30 \ldots$

K. V. Decker, W. Selzer, Mogontiacum, Aufstieg und Niedergang der Römische Well, II, 5.1, p. 457559 .

15 Niederlahnstein (Rhénanie-Palatinat, HFA)

Tête de pont fortifiée de la laahn sur la rive droite du Rhin

U.C. $43,131,179 \ldots$

UNVERZAGT, 1919

16 Nimègue (Pays-Bas)

Noviomagus, castellum rhénan et cimetière attenant

U.C. $175,199,93,24,178 \ldots$

Chenet, 1941.

17 Rövenich (Rhénanie-Westphalie, RFA)

Burgus de l'arrière-pays de Cologne

U.C. 86 ..

V. Heinberg, Römische Ausgrabungen, Bonner Jahrbücher, 177, 1977, p. 580-593.

18 Rumersheim (Haut-Rhin)

Burgus sur le Rhin

U.C. 82, 259

Chenet, 1941 ; - Schweitzer, 1977, p. 67.

19 Spire (Rhénanie-Palatinat, RFA)

Noviomagus ou Nemetae, castrum rhénan

U.C. $112,113 \ldots$

Chenet, 1941.

\section{Strasbourg (Haut-Rhin)}

Argentorate, castellum rhénan

U.C. $27,104,43$ (?), 68, 108, 28 ..

Chenet, 1941 ; - Hübener, 1968.

21 Wiesbaden (Hesse, RFA)

Aquae Mattiacorum

"Heidenmauer" vaste fortification située non loin de Mayence sur la rive droite du Rhin

U.C. $43,119,29 \ldots$

UNVERZAGT, 1919.

22 Zullenstein (Hesse, RFA)

Burgus des bords du Rhin

U.C. $98 \ldots$
W. Jorns, Der spätrömische Burgus mit Schiffslände und die Karolingische Villa Zullenstein, Archäologisches Korrespondenzblatt, 3, 1973, p. 7580 .

II Les villes et points fortifiés des secteurs frontaliers de Séquanaise et de Rhétie

23 Augsbourg (Bavière, RFA)

Augusta Vindelicum, capitale de Rhétie II

U.C. $131 \ldots$

L. BAKKer, Ausgewählte Gefässkeramik der frühen und späten Kaiserzeit aus Augusta VindelicumAugsburg, Forschungen zur provincial-römischen Archäologie in Bayerisch-Schwaben, Augsbourg, 1985 , p. $45-77$.

24 Bâle (Suisse)

Basilia, castellum rhénan

U.C. 28,23 (?) ...

L. Berger, Die Ausgrabungen am Petersberg in Basel, 1963 , p. 34 , pl. 18, n $^{\circ} 27$.

25 Lorenzberg bei Epfach (Bavière, RFA)

Abodiacum, fortification routière de Rhétie

U.C. 46 ou 48,109 (?), 26, $293 \ldots$

J. Werner (dir.), Der Lorenzberg bei Epfach, die spätrömischen und mittelalterlichen Anlage, Münchner Beiträge zur Vor- und Frühgeschichte, 12, 1969 , p. $153-159$.

26 Goldberg bei Türkheim (Bavière, RFA)

Rostrum Nemaviae, castellum routier

U.C. $26,293 \ldots$

J. Moosdorf-Ottinger, Der Goldberg bei Türkheim, Bericht über die Grabungen in den Jahren 1942-44 und 1958-61, Münchner Beiträge zur Vorund Frühgeschichte, 24, 1981, p. 87.

27 Kellmünz (Bavière, RFA)

Caelius Mons, castellum du limes rhétique U.C. 163

UNVERZAGT, 1919.

28 Moosberg bei Murnau (Bavière, RFA)

Coveliacae, fortification routière de Rhétie

U.C. 26, 293 ...

J. Garbsch, Der Moosberg bei Murnau, Münchner Beiträge zur Vor- und Frühgeschichte,1966, p. 97.

29 Seebrück (Bavière, RFA)

Bedaium, castellum en Rhétie

U.C. 27, 26

UNVERzaGt, 1919.

30 Windish (Suisse)

Castrum vindonissense ou Vindonissa, castrum de Séquanaise

U.C. $70 \ldots$

W. Hübener, Rädchenverzierte Argonnensigillata 
aus Vindonissa, Gesellschaft Pro Vindonissa, Jahresbericht 1968, Brugg, 1969.

31 Yverdon (Suisse)

Eburodunum, castellum (aurait pu être placé en classe V) U.C. 152

Hübener, 1969.

III Les villes fortifiées du "limes belgicus» auxquelles a été adjoint Alet sur le tractus armoricanus

32 Alet, commune de Saint-Malo (Ille-et-Vilaine)

Aleto, castrum du tractus armoricanus

U.C. 28,78 (?), 99, 163, $122 \ldots$

P.-H. Mrtard, La céramique d'Argonne du IV siècle ornée à la molette d'Alet (Saint-Malo, Ille-et-Vilaine), Les Dossiers du Centre Régional Archéologique d'Alet, 2, 1974, p. 41-48; - L. LANGOUËT, Un nouveau lot de céramiques d'Argonne décorées à la molette retrouvé à Alet (Saint-Malo), réflexions sur les importations de cette céramique en Armorique, Les Dossiers du Centre Régional Archéologique d'Alet, 5, 1977, p. 3-18.

33 Bavay (Nord)

Bagacum, casiellum

U.C. $25,71,85,98,112,113,117,175,199,43,68,86$, $119,120,108,152,26,30,198,293,106$, Piton, Bayard (P.B.) 95, P.B. 126, U.C. 28, 128 (?), 162, 163, 83, $122,154 \ldots$

J. Gricourt, La terre sigillée argonnaise du IV siècle décorée à la molette à Bavai (Nord), Gallia, 8, 1950, p. 55-76; - J. GricourT, D. Piton, D. BAYARD, La sigillée d'Argonne décorée à la molette à Bavai (Nord), Cahiers Archéologiques de Picardie, 4, 1977, p. 205-219; - J.-C. Carmelez, P.-H. Tellier (dir.), La céramique sigillée du Bas-Empire conservée au Musée de Bavay, Archéologie et Pédagogie, Lycée de Bavay, 8, 1986, p. 91-130.

34 Cuijk (Pays-Bas)

Ceuclum, castellum à proximité de Nimègue

U.C. $117,199,129,122,131,154,168 \ldots$ HÜBENER, 1968.

35 Famars (Nord)

Fanum Martis (?), castellum proche de Bavay

U.C. 154 ...

Chenet, 1941.

36 Goudsberg (Pays-Bas)

Burgus de la voie Bavay-Cologne

U.C. 108

J.H. Holwerda, De Goudsberg bij Valkenburg, 1916.
37 Heerlen (Pays-Bas)

Coriovallum, castellum de la voie Bavay-Cologne, près de Maastricht

U.C. $199,93,198 \ldots$

Chenet, 1941.

38 Liberchies (Belgique)

Castellum du "limes belgicus"

U.C. $58,122 \ldots$

J. Mertens, R. Brulet, Le Castellum du BasEmpire romain de Brunehaut-Liberchies, I, Archaeologia Belgica, 163, 1974.

39 Maastricht (Pays-Bas)

Trajectum Mosae, castellum sur la Meuse

U.C. $117,77,163,173,181,183,184,186,257,258$, 259 ...

Hübener, 1968; W. Dijkman, La terre sigillée tardive décorée à la molette à motifs chrétiens, trouvée dans la vallée mosane, en particulier à Maastricht (Pays-Bas), SFECAG, Acles du congrès de Reims, 1985, p. 57-62.

40 Oudenbourg (Belgique)

Castellum du litus Saxonicum

Les molettes proviennent de la nécropole.

U.C. $103,117 \ldots$

J. Mertens, L. Van Impe, Het laat Romeins Grafeld van Oudenburg, Archaeologia Belgica, 135, 1971.

\section{Tongres (Belgique)}

Castrum, chef-lieu de la cité des Tungri

U.C. $25,27,37,38,57,112,117,68,120,129,58$, 108 (?), 152, 30, 126, 293, 106, 163, 216 (var.), 122, 23, 178,179

M. Vanderhoeven, De Terra Sigillata te Tongeren V. De Radjessigillata, Tongres, 1979, 68 p.

IV Les villes fortifiées de l'intérieur

a Villes fortifiées proches du "limes belgicus»

42 Arras (Pas-de-Calais)

Nemetacum, castrum, chef-lieu de la cité des Atrebates U.C. $70,93,152,154$ (?), $178 \ldots$

Fouilles Alain Jacques, cf. E. Belot, A. Jacques, Les cultes orientaux dans l'Antiquité tardive, Archéologia, 232, 1988, p. 26-33.

43 Boulogne-sur-Mer (Pas-de-Calais)

Bononia, castrum, chef-lieu de la cité des Bononienses U.C. 25, 113, 117, $126 \ldots$

D. Piton, D. Bayard, La sigillée d'Argonne décorée à la molette dans le Nord-Ouest de la France, Cahiers Archéologiques de Picardie, 4, 1977, p. 221-275; - Cl. Seillier, Des origines aux invasions du v viècle, Hisloire de Boulogne-sur-Mer, Presses Universitaires de Lille, 1983, p. 11-32. 
44 Thérouanne (Pas-de-Calais)

Tervanna, castrum, chef-lieu de la cité des Morini

U.C. $43,29,126,106 \ldots$

Piton, Bayard, 1977 ; - H. Bernhard, Thérouanne antique. A propos des découvertes relatives au Bas-Empire : état de la question à l'issue de la campagne de 1984, Bulletin de la Commission Départementale d'Histoire et d'Archéologie du Pasde-Calais, XII, I, 1986, p. 7-33.

b Autres villes fortifiées de l'intérieur

\section{Amiens (Somme)}

Samarobriva, castrum, chef-lieu de la cité des Ambianenses

U.C. $112,210,58,293$ (var.), 131, 182, 257, $258 \ldots$

D. BAy ARD, J.-L. MAssy, Amiens romain, Amiens, $1983 ;$ - Piton, Bayard, 1977.

46 Auxerre (Yonne)

Autissiodurum, castrum, chef-lieu de la cité des Autissiederi

U.C. 178, Nicolle 8-48 ...

J. Nicolle, La céramique d'Argonne décorée à la molette dans le département de l'Yonne, Gallia, 20, 1962, p. 380-392.

\section{Châlons-sur-Marne (Marne)}

Durocatalaunum, castrum, chef-lieu de la cité des Calalauni

U.C. $70,216,131,181 \ldots$

Fouilles Lenoble et Chossenot, cf. M. Lenoble, Céramique sigillée provenant d'un entrepôt, rue Saint-Dominique à Châlons-sur-Marne, Bulletin de la Société Archéologique Champenoise, 79, 1986, 2, p. 73-82.

48 Genève (Suisse)

Genava, castrum

U.C. 119,131 ..

D. Paunier, La céramique gallo-romaine de Genève, Genève, $1981, \mathrm{n}^{\circ} 132$, p. 189 et 334 .

\section{Lisieux (Calvados)}

Noviomagus, castrum, chef-lieu de la cité des Lexovii U.C. $85,113,212,79,119$

P.-H. Mitard, La céramique gallo-romaine d'Argonne du IV ${ }^{e}$ siècle à Lisieux (Calvados), Annales de Normandie, 1968, p. 301-309.

50 Metz (Moselle)

Divodurum, castrum, chef-lieu de la cité des Mediomatrici

Le grand amphithéâtre

U.C. $93,152,26,29,30,198,293,90$, P.B. 95 , U.C. 24 , $28,41,78,91,99,128,149,162,216(?), 83,122,122$ (var.), 131, 275, 23, 154, 178, 179, 124, 174, Nicolle $8-48$, U.C. $181,182,183,259,184,186,260,263,276$, 329 et inédites
E. Schramm, G. Wolfram, J.B. Keune, Das grosse römische Amphitheater zu Metz, Jahrbuch der Gesellschaft für Lothringische Geschichte und Altertumskunde, XIV, 1902, p. 340-430;-UNVERZAGT, 1919.

\section{Paris}

Lutetia ou Parisii, castrum, chef-lieu de la cité des Parisii, au Musée Carnavalet

U.C. $38,70,112,28$ (var.), 122 (var.), 131, 154, 258 Chenet, 1941

52 Reims (Marne)

Durocortorum, castrum, chef-lieu de la cité des Remi U.C. 109, 79, 93, 24, 163 (var.), 122 (var.), 131, 179, Metz 1, 124 (?), 174, 181, 182, 183-259, 184, 185, 186, 257

Chenet, 1941; - Fouilles F. Berthelot de la Maison du Trésor, cf. R. Neiss, Circonscription de Champagne-Ardenne, Gallia, 43, 1985, p. 372-373; - B. Christophe, R. Ertlé (introduction de), En marge des recherches en cours au forum de Reims, Bulletin du Groupe d'Étude archéologique de Champagne-Ardenne, 1968, 1, 25 p.

53 Rouen (Seine-Maritime)

Rotomagus, castrum, chef-lieu de la cité des Rotomagenses

U.C. $181,182,183,184,185,186$

Cl. Jigan, P. Halbout, La céramique d'Argonne décorée à la molette des Iv ${ }^{e}-v^{e}$ siècles en Normandie, SFECAG, Actes du congrès de Caen, 1987, p. 45-50.

\section{Sens (Yonne)}

Agedincum, castrum, chef-lieu de la cité des Senones U.C. $109,43,79,86,119,93,152,26,30,293,28$, 99 (?), 163 (var.). 154, 178, Nicolle 8-48, 181, 257 Nicolle, 1962; - renseignements D. Guillot (fouilles de sauvetage inédites dans le musée, cf. H. Gaillard de SÉmainville, Circonscription de Bourgogne, Gallia, 41, 1983, p. 416-417; - ibid., 43, 1985, p. 276-277).

55 Trèves (Rhénanie-Palatinat, RFA)

Augusta Treverorum, chef-lieu de la cité des Treveri Capitale du diocèse des Gaules jusqu'à la fin $d u{ }^{\prime} v^{e} s$. Unverzagt, 1919 ; - L. Hüssong, H. Cüppers, Die Trierer Kaiserthermen, I, 2, Die spätrömische und frühmittelalterliche Keramik, Trèves, 1972.

55a Trèves

Amphithéâtre

U.C. $117,175,29$ UnVERZaGt, 1919.

55b Trèves

Palais Kesselstadt Unverzagt, 1919; - Hüssong, Cüppers, 1972. 


\section{Trèves}

Thermes Sainte-Barbe

U.C. $58,108,30,106,77,99,163,122$, Metz 3, 23, $154,178,179,124,174,173,181,183-259$

Unverzagt, 1919; - Hüssong, CüPpers, 1972.

\section{Castella et refuges de l'intérieur}

57 Bitburg (Rhénanie-Palatinat, RFA)

Beda, castellum des Treveri

U.C. $86,119,108,152$

UNVERZAGT, 1919.

58 Dourbes (Belgique)

Refuge fortifié des Ardennes

U.C. 152, 29, 293 (var.)

R. BRulet, La Roche à Lomme à Dourbes, Archaeologia Belgica, 160, 1974; - Cl. Robert, La terre sigillée argonmaise décorée à la molelte de la Roche à Lomme, Dourbes (Belgique), Gallia, 27, 1969, p. 135-147.

59 Echternach (Luxembourg)

Saints-Pierre-et-Paul, refuge fortifié de la cité des Treveri

U.C. 46 (?), 79, 293, 106, P.B. 126, Metz 5, 28, 91, 128, $162,163,216,83,131, \operatorname{Metz} 3,154,178,179,124,174$, 181,257

BАKKER, 1981.

60 Fort-Harrouard, commune de Sorel-Moussel (Eureet-Loir)

Ancien oppidum réoccupé

U.C. 152,30

Chenet, 1941.

61 Furfooz (Belgique)

"Hauterecenne» refuge fortifié des Ardennes

U.C. $46,91 \ldots$

R. Brulet, La fortification de Hauterecenne à Furfooz, Louvain-la-Neuve, 1978, 106 p., dépliant.

62 Kobern-Gondorf (Rhénanie-Palatinat, RFA)

Refuge fortifié de la cité des Treveri sur la Moselle

U.C. 30, Metz 2, 174

K.J. Gilles, Spätrömische Höhensiedlungen in Eifel und Hunsrück, Trierer Zeitschrift, Beiheft 7, 1985.

63 Lausanne (Suisse)

Lousonna, vicus?

U.C. 293

HüBener, 1969.

64 Laon (Aisne)

Lugdunum Clavatum, castellum de la cité des Remi

U.C. 181

Fouilles J.-P. Jorrand, inédit.

65 Minheim (Rhénanie-Palatinat, RFA)
Refuge fortifié de la cité des Treveri

U.C. 68 ou 67

Gilles, 1985.

66 Neef-Petersberg (Rhénanie-Palatinat, RFA)

Refuge fortifié de la cité des Treveri sur la Moselle

U.C. 58 (?), 30, 78, 149, 122, 179, Metz 2, 174 Gilles, 1985.

67 Neumagen (Rhénanie-Palatinat, RFA)

Noviomagus, castellum de la cité des Treveri sur la Moselle

U.C. $119,58,106,78,179$

UNVERZAGT, 1919.

68 Noyon (Oise)

Noviomagus, castellum de la cité des Veromandui, siège du praefectus des Laetii contraginenses

U.C. 26,216

Fouilles T. Berredjeb, inédit.

69 Traben-Trarbach (Rhénanie-Palatinat, RFA)

Refuge fortifié de la cité des Treveri sur la Moselle U.C. 26 (?), 154,179

Gilles, 1985.

70 Vix (Côte-d'Or)

Ancien oppidum réoccupé

U.C. 178, Nicolle 8-48, 181, 182, 185, 186, 260-274, 329 R. Joffroy, L'oppidum de Vix el la civilisation hallstattienne finale dans l'Est de la France, Université de Dijon et Société des Belles Lettres, Dijon, 1960 , p. 184-185.

VI Villae et loci

71 Amiens, "ferme de Grâce» (Somme)

Villa

U.C. $38 \ldots$

Prospections D. Bayard, inédit.

72 Arvillers (Somme)

Villa

U.C. 112

Fouilles et prospections C. Chardonnet, inédit.

73 Beckingen (Sarre, RFA)

Villa?

U.C. 48

Chenet, 1941.

74 Berry-au-Bac (Aisne)

Locus

U.C. 86

Fouilles B. Illet-Fleury, inédit; - J.-L. CADoux, Girconscription de Picardie, Gallia, 39, 1981, p. 257-259, fig. 1.

75 La Chalade (Meuse)

U.C. 86

Chenet, 1941. 
76 Denning, Munich (Bavière, RFA)

Villa

U.C. 58

W. Czysz, Die römische Gulshof in München Denning und die römerzeitliche Besiedlung der münchner Schotterebene, Katalog der prähistorischen Staatssamlung, 16, Kallmünz, 1974, p. 7778 , pl. 9.

77 Chilleurs (Loiret)

Villa ou peut-être vicus

U.C. 181

Renseignement J.-F. Baratin, inédit.

78 Echternach (Luxembourg)

Grande villa

U.C. $26,117 \ldots$

BAKKER, 1981.

79 Ercheu (Somme)

Villa ou vicus

U.C. 102

Inédit.

80 Guiry-Gadancourt (Seine-et-Oise)

Villa

U.C. $212\left(\mathrm{n}^{\circ} 18\right)$

P.-H. Mitard, La céramique argonnaise du IV siècle décorée à la molette à Guiry-Gadancourt (S.-et-O.), Gallia, 16, 1958, p. 293-299.

81 Jumel (Somme)

Villa

U.C. 58,178 , Metz $1 \ldots$

Fouilles D. Bayard, inédit.

82 Juvincourt-et-Damary (Aisne)

Villa

U.C. 109

Fouilles D. Bayard, inédit.

83 Mercin-et-Vaux (Aisne)

Villa

U.C. $30,163,216,216$ (var.), U.C. 24,41 (?), 178, 181

A. Barbet, Mercin-et-Vaux (Aisne) un établissement gallo-romain à bassin en forme de $\mathrm{T}$, Revue du Nord, 53, 1971, p. 631-663; - Prton, BayARD, 1977.

84 Plémy (Côtes-d'Armor)

Villa

U.C. 117

L. LANGoUËT, Céramiques d'Argonne, décorées à la molette, conservées dans des collections publiques bretonnes, Archéologie en Bretagne, Bulletin d'information de la Direction des Antiquités historiques, 4, 1974, p. 27-32.
85 Pontavert (Aisne)

Villa

U.C. 112

Prospections D. Bayard, inédit.

86 Pont d'Ancy (Aisne)

Villa (?)

U.C. 152

Inédit.

87 Pont-Sainte-Maxence (Oise)

Locus?

U.C. 38

Inédit.

88 Rigny-la-Salle (Meuse)

Locus? villa?

U.G. 117

Inédit.

89 Rousseloy (Oise)

Villa

U.G. 93

Prospections D. Vermeersch, inédit.

90 Thiverny (Oise)

Villa-locus

U.C. 104

Inédit.

91 Vesigneul (Marne)

U.C. $198,182,126$

Chenet, 1941.

92 Vincy, commune de Létane (Ardennes)

Villa?

U.C. 181

Prospections J.-P. Lémant; - J.-P. Lémant, Aspect du peuplement franc dans la haute vallée mosane, in: La civilisation mérovingienne dans le bassin mosan, Etudes et Recherches Archéologiques de l'Université de Liège (ERAUL) 22, 1986, p. 121-152, en particulier p. 152.

93 Vrely (Somme)

Villa

U.C. 120

Inédit.

VII Sites ruraux groupés ou indéterminés : stations routières, sanctuaires, vici non fortifiés (hors Ardennes)

94 Chameleux (Belgique)

Station routière

U.C. $103 \ldots$

J. Mertens, Relais de Chameleux, Archéologie, 1962, p. 67. 
95 Champlieu (Oise)

U.C. $129 \ldots$

Piton, Bayard, 1977.

96 Escolives (Yonne)

U.C. 103 , molette chrétienne inédite Nicolle, 1962.

97 Les Fontaines-Salées, commune de Foissy-sousVézelay (Yonne)

Sanctuaire

U.C. $175,57,275$

Nicolle, 1962 ; - A.B. Lacroix, Mobilier d'un habitat du Iv ${ }^{e}$ siècle aux Fontaines-Salées, Revue Archéologique de l'Est et du Centre-Est, XIX, 1968, 1-4, p. 191-233.

98 Matagne-la-Petite (Belgique)

Sanctuaire

U.C. 98,175

M. Vanderhoeven, Terre sigillée de Malagne-laPetite, Pommereul et Saint-Mard, Archaeologia Belgica, 243, 1981, p. 10-11, $\mathrm{n}^{\circ} 17$.

99 Morains (Marne)

Vicus

U.C. $27,26,85,117,293,126$

Chenet, 1941.

100 Proyart (Somme)

Sanctuaire

U.C. 112,117

Inédit.

101 Ribemont-sur-Ancre (Somme)

Sanctuaire

U.C. 98 (var.)

J.-L. CADoux, Un sanctuaire gallo-romain isolé : Ribemont-sur-Ancre (Somme), Latomus, XXXVII, 2,1978 , p. $325-360,35 \mathrm{pl}$.

102 Saint-Moré (Yonne)

U.C. 124

NiCOLLE, 1962.

103 Saulsotte (La) (Aube)

Atelier de potier du Haut Moyen Age

U.C. 182

Chenet, 1941.

104 Tournelles (Les) (Oise)

Forêt de Compiègne

U.C. 129

Chenet, 1941.

105 Vendeuil-Caply (Oise)

Théâtre d'un vicus réoccupé

U.C. $38,79,98,293$

Piton, Bayard, 1977.

106 Vermand (Aisne)
Ancien oppidum des Viromandui, vicus devenu chef-lieu de la cité selon certains auteurs

U.C. $112 \ldots$

Piton, Bayard, 1977.

VIII Nécropoles romaines tardives (hors Ardennes)

107 Aulnizeux (Marne)

U.C. 68

Chenet, 1941.

108 Bornheim-Widdig (Rhénanie-Westphalie, RFA)

Sépulture isolée

Nicolle 8-48

L. BAKKer, Ein Grab des frühen 5. Jahrhunderts aus Bornheim-Widdig (Rhein-Sieg-Kreis), Bonner Jahrbücher, 1977, p. 605-610.

109 Candor (Oise)

U.C. 38

Inédit.

110 Chevincourt (Oise)

U.C. 112

Chenet, 1941.

111 Cortrat (Loiret)

U.C. 23

H. W. Böнme, Germanische Grabfunde des 4. bis 5 . Jahrhunderts zwischen unterer Elbe und Loire, Studien zur Chronologie und Bevölkerungsgeschichle, Münchner Beiträge zur Vor- und Frühgeschichte, 19, 1974, p. 312.

112 Jonchery-sur-Suippe (Marne)

U.C. 117

Chenet, 1941.

113 Mézières (Ardennes)

Quartier Saint-Julien

U.C. 57,129

Renseignements J.-P. Lémant.

114 Normée (Marne)

U.C. 108

Chenet, 1941.

115 Noyelles-Godault (Pas-de-Calais)

U.C. 38

Inédit, étude de G. Blieck en cours.

116 Rheingöhnheim (Rhénanie-Palatinat, RFA)

U.C. 93

Chenet, 1941.

117 Schifferstadt (Rhénanie-Palatinat, RFA)

U.C. 112

Chenet, 1941.

118 Vieux Mont, commune de Cambronne (Oise) U.C. 48

La Picardie, berceau de la France, Clovis et les 
derniers Romains, Catalogue de l'exposition, Amiens, 1986, p. 88.

119 Vron (Somme)

U.C. 109 (t. 186), 38 (t. 234)

Fouilles Cl. Seillier, inédit.

IX Nécropoles mérovingiennes (hors Ardennes)

120 Arcy-Sainte-Restitue (Aisne)

U.C. 37

Chenet, 1941.

121 Bulles (Oise)

Metz 2

$R$. et Y. LEgoux, Le cimetière mérovingien de Sainte-Fontaine à Bulles (Oise) — étude des 155 premières sépultures, Cahiers Archéologiques de Picardie, 1, 1974, p. 123-180 (p. 177).

122 Cierges (Aisne)

U.C. 23, 26, 27

Chenet, 1941.

123 Dieue-sur-Meuse (Meuse)

U.C. 263

J. Guillaume, La chronologie des nécropoles mérovingiennes de Dieue-sur-Meuse (France, Meuse), in: M. Fleury, P. Perin, Problemes de chronologie relative et absolue concernant les cimetières mérovingiens d'entre Loire et Rhin, Paris, 1978 , p. $87-103$, fig. 103 .

124 Fère-en-Tardenois, "Sablonnières" (Aisne)

U.C. 186

Chenet, 1941 ; - La Picardie, berceau de la France, 1986 , notice 123 .

125 Harmignies (Belgique)

U.C. 131 (?)

M. Amand, H. Lambert, H. Roosens, Le sous-sol archéologique de l'église Saint-Pial à Tournai, Archaeologia Belgica, 222, 1980, p. 58.

126 Lavoye (Meuse)

U.C. 184

Chenet, 1941 ; - R. Joffroy, Le cimetière de Lavoye, nécropole mérovingienne, Paris, 1974, pl. 19.

127 Moreuil (Somme)

U.C. 329

D. Bayard, D. Piton, R. Schuler, Le cimetière mérovingien de Moreuil (80), Cahiers Archéologiques de Picardie, 1981, 8, p. 157-216, fig. 3A.

128 Nesle-Hodeng (Seine-Maritime)

U.C. 168

Chenet, 1941.
129 Neuville-sur-Escaut (Nord)

U.C. 329

P. Leman, G. Hantute, avec les contributions de J. Blondiaux et Cl. Seillier, Le cimetière mérovingien de Neuville-sur-Escaut (Nord) ve-vI' siècles, Septentrion, 12-13 et musée de Denain, 1989, p. $42-43$.

130 Oyes (Marne)

U.C. 23, 186

Chenet, 1941.

131 Péronne (Somme)

U.C. 276 (var.)

Piton, Bayard, 1977.

132 Sauville (Vosges)

U.C. 212

Chenet, 1941.

133 Trivières (Belgique)

U.C. 329

G. Faider-Feytmans, Les collections d'archéologie régionale du musée de Mariemont, II, Les nécropoles mérovingiennes, Mariemont, 1970, pl. I.

\section{$X$ Les habitats en Ardennes}

134 Herstal, Pré-Wigy (Belgique)

U.C. $163,78,131,168,182,258 \ldots$

J.-P. Lensen, P. Van Ossel, Le Pré Wigy à Herstal, ERAUL, 20, 1984, p. 29.

135a Huy, quartier de "Batta» (Belgique)

U.C. 26, 124, 174, 168, 183-259, 257, 258, 329, Metz 1. J. Willems, Le quartier artisanal gallo-romain et mérovingien de "Batta» $\grave{a} H u y$, Archaeologia Belgica, 148, 1973.

135b Huy, rue des Augustins (Belgique)

U.C. 182 et Trivières III

C. Tilkin-Peters, D. Marcolungo, Le matériel mérovingien de la rue des Augustins à Huy, Activités 84 à 85 du SOS Fouilles, 4, 1986, p. 201-209.

136 Namur, rue Notre-Dame (Belgique)

Castellum?

U.C. 124

F. Jurion, Traces d'occupation romaine et médiévale à Namur, rue Notre-Dame, Activités $80 d u$ SOS Fouilles, 2, 1981, p. 48-56.

137 Swalmen (Pays-Bas)

Habitat sur les bords de la Meuse (peut-être à classer en XIV)

U.C. 168 (?) et un décor non identifié proche de Trivières II

E. Milıkowski, Een Frankisch Grafveld en sporen 
van Bewoning uit de laatromeinse Tijd en vroege middeleeuwen bij Swalmen, Limburg, Oudheidkundige Medelingen uit het Rijksmuseum van Oudheden te Leiden, 66, 1986, p. 115-137.

\section{Les nécropoles en Ardennes}

138 Éprave, Devant le Mont (Belgique)

U.C. $29,28,41,179,174,182$

A. Dasnoy, Le cimetière situé Devant-le-Mont à Éprave ( $\left.\mathrm{v}^{\mathrm{e}}-\mathrm{vI}^{\mathrm{e}} \mathrm{s}.\right)$, Annales de la Société Archéologique de Namur (ASAN), 54, 1967, p. 68-105.

139 Fallais (Belgique)

U.C. 182, 183, 259, 185 (var.), 183-259, 263

P. Van Ossel, La nécropole du Mont-SaintSauveur à Fallais, Bulletin de l'Institut Archéologique Liégeois, 94, 1982, p. 143-231.

140 Flavion (Belgique)

U.C. 57

A. DAsnoy, Quelques ensembles archéologiques du Bas-Empire provenant de la région namuroise (Spontin, Flavion, Tongrinne, Jamiolle, Jambes, Treigne), $A S A N, 53-2,1966$, p. 169-231.

141 Furfooz (Belgique)

U.C. 57, 68, 29

J.A.E. Nenquin, La nécropole de Furfooz, Dissertationes Archae. Gandenses I, 1953;-A. Dasnoy, Là nécropole de Furfooz, ASAN, 55, 1969, p. 120 194.

142 Haillot (Belgique)

U.C. $124,184,185$

J. Breuer, H. Roosens, Le cimetière franc de Haillot (avec annexes de J. Werner et A. Dasnoy), Archaeologia Belgica, 34, 1957.

143 Han-sur-Lesse (et Éprave), "Rouge Croix» (Belgique)

U.C. $26,28,131$

DASNOY, 1967.

144 Herstal (Belgique)

U.C. $113,118,175,212,41,184,257,258$ Chenet, 1941.

145 Huy (Belgique)

U.C. $183-259$

J. Docquier, R. Bit, Nécropole de Saint-Victor à Huy, in: La civilisation mérovingienne dans le bassin mosan, ERAUL, Liège, 22, 1986, p. 195-209, pl. 2.

146 Jamiolle (Belgique)

U.C. $68 \ldots$
A. Dasnoy, 1966.

147 Modave (Belgique)

U.C. 184,276

Chenet, 1941.

148 Pry (Belgique)

U.C. $183-259$

A. Dasnoy, Quelques tombes du cimetière de Pry ( $I v^{e}-v I^{e}$ siècle) (Belgique, province de Namur), in : Fleury, Perin, 1978, p. 69-79.

149 Rochefort (Belgique)

U.C. $182,26 \ldots$

A. Dasnoy, Le cimetière de Corbois à Rochefort (ve-vil ${ }^{\mathrm{e}}$ siècles), Namurcum, XI, 1968, p. 1-14.

150 Samson (Belgique)

U.C. $68,29,163$ (?), 154, 181, 186, 257

A. Dasnoy, La nécropole de Samson, $A S A N, 54$, 1968, p. 269333.

151 Spontin (Belgique)

U.C. 68

DAsNoy, 1966.

152 Vireux-Molhain (Ardennes)

U.C. $68,163,154,178$

J.-P. LÉMANT el alii, Le cimetière et la forlification du Bas-Empire du Vireux-Molhain (département des Ardennes), Römisch-germanisches Zentralmuseum Mainz, 7, Mayence, 1985, p. 71-75.

XII Les habitats alamans-burgondes

153 Francfort (Hesse, RFA)

U.C. $152,41,174$

0. Sтамм, Spätrömische und frühmittelalterliche Keramik der Altstadt Frankfurt am Main, Francfort-sur-le-Main, 1962, pl. 19.

154 Glauberg (Hesse, RFA)

Fortification de hauteur de la Hesse rhénane

U.C. $28,24,154$ (?), 43 (?)

S. SPoRs, Spätrömische Drehscheibenkeramik vom Glauberg (Wetterauskreis), Jahrbuch des römischgermanischen Zentralmuseums Mainz, 33, 2, 1986, p. 417-468.

155 Grosskrotzenburg (Bavière, RFA)

Ancien castellum réoccupé

U.C. 38

R. Roeren, Zur Archäologie und Geschichte Südwestdeutschlands ins 3. bis 5 . Jahrhunderts n. Chr., Jahrbuch des römisch-germanischen Zentralmuseums Mainz, 7, 1960, p. 243.

155b Runder Berg près d'Urach (Bade Wurtenberg, RFA)

Fortification de hauteur du Bade Wurtemberg

Molette non identifiée proche de U.C. 24-28 
R. Christlein, Die Alemannen Archäologie eines lebendiges Volkes, Stuttgart-Aalen, 1978, fig. 71, notice 367, p. 171.

156 Saalburg (Hesse, RFA)

$\Lambda$ ncien castellum rćoccupé

U.C. 24

ROEREN, 1960.

157 Schlufter (Thuringe, RDA)

Indéterminé

U.C. 152

Chenet, 1941.

158 Seligenstadt (Hesse, RFA)

U.C. 28

E. Schallmayer, Ausgrabungen in Seligenstadt, zur römischen und mittelalterlichen Topographie, Saalburg Jahrbuch, 43, 1987, p. 28-29, fig. 19 et 20.

159 Stockstadt (Bavière, RFA)

Ancien castellum réoccupé

U.C. 98

Roeren, 1960.

XIII Les nécropoles en pays alaman-burgonde

160 Dettingen (Bavière, RFA)

Molette très proche de U.C. 154

D. Rosenstock, Zwei völkerwanderungszeitliche Körpergräber aus Dettingen, Karlstein-am-Main, Ldks Aschaffenburg, Unterfranken, Bayerische Vorgeschichtsblätter, 52, 1987, p. 105-131.

161 Herthen (Bade-Wurtumberg, RFA)

Cimetière alaman des $\mathrm{IV}^{\mathrm{e}}$-VII ${ }^{\mathrm{e}} \mathrm{s}$. proche de Bâle

U.C. 106

F.Y. Garscha, Die Alamannen in Südbaden, der Katalog der Grabfunde, Berlin, 1970, pl. 51.

162 Trebur (Bade-Wurtemberg, RFA)

U.C. 163

Unverzagt, 1919; - J. Moller, Katalog der Grabfunde aus Völkerwanderungs- und Merowingerzeit im südmainischen Hessen (Starkensburg), Römisch-Germanischen Kommission des Deustchen Archäologische Instituts, II, 1987.

163 Untertürkheim (Bade-Wurtemberg, RFA)

Cimetière proche de Stuttgart

U.C. 162

Roeren, 1960.

164 Weilbach (Hesse, RFA)

U.C. 178

H. Sснорра, Die fränkischen Friedhöfe von Weilbach-Maintaunuskreis, 1959, p. 59, pl. 19.
XIV Les habitats en pays franc-frison

165 Arnhem Meinerswijk (Pays-Bas)

Camp romain?

U.C. 293

W.J.H. Willems, Romans and Batavians. A Regional Study in the Dutch Eastern River Area I, Berichten van de Rijksdienst voor het Oudheidkundig Bodemonderzoek (ROB), 31, 1981, p. 7-219, site 126 ; - ID., Romans ... II, ROB, 34, 1984, p. 169196.

166 Bayum (Pays-Bas)

"Terpen» de Frise

U.C. 257

Boeles, Friesland tot de elfde eeuw, 1951, p. 167171, fig. 36.7.

167 Dronrijp (Pays-Bas)

"Terpen» de Frise

U.C. 186

Boeles, 1951.

168 Ferwerd (Pays-Bas)

"Terpen" de Frise

U.C. 122 (var.), 257,181

Boeles, 1951.

169 Gennep, Maaskemp (Pays-Bas)

U.C. 257

WILLEMS, 1981, site 369 .

170 Lent (Pays-Bas)

U.C. 257

Willems, 1981, site 156.

171 Ressenkerkenhof (Pays-Bas)

U.C. 68

Willems, 1981, site 150 .

172 Wijchen-Tienakker (Pays-Bas)

U.C. 29,38

WiLLEMs, 1981, site 315 .

$\mathrm{XV}$ Les nécropoles en pays franc-frison

173 Rhenen (Pays-Bas)

U.C. 154

J. YPEY, La chronologie du cimetière franc de Rhenen (Pays-Bas, province d'Utrecht), in: Fleury, Perin, 1978, p. 89-127; - Böhme, 1974, p. 270 , pl. 43.

\section{Grande-Bretagne}

174 Londres

Londinium, castrum, capitale de la province

U.C. 97

Chenet, 1941. 


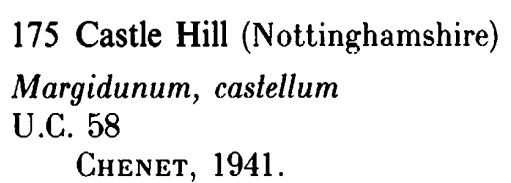

Lieux de production

176 Châtel-Chéhéry (Ardennes)

U.C. $199,43,82,108,26,28,91,99,162,83,131,275$,

$168,124,174,181,182,183,259,185,186,257,258$, $260,274,276 \ldots$

Chenet, 1941 ; - Prospections J.-P. Lémant.

177 Lavoye (Meuse)

U.C. $117,152,41 \ldots$ Chenet, 1941.

178 Pont des Quatre Enfants, Avocourt (Meuse)

U.C. 41 (2 ex.), 76 (6 ex.), 77 (3 ex.), 114-340 (7 ex.), 162 (2 ex.), 169 (5 ex.), 178, 179 (14 ex.), 219, 220 Unverzagt, 1919; - Chenet, 1941.

179 Vauquois, Les Allieux (Meuse)

U.C. 25 (?), 57, 58, 129, 68, Metz 5, U.C. 24, 41, 152,

$26,149,160,163,216,122,154,178 \ldots$

Chenet, 1941 ; - Prospections M. Feller.

\section{Phase 4}

180 Amifontaine, Le Petit Ranicourt (Aisne)

Habitat mérovingien

Molette inédite $\mathrm{n}^{\circ} 3$

Fouilles D. Bayard, inédit.

181 Berry-au-Bac (Aisne)

Habitat mérovingien

Maastricht 4 (?) et inédite $n^{\circ} 1$

Fouilles B. Illet-Fleury, inédit; - Cadoux, 1981, p. 257-259.

182 Berry-au-Bac, La Fosse au Puits (Aisne)

Habitat mérovingien

Molette inédite $\mathrm{n}^{\circ} 3$ Fouilles D. Bayard et G. Flucher, inédit.

183 Châtel-Chéhéry (Ardennes)

Maastricht 2 Prospections J.-P. Lémant, inédit.

184 Concevreux (Aisne)

Nécropole mérovingienne

Trivières III

Musée de Laon; - J. Pilloy, La gourde de Concevreux, Bulletin Archéologique du Comité des Travaux Historiques et Scientifiques, 1903, p. 467.

185 Han-sur-Lesse, "Rouge Croix" (Belgique)

Nécropole

Molette de Merlemont peut-être Maastricht 5, T. 282 WaUtelet, 1977, p. 34.
186 Herstal, Pré Wigy (Belgique)

Habitat

Trivières III

VAN OsseL, 1984.

187 Huy, rue des Augustins (Belgique)

Trivières III

Tilkin-Peters, Marcolungo, 1986.

188 Juvincourt-et-Damary, Gué de Mauchamp

(Aisne)

Habitat mérovingien

Trivières I, St. 5251

Fouilles D. Bayard, inédit.

189 Liège, place Saint-Lambert (Belgique)

Habitat mérovingien

Maastricht 3

D. Marcolungo, La céramique gallo-romaine, Les fouilles de la place Saint-Lambert à Liège - le vieux marché, 2, ERAUL 23, n 10, p. 141.

190 Maastricht (Pays-Bas)

Maastricht 1 à 6

DiJKMan, 1985.

191 Merlemont (Belgique)

Nécropole mérovingienne, tombe XXIV

Molette proche de Maastricht 5

WaUtelet, 1977, p. 32, fig. 21.

192 Mézières, hôpital de Manchester (Ardennes)

Nécropole mérovingienne

Molette inédite $\mathrm{n}^{\circ} 2$

Fouilles J.-P. Lémant (sur le cimetière, cf. P. Perin, Ensembles archéologiques mérovingiens de la région ardennaise 4 . Le cimetière de l'hôpital de Mézières (fouilles 1969-1971), Revue Historique Ardennaise, 1975, 10, p. 1-47.

193 Namur, rue de l'Ange (Belgique)

Probablement molette du type de Merlemont. Est-ce le même vase que celui de la place Saint-Aubin décoré de la molette Maastricht 5 trouvé dans la tombe mérovingienne?

WaUTelet, 1977, p. 34; - A. Dasnoy, Les origines romaines et mérovingiennes, Namur, le site, les Hommes, de l'époque romaine au xvIIr' siècle, Liège, 1988, p. 26.

194 Penchard (Seine-et-Marne)

Vicus (?) situé près de Meaux

Maastricht 2

P. Thion, Collections du musée de Meaux, Meaux, 1984.

195 Pontavert, Le Port au Marbre (Aisne)

Habitat mérovingien, structure 10

Trivières II

Fouilles CNRS-URA 12, inédit. 
196 Saint-Sauveur, La Haie Pâtissière (Somme)

Nécropole mérovingienne, tombe 149

Trivières III

Fouilles T. Berredjeb, inédit.

197 Tourcoing (musée de) (Nord)

Maastricht 5

Le Nord de la France de Théodose à Charles Martel, Catalogue d'exposition, Aire-sur-la-Lys, 1984, $\mathrm{n}^{\circ} 161$, p. 141.

198 Soupir (Aisne)

Habitat romain et médiéval

U.C. 329

Prospections de l'Université de Durham, inédit; - renseignements C. Haselgrove et C. Scull.
199 Trivières (Belgique)

Nécropole mérovingienne

Trivières I à IV

Faider-Feytmans, 1970, pl. I.

200 Vermand (Aisne)

Castrum des Veromandui (?)

Molette inédite $\mathrm{n}^{\circ} 2$

Renseignement S. Sallandre.

201 Vireux-Molhain, quartier de Wallerant, dans un crassier (Ardennes)

Maastricht 2

J.-P. LÉmant, Sauvetages sur les sites archéologiques de Vireux, Revue Historique Ardennaise, XVI, 1981, p. 207-229. 